\title{
Mississippi State Biodiesel Production Project
}

Rafael Hernandez (Project Director), Todd French, Sandun Fernando, Tingyu Li, Dwaine Braasch, Juan Silva, and Brian Baldwin

DOE Award Number: DE-FG36-04G014251

Dave C. Swalm School of Chemical Engineering Mississippi State University Mississippi State, Mississippi 
Acknowledgement: This material is based upon work supported by the Department of Energy under Award Number DE-FG36-04GO14251.

Disclaimer: This report was prepared as an account of work sponsored by an agency of the United States Government. Neither the United States Government nor any agency thereof, nor any of their employees, makes any warranty, express or implied, or assumes any legal liability or responsibility for the accuracy, completeness, or usefulness of any information, apparatus, product, or process disclosed, or represents that its use would not infringe privately owned rights. Reference herein to any specific commercial product, process, or service by trade name, trademark, manufacturer, or otherwise does not necessarily constitute or imply its endorsement, recommendation, or favoring by the United States Government or any agency thereof. The views and opinions of authors expressed herein do not necessarily state or reflect those of the United States Government or any agency thereof. 


\section{Final Technical Report}

Project Title: Mississippi State Biodiesel Production Project

Award Number: FG36-04G014251

Recipient: Mississippi State University

Project Location(s): Mississippi State University, Texas A \& M University

Project Period: 09/01/2004 through 09/29/2007

Date of Report: 03/20/2008

Written by: Rafael Hernandez(Project Director), Todd French, Sandun Fernando, Tingyu Li, Dwaine Braasch, Juan Silva, and Brian Baldwin

Principle Investigators: Rafael Hernandez

\section{Subcontractors:}

Cost-Sharing Partners:

DOE Project Team

DOE-HQ contact: Mark Decot, mark.decot@ee.doe.gov

DOE Field Project Officer: Fred Gerdeman, fred.gerdeman@go.doe.gov

DOE Project Engineer: Nicholas Frasier, nicholas.frasier@go.doe.gov 


\section{Executive Summary}

Municipal wastewater treatment plants in the United States produce over 6.2 million metric tons of dried sewage sludge every year. This microorganism rich sludge is often land filled or used as fertilizer. Recent restrictions on the use of sewage sludge, however, have resulted in increased disposal problems. Extraction of lipids from sludge yields an untapped source of cheap feedstock for biodiesel production. Solvents used for extraction in this study include $n$-hexane, methanol, acetone, and supercritical $\mathrm{CO}_{2}$. Gravimetric yield of oil was low for non-polar solvents but addition of polar solvents gave a considerably increased yield. However, the percent of saponifiable material was less. Extraction of lipids with a mixture of $n$-hexane, methanol, and acetone gave the largest conversion to biodiesel for a solvent system, $4.41 \%$ based on total dry weight of sludge. In Situ transesterification of dried sludge resulted in a yield of $6.23 \%$. Assuming a $10 \%$ dry weight yield of FAMEs the amount of biodiesel available for production in the United States is 1.4 million cubic meters per year. Outfitting 50\% of municipal wastewater plants for lipid extraction and transesterification could result in enough biodiesel production to replace $0.5 \%$ of the national petroleum diesel demand ( 0.7 million cubic meters).

Other sources of lipids investigated were Black mustard, birdseed rape, canola, Camelina, Crambe, flax, and Hesperis. These plants were selected based on their oil content and their capability to grow in the US Southeast. Genetic procedures were developed to increase the oil content of these plants. Of the species investigated, canola, sunflower, and okra have the greatest potential. However, it should be noted that even 
record yields of all the crops mentioned above will not come close to fully replacing the U.S. need for oil/petroleum.

Extraction procedures were developed to recover nutritional components, such as omega-3 fatty acid eicosapentaenoic acid (EPA) and docosahexaenoic acid (DHA), from oil and biodiesel. Additionally, a method was developed to isolate another value added product, Vitamin E, from oils. The methods developed were based on differences in binding between polyunsaturated fatty acid methyl esters and the transition metal ions. More than 90\% EPA was recovered using AgBF4/SiO2 $\bullet \mathrm{Im}+\bullet \mathrm{PF}^{-}$. After a consecutive two-step stripping by ethyl ether and then 1-hexene, the concentration of EPA increased from $7 \%$ in the feed stock solution to about $90 \%$ in the 1 -hexene stripping solvent. After five recycles, the sorbent is still usable.

Ordered mesoporous adsorbents were prepared by physically coating functionalized ionic liquids onto mesoporous silica gel. These adsorbents were successfully applied to the selective extraction and separation of vitamin E from a model mixture of soybean oil deodorizer distillate. Five adsorbent recycle tests showed good reusability of this ionic liquid-modified mesoporous adsorbent.

Another approach to improve the overall economic feasibility of biodiesel production is the conversion of glycerine into value added chemicals. Microorganisms capable of converting glycerine to 1,3-propanediol and lactic acid were isolated from various environments ranging from manure to sewage treatment plants. There was one notable isolate that co-produce both products and one in particularly high concentrations. This culture with more understanding of its metabolic pathways could prove a useful biological agent for the conversion of glycerol. 
Homogeneous acid or base catalysts dissolve fully in the glycerol layer and partially in the fatty acid methyl esters (biodiesel) layer in the triglyceride transesterification process. Heterogeneous (solid) catalysts, on the other hand, can prevent catalyst contamination making product separation much simpler. In the present work, the transesterification kinetics of five different solid catalysts with soybean oil is presented. It was determined that heterogeneous catalysts require much higher temperatures and pressure to achieve acceptable conversion levels when compared to using homogeneous catalysts. Subsequent to preliminary investigations, transesterification was conducted for selected high performance solid catalysts, i.e., $\mathrm{MgO}, \mathrm{CaO}, \mathrm{BaO}, \mathrm{PbO}$, and $\mathrm{MnO}_{2}$ in a high pressure reactor up to a temperature of $215^{\circ} \mathrm{C}$. The yield of the fatty acid methyl esters and the kinetics (rate constant and order) of the reaction were estimated and compared for each catalyst.

Meeting sustainable energy demand with minimum environmental impact is a major area of concern in the energy sector. Alternative fuels such as biodiesel, ethanol etc. have been quite promising for fulfilling both these aspects. While biodiesel reduces emissions of $\mathrm{CO}$, life cycle $\mathrm{CO}_{2}, \mathrm{SO}_{\mathrm{x}}$, volatile organic compounds (VOC) and particulate matter (PM) significantly, the propensity for the production of $\mathrm{NO}_{\mathrm{x}}$ is an important problem that requires extensive research. $\mathrm{NO}_{\mathrm{x}}$ emission from a direct-injection diesel engine is mainly due to formation of thermal NO that is described by Zeldovich mechanism. Thus, studying temperature profile during biodiesel combustion can provide useful insights to the formation and destruction of $\mathrm{NO}_{\mathrm{x}}$. The main objective of this work is to investigate the effect of component methyl esters of biodiesel on open air flame temperature distribution and the effect of blending biodiesel with diesel and oxygenates 
(ethanol and methyl acetate) on open air flames. This objective was achieved by obtaining thermocouple measurements and thermal infrared imaging of local flame temperatures of wick-generated open air flames. A relationship between blend proportions and relative flame temperatures were obtained. In general, it was found that blending oxygenates such as ethanol and methyl acetate into petroleum diesel tended to increase the flame temperature in comparison with straight diesel fuel. The analyses of relative flame temperatures of different components of biodiesel were performed to evaluate the effect of unsaturation level and the hydrocarbon chain length on the flame temperature. It was found that the saturated methyl esters resulted in greater flame temperatures in comparison to unsaturated methyl esters. It was also revealed that shorter chained fatty acid methyl esters lead to higher flame temperatures as compared to its longer chained counterparts.

The monoalkylesters of fatty acids derived from vegetable oils or animal fats, are considered as an attractive alternative fuel for diesel engines. This interest is based on a number of properties of biodiesel including the fact that it is produced from a renewable resource and its potential to reduce exhaust emissions. Although several studies have been performed on biodiesel emissions, the results have been contradictory with some studies reporting a reduction of $\mathrm{NO}_{\mathrm{x}}$ emissions while others reporting an increase. Also, thus far, there has been no promising method on record which has been successful in reducing biodiesel related $\mathrm{NO}_{\mathrm{x}}$ emissions. The objective of this study was to evaluate the effect of blending biodiesel and ethanol into conventional diesel fuel on exhaust gas emissions. Ethanol could be added to diesel in limited quantities along with biodiesel since biodiesel stabilizes the ternary system by acting as an amphiphile. This paper 
illustrates the emission characteristics of diesel-biodiesel-ethanol (DBE) fuel blends on one used and two brand new engines. DBE is a new form of oxygenated diesel fuel blend and has a potential to reduce $\mathrm{NO}_{\mathrm{x}}$ emissions and to be an alternative to diesel fuel. The blend ratio (diesel: Biodiesel: ethanol) by volume used in this study was 70:25:5, 70:20:10 and 70:15:15. The results from the operation of diesel engine with DBE showed a significant reduction in $\mathrm{NO}_{\mathrm{x}}$ emissions in new engines with increased ethanol concentration where as with the old engine under similar conditions, an increased $\mathrm{NO}_{\mathrm{x}}$ emissions profile was observed. $\mathrm{CO}$ emission increased with increasing ethanol proportion in the blends in both new and old engines.

\section{List of Peer Reviewed Publications}

1. Paraschivescu, M.C., Alley, E.G., French, W.T., Hernandez, R, Armbrust, K., "Determination of Methanol in Biodiesel by Headspace Solid-Phase Microextraction," Bioresource Technology, Accepted for Publication, September 2007.

2. Liang, K., Toghiani, H., Hernandez, R., French, W.T., Dufreche, S., Mondala, A., "Biodiesel Production by In-Situ Transesterification of Primary and Secondary Sludge," Bioresource Technology, Submitted June 2007. Conditionally accepted. Revision required.

3. Dufreche, S., Hernandez, R., French, T., Sparks, D., Zappi, M., and Alley, E., "Extraction of Lipids from Municipal Wastewater Plant Microorganisms for Production of Biodiesel," J. Amer Oil Chem Soc, 2007, 84, 181-187.

4. Singh, A.K., Fernando, S., and Hernandez, R., "Base-Catalyzed Fast Transesterification of Soy Bean Oil Using Ultrasonication," Energy \& Fuels, 2007, 21, 1161-1164.

5. Li, M., Wang, T., Pham, P.J., Pittman, Jr., C.U., Li, T., "Liquid Phase Extraction and Separation of Noble Organometallic Catalysts by Functionalized Ionic Liquids," Separation Science and Technology, 2008, 43, 1-14.

6. Li, M., Pham, P.J., Li, T., "Extraction and Concentration of Omega-3 Fatty Acid Methyl Esters by Ionic Liquids Containing Silver Salt," Separation Science and Technology. Conditionally accepted. Revision required.

\section{Technical Presentations at National and State Conferences}

1. French, W.T., Hernandez, R., Zappi, M., Dufreche, S.T., Sparks, D.L., "Production of Biodiesel from Wastewater Treatment Sludge," World Renewable Energy Congress IX, 19-25 August 26 Florence, Italy. 
2. Hernandez, R., "Novel Processes and Feedstocks for Producing Biodiesel," Energy Summit Sponsored by Congressman Chip Pickering, Pearl, Mississippi.

3. Hernandez, R., Sparks, D., French, T., Toghiani, H., Toghiani, R., Zappi, M., "Production of Value-Added Chemicals via Oxidation of Lipids in Supercritical Carbon Dioxide," $97^{\text {th }}$ AOCS Annual Meeting \& Expo, April 30-May 3, 2006, St.Louis, Missouri.

4. Dufreche, S., Hernandez, R., Zappi, M., French, T., Sparks, D., Alley, E., "Production of Low-Cost Biodiesel Using a Novel Bacterial-Based Feedstocks," $97^{\text {th }}$ AOCS Annual Meeting \& Expo, April 30-May 3, 2006, St.Louis, Missouri.

5. Hernandez, R., "Biodiesel from Non-Traditional Feedstocks," Southeast Diesel Collaborative Meeting Sponsored by the Environmental Protection Agency, April 26, Atlanta, GA.

6. Hernandez, R., French, T., Dufreche, S., Sparks, D., Zappi, M., "MSU Biodiesel Production Process," 2006 Bioproducts Conference Sponsored by the Mississippi Biomass Council, April 23, 2006, Philadelphia, Mississippi.

7. Hernandez, R., and French, W.T., "Overview of the Biodiesel Industry," Mississippi Young Farmers Association, $21^{\text {st }}$ January, 2006, Jackson MS.

8. Hernandez, R., French, T., Sparks, D., Dufreche, S., "Biodiesel Production Using Alternative Feedstocks," $87^{\text {th }}$ Annual Convention of the Southern Seed Association," January 15, 2006, San Antonio, TX.

9. Benson, T., Hernandez, R., French, T., and Zappi, M., "Production of Biodiesel from Wastes Associated with Meat Butchering Processes," Presented at the 2005 AIChE Annual Meeting, Cincinnati OH.

10. French, T., Hernandez, R., Easterling, E., and Zappi, M., "Extraction and Production of Value-Added Products from Waste Feedstocks," Presented at the 2005 AIChE Annual Meeting, Cincinnati OH.

11. Dufreche, S., Hernandez, R., French, T., Zappi, M., Sparks, D., and Alley, E., "Production of Low-Cost Biodiesel Using a Novel Bacterial-Based Feedstock," Presented at the 2005 AIChE Annual Meeting, Cincinnati OH.

12. Hernandez, R., Zappi, M., French, T., Whitlock, J., and Alley, E., "Production of Biodiesel Using an Integrated Extraction Reaction Method," Presented at the 2005 AIChE Annual Meeting, Cincinnati OH.

\section{Refereed Proceedings}

1. Holmberg, K.B., K.D. Jones, B.S. Baldwin, J.L. Douglas, J.M. Grabowski. 2006. Progress and Problems in Selecting Six Native Grass Species. Pp. (Proc.) Fifth Eastern Native Grass Symposium. Harrisburg, PA. Oct 10-13.

\section{Edited Proceedings}

1. Oldham, L.O., B.S. Baldwin, D.J. Lang, and M. Collins. Biofuel research efforts in Mississippi. In Carl Crozier ed. Southern Plant Nutrient Management Conference Proceedings. October 2-3, 2007. Olive Branch, MS. Publisher: The Noble Foundation. 


\section{Other Publications:}

1. National Winter Canola Variety Trail. 2007. Report of Progress 973. Kansas State Uni. Agric. Expt. Stat. And Coop. Ext. Ser. Contribution No. 07-187-S.

2. National Winter Canola Variety Trail. 2006. Report of Progress 973. Kansas State Uni. Agric. Expt. Stat. And Coop. Ext. Ser. Contribution No. 07-187-S.

\section{Theses and Dissertations:}

1. Holmberg, Kyle B. Selection for reduced seed dormancy in seven native grass species. M.Sc. Mississippi State Univ. Plant and Soil Sci. Dec. 2007. 


\section{Table of Contents}

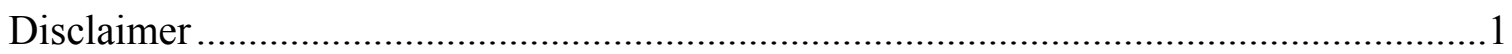

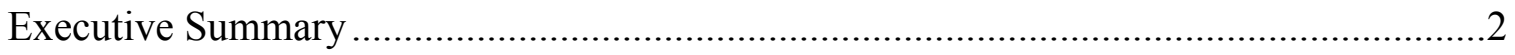

List of Peer Reviewed Publications ..................................................................

Technical Presentations at National and State Conferences ....................................6

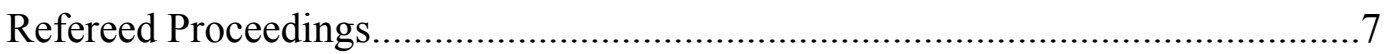

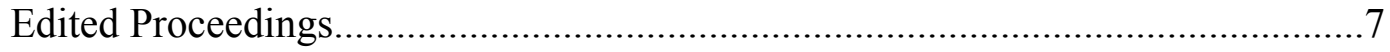

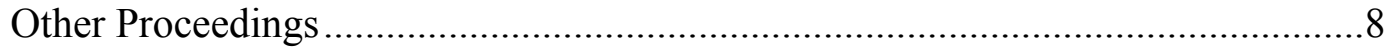

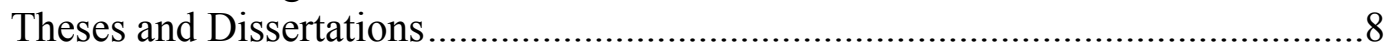

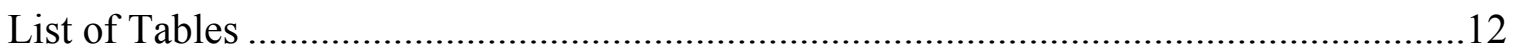

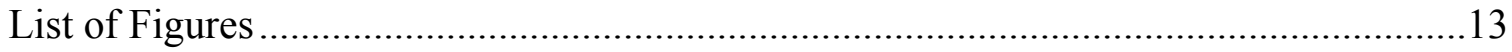

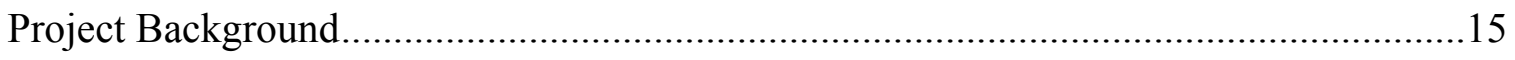

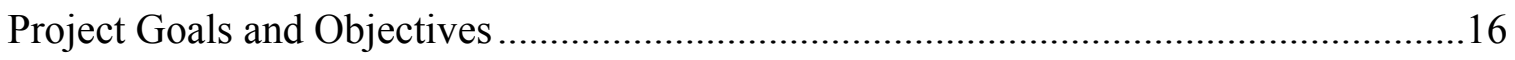

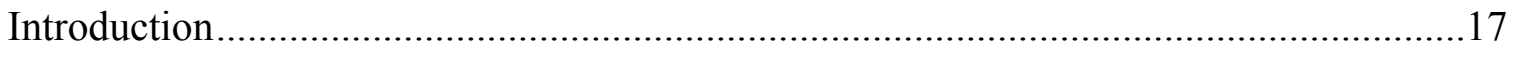

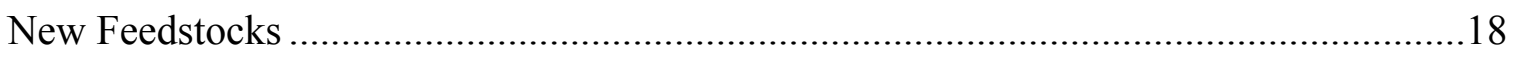

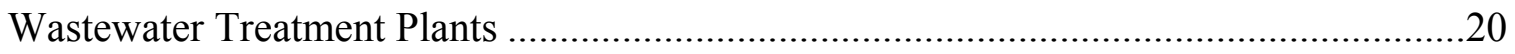

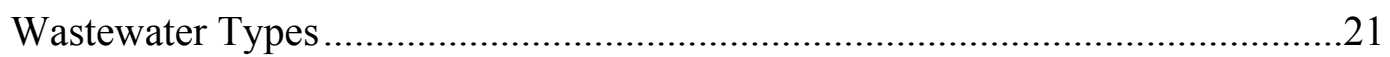

Wastewater Treatment Plant Hydraulic Capacities ................................................22

Overview of the Activated Sludge Process.........................................................23

System Management .....................................................................................25

Municipal Treatment Plants ................................................................2.

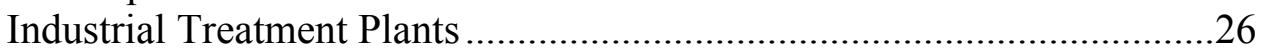

Agricultural Treatment Plants ................................................................26

Lipid Origins in Wastewater Treatment Facilities......................................................26

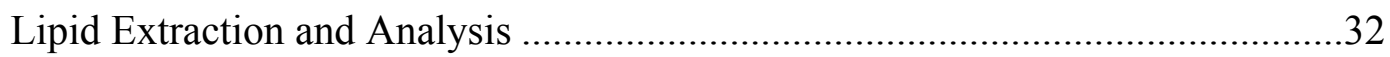

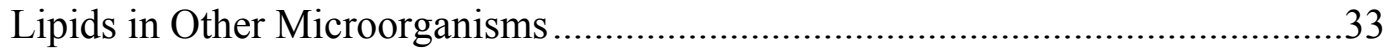

MSU Research on Southeast Oil Crops .........................................................................

MSU Research on Genetics of Oil Bearing Plants .........................................................37

Research on Sludge Oil Extraction and Biodiesel Production...........................................42 


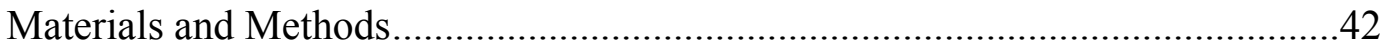

Extraction of Lipids from Sewage Sludge ...............................................42

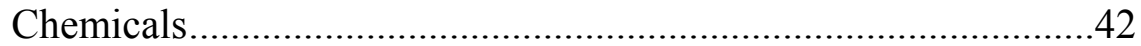

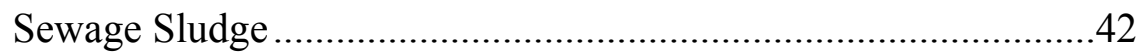

Sample Preparation .....................................................................42

Organic Solvent Extraction.............................................................43

In Situ Transesterification .....................................................................44

Analysis of Fatty Acid Methyl Esters ........................................................44

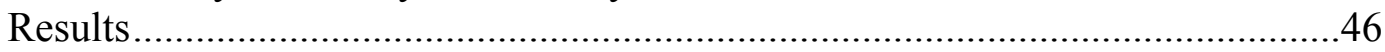

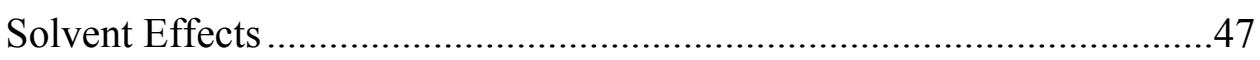

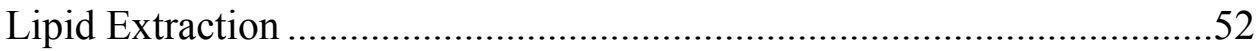

Research on Extraction of Nutritional Components from Biodiesel .................................57

Part 1: Extractive Separation of Polyunsaturated Fatty Acid Methyl Esters .........57

Part 2: Separation of Vitamin E from Soybean Oil ..................................................60

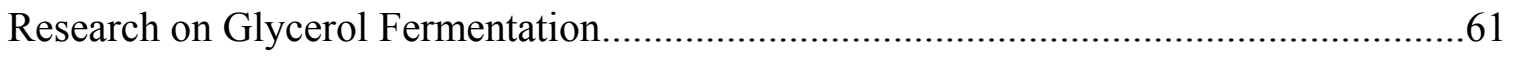

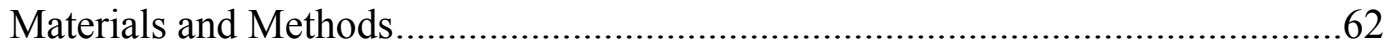

Glycerol-Fermenting Cultures ............................................................62

Isolation of Glycerol-Fermenting Cultures ................................................64

Glycerol GC-FID Analytical Method .........................................................66

Lactic Acid and 1,3-Propanediol Analysis with HPLC ..............................66

Correlating Cell Mass to Optical Density ……………….........................67

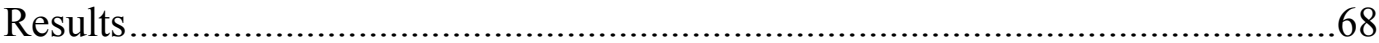

Glycerol Conversion by C. acetobutylicum, C. beijerinckii, and $C$.

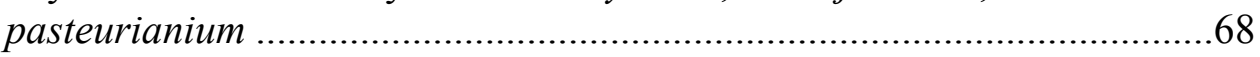

Glycerol Conversion by MSU Isolates …………………………….........70

Research on Reaction Kinetics of Soybean Oil Transesterification Using Heterogeneous

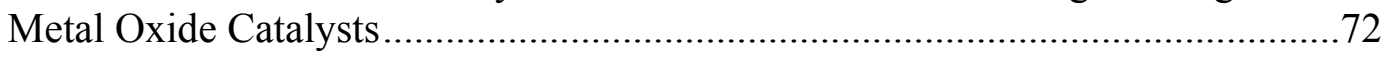

Biodiesel Production Using Solid Catalysts ........................................................73

Reaction Kinetics of Transesterification Reaction ................................................75

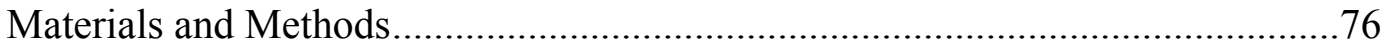

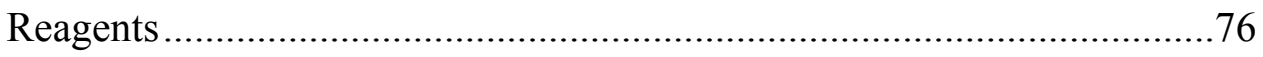

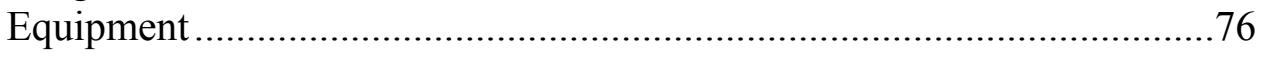

Soybean Oil and Methanol Solution .......................................................76

Transesterification..............................................................................76

Gas Chromatography Analysis ...............................................................77

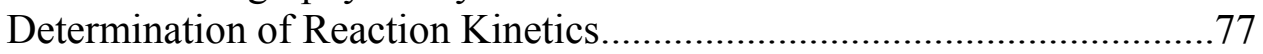

Determination of Surface Area of the Catalysts .......................................80

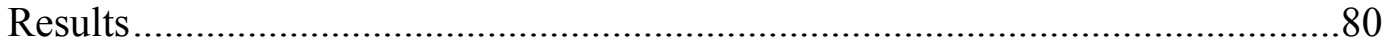

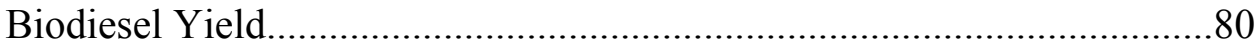

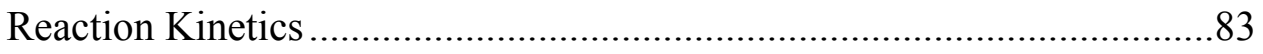




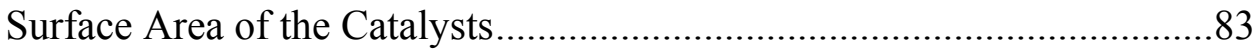

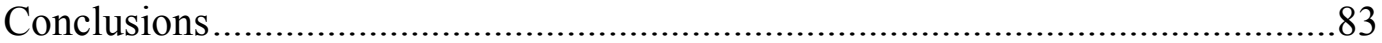

Research on Flame Temperature Analysis of Biodiesel Blends and Components .............88

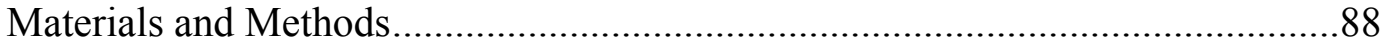

Thermodynamics of Combustion Using Fatty Acid Methyl Esters............90

Energy Flow Analysis........................................................................91

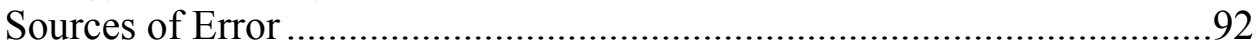

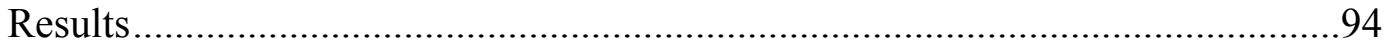

Research on Exhaust Emissions Using Diesel-Biodiesel-Ethanol Blends in New and Used

Compression Ignition Engines .......................................................................100

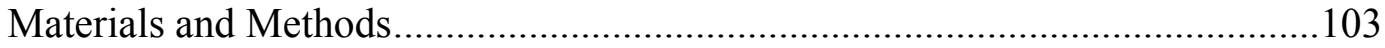

Engine and Instrumentation .............................................................103

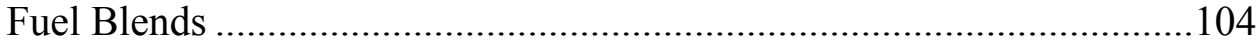

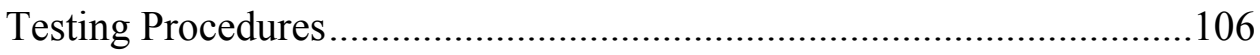

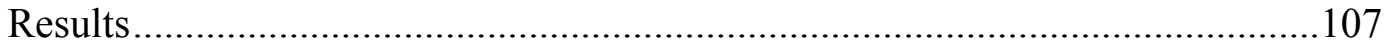

CO Emissions...................................................................................107

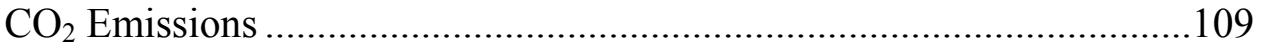

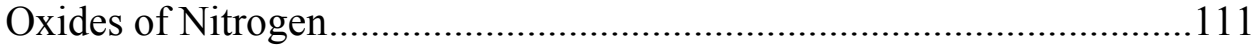

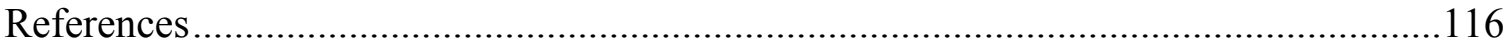




\section{List of Tables}

Table

1 Comparison of Fatty Acid Distribution of Wastewater vs. Microalgae

2 Lipid Biosynthesis Genes of Interest Names, Sequence Source Species, and

Functions.

3 Extraction and Transesterification Yield of Waste Activated Sludge . .48

4 Solvent Solubility Parameters for Extraction Systems

5 Production Cost Estimate for Sludge Lipids 56

6 Final Concentration of 1,3-Propanediol and Lactic Acid in the Fermentation Medium When the ATCC Cultures Were Offered ATCC 1500 Glycerol Medium

7 Final Concentration of 1,3-Propanediol and Lactic Acid in the Fermentation Medium When Offered ATCC 1500 Glycerol Medium to the MSU isolates ...71

8 The Value of Coefficient of Correlation $\left(\mathrm{R}^{2}\right)$ of All Eight Cases for Each Catalyst 84

9 Reaction Order of the Transesterification w.r.t. Each of the Reactant as well as Overall and the Rate Constant ....................................................................8 84

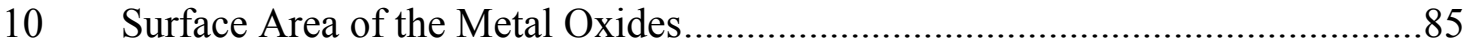

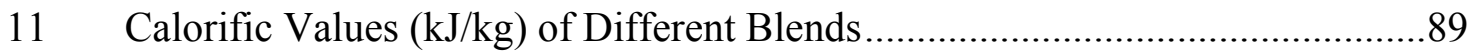

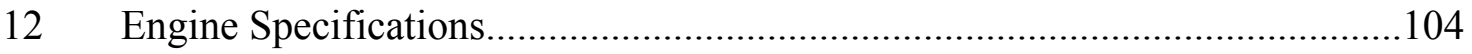

13 Fuel properties of diesel, biodiesel, and blends ............................................. 


\section{List of Figures}

Figure

1 Standard Municipal Wastewater Treatment Plant .29

2 Impact of Extraction Medium on Fatty Acid Composition of Oil.....................54

3 Comparison of Saturated vs. Unsaturated Fatty Acids Present in Waste Activated Sludge Samples .55

4 Comparison of Various Extraction Systems ..................................................58

5 Comparison of Extraction of EPA (20:5) in Hexane with Metal Ions in Ionic Liquids

$6 \quad$ Fully Developed Winogradsky Column with Distinct Biofilm Layers and Glycerol-Fermenting Microorganisms Label Clostridium

7 Worker Transferring Cultures in the Coy Flexible Anaerobic Chamber.....

8 Correlation of Absorbance to Dry Mass Concentration for Clostridium acetobutylicum

9 Correlation of Absorbance to Dry Mass Concentration for Clostridium beijerinckii

10 Correlation of Absorbance to Dry Mass Concentration for Clostridium pasteurianium

11 Transesterification of Soybean Oil into Biodiesel ...........................................72

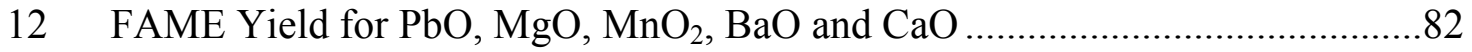

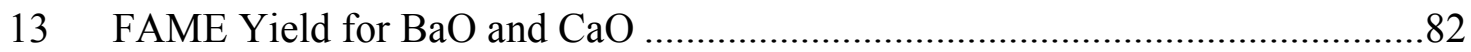

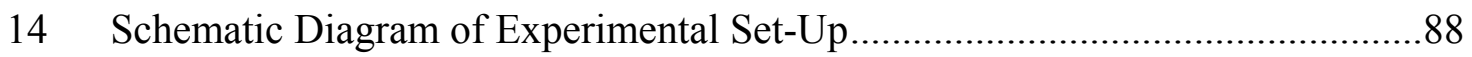

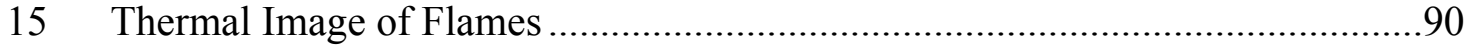

16 Estimates of Stoichiometric Air-Fuel Ratio for Different Fatty Acid Methyl Esters

17 Lower Heating Value and Adiabatic Flame Temperature of FAMEs .92 
18 Effect of Blending Soybean Biodiesel with Ethanol, Methyl Acetate and

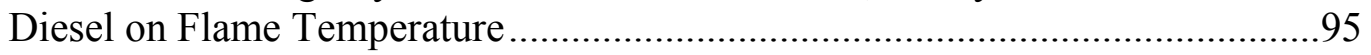

19 Comparative Fuel Consumption Rate of Soybean Biodiesel Blends with Ethanol, Methyl Acetate and Diesel with Respect to Pure Soybean Biodiesel

20 Flame Temperature and Calorific Value of Different Components of

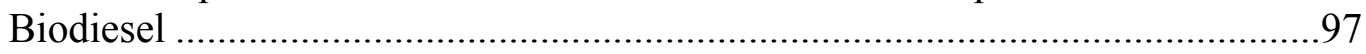

21 Effect of Change in Unsaturated Methyl Ester Proportion in Fatty Acid Methyl Ester Blends.

22 Comparative Fuel Consumption Rate of Biodiesel Components with Respect to Pure Soybean Biodiesel ...............................................................................98

23 Comparison of the Carbon Monoxide Level ..................................................108

24 Comparison of the Carbon Dioxide Level ......................................................110

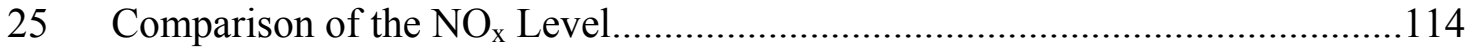


Project Background: Biodiesel is widely considered to be a renewable transportation fuel that holds some promise as a means of displacing appreciable quantities of petroleum-based diesel fuel. Biodiesel is produced via the transesterification of lipid feedstocks that are extracted from plant or animal sources. Unfortunately, the future of this fuel based on its current status appears to provide limited impacts to truly reducing foreign oil dependency because of high production costs (approximately $\$ 4.00$ per gallon for soy oil) and relatively low US production capability (if all of the existing oleochemical capability within the US is utilized only 500 million gallons of biodiesel could be produced per year; yet, the US burned over 60 billion gallons of petroleumbased biodiesel last year). Lipid feedstocks represent over $75 \%$ of biodiesel production costs. This project focused significant research efforts on developing several potential candidate lipid feedstocks for their applicability for use in the production of biodiesel. Additionally, innovative extraction techniques, such as co-solvent amended supercritical extraction, were studied as potential replacement processing steps that may offer reduced production costs, improved extraction efficiency (phospholipids capture), and a much more environmentally friendly process. To increase the profitability of biodiesel production, the extraction and separation of novel secondary products, such as selected lipids (lecithin) and fatty acids (DHA and EPA), prior to transesterification were researched; thus moving this proposed second generation processing approach to biodiesel production toward the status of a true biorefinery. As a means of further enhancing the market appeal of biodiesel, several techniques to improve environmental performance were evaluated including reducing oxide emissions and utilization of more environmentally friendly process chemical reagents. To accomplish the above stated 
efforts, developmental tasks were performed by a research team consisting of process engineers, mechanical engineers, plant scientists, biochemists, economists, chemists, biologists, and microbiologists.

\section{Project Goals and Objectives}

Biodiesel holds significant promise as a potential displacement fuel for petroleum-based diesel fuel. However, due to high production costs using commonly used feedstocks, such as soybeans and rapeseed, its utilization rate has been marginal at best. The two biggest culprit costs causing this high production cost are raw feedstock and extraction/processing costs. Within the Southeastern United States (SE-US), the establishment of a viable biodiesel industry has been particularly very slow. The reasons for this are the high level of heterogeneity of feedstocks within this region, the relatively low density of soybean cultivation, and limited expertise on the application developing design concepts for biodiesel production.

The overall goal of this effort was to develop a research base within Mississippi that can address key technology hindrances to process maturation within the SE-US that are associated with technology, economic, and agricultural limitations and data gaps. To accomplish the above stated overall goal, a multi-disciplined research team consisting of process engineers, mechanical engineers, plant scientists, biochemists, economists, chemists, biologists, and microbiologists has been organized. Academic units from Mississippi State University (MSU) participating with this project include those from the MSU Bagley College of Engineering (Dave C. Swalm School of Chemical Engineering and the Agricultural, Mechanical Engineering, and Biological Engineering Department); Mississippi Agricultural and Forestry Experiment Station (Departments of Plant and Soil 
Science, Biochemistry, Agricultural Economics, and Food Sciences); and The MSU College of Arts and Science (Chemistry Department).

\section{Introduction}

Biodiesel is typically defined as the alkyl ester of a fatty acid. The production of these chemicals involves the esterification of a fatty acid or the trans-esterification of a glycerin-bound fatty acid (in the form of a di- or tri-glyceride). The primary reagents for the very common transesterification reaction are a lipid (fat and/or oil), a simple aliphatic alcohol - methanol or ethanol are almost exclusively used (with methanol being by far the most commonly used), and a base (potassium or sodium hydroxides). When methanol is used, the biodiesel may be called a fatty acid methyl ester or FAME. The two key products (almost exclusive from a mass perspective) of the transesterification of a triglyceride are the FAME and the free glycerin. The mass yield ratio of FAME to glycerin is approximately 10:1. Given the stoichiometric requirement of the alcohol and the amount of glycerin produced, approximately one volume of the lipid yields about one volume of FAME. Hence, the lipid source is a key reagent for the production of biodiesel. In fact, it represents the single most expensive feedstock of the biodiesel production process. Using most commonly available oilseeds from the US, the lipid costs amount to approximately $80 \%$ of production costs (production cost have most recently ranged from $\$ 3.50$ to over $\$ 4.00$ per gallon). During the early 2000 's, domestic biodiesel production was about $40 \mathrm{Mgal}$ per year with plants running at about $60 \%$ of total production capacity.

The US Congress during the 2005 session passed a biodiesel tax incentive (a blender's credit) which amounted to $\$ 1.00$ per gallon blended if the lipid derived from 
most major oilseeds grown within the US or animal-based lipids (the law provides a list of all involved lipid feedstocks eligible for the $\$ 1.00$ per gallon). All other lipid feedstocks receive $\$ 0.50$ per gallon when blended. This tax incentive has sparked a dramatic growth in the biodiesel industry. The 2006 production saw the total production capacity grow to over $80 \mathrm{Mgal}$ with production using approximately $75 \%$ of available capacity. Another boom that was experienced was in the construction of biodiesel plants. It is estimated that 2007 will result in the total US biodiesel production capacity to be well in excess of 300 Mgal.

This dramatic growth in both production and production capacity may cool down due to regional shortages of lipids and increasing methanol prices. In fact, many new biodiesel facilities are being constructed with the flexibility to produce biodiesel using either acid esterification or base transesterification. Additionally, many lipid feedstocks overlooked as poor sources during the early 2000's (such as palm oil) have seen tremendous market growth spurred by the US biodiesel industry. Many regions of the US, like the Deep South, will have much more production capacity than the total volume of acceptable lipids produced within that region. The lack of viable lipid feedstocks (economically and technically) will very likely stifle the realization of biodiesel as a significant fuels displacement option for the US. With the US burning approximately 60 Bgal of petrol diesel each year, clearly, either significant volumes of new lipid feedstocks must be found or the US biodiesel industry will stagnate.

\section{New Feedstocks}

The foremost issue with current feedstocks is limited availability in the face of increasing demand. A common theme is the use of food crops to produce fuel, a non- 
sustainable long-term model. Large amounts of corn grown in the heartland are turned into ethanol, and most surplus soybean oil is converted to biodiesel [1]. Replacement feedstocks are therefore needed that will not place unreasonable demands on the nation's foodstuffs. New technologies are currently being developed to augment the feedstocks used today. Processes such as fermentation of cellulosic sugars for ethanol production are expanding the pool of available feedstocks to materials which were previously ignored by industry.

For diesel replacement, new plant oil sources are constantly evaluated on their properties as a transesterified product. These range from trees, such as the Chinese tallow tree, to plants such as Castor.

Microbial sources have also caught the attention of several researchers as a new feedstock. Work on farming algae for lipids was started during the oil crunch of the 70's, but declined after the drop in crude oil prices. While interest has recently picked up in using harvested lipids as biodiesel feedstock, problems still exist regarding the cost of raising the algae since they must be grown for harvest [2].

One of the most novel and promising feedstocks, however, involves the use of readily available microorganisms as a lipid source. Municipal wastewater treatment facilities (MWWTF) in the USA produce $6.2 \times 10^{6}$ tons (dry basis) of microbial sludge annually [3]. This sludge is composed of a variety of organisms which consume organic matter in wastewater. The content of phospholipids in these cells have been estimated at $24 \%$ to $25 \%$ of dry mass $[4,5]$. Since phospholipids can be transesterified they could serve as a ready source of biodiesel. The sludge produced is currently viewed as a waste product and disposed of through landfills, land application on farms, or incineration. 
Since the sludge is produced through an established, necessary process, there is no extra cost associated with raising the microorganisms.

\section{Wastewater Treatment Plants}

Since the process under development involves the use of sludges produced at wastewater treatment plants (aka. sewage treatment plants) a brief overview of these plants is presented. Wastewaters whether produced from municipal or industrial sources typically require some form of treatment prior to discharge into environmental receptors. Wastewater treatment systems may be classified as either aerobic or anaerobic systems. Aerobic systems utilize microorganisms that produce much larger quantities of biomass during treatment than the anaerobic systems (approximately 30 times more for the same amount of waste carbon added to the treatment plant). Hence, from a pure tonnage produced standpoint, aerobic systems should provide more biomass and hence lipids than would the anaerobic systems. This is true unless archea (the key organisms within anaerobic systems) produce more lipids, or possibly, better lipid profiles than would the aerobic organisms - albeit, this is doubtful, thus indicating that aerobic systems are likely the better treatment plants to focus on at this time.

Aerobic treatment plants are actually a category of many designs that all utilize aerobic microorganisms as the biocatalyst that degrades the carbon within the wastewater influent. A technique commonly used for classifying aerobic treatment plants is based on the physical state of the microorganisms - whether they are suspended (or highly motile) or attached onto a support media. Among the suspended systems activated sludge is by far the most commonly used design within the US. Others include oxidation ditches, sequential batch reactors (SBRs), and lagoons. Attached growth systems commonly used 
in the US are trickling filters, rotating contactors, and packed reactors. In any treatment system in which the carbon within the influent or "food" enters the system, the result is respiration (production of energy used for cell maintenance) and reproduction (growth of the total biomass due to more cells being produced). Within any of these systems, the primary microorganisms found within the reactors are bacterial species. Additionally, bacteria-grazers are also found, such as rotifiers, ciliates, etc. However, still the vast majority of the active biomass within the systems is bacteria and as such the discussion herein will use biomass interchangeably with bacteria (do note that in the case of lagoons, algae can be a primary biomass component as well - discussed later).

Most of the aerobic systems result in the production of vast quantities of biomass as waste carbon is added into the system. However, these systems often operate hydraulically such that the bacteria are reproducing faster than they die-off or are consumed by grazers - often called indigenous decay. Thus, the systems can reproduce to a point where biomass must be "wasted" or removed to maintain a consistent population of bacteria. This wasted sludge is often referred to as "waste sludge" or "secondary sludge". In essence, waste sludge is produced to keep the system or bioreactor at a microorganism population steady-state condition.

\section{$\underline{\text { Wastewater Types }}$}

There are a wide variety of wastewaters produced. The three most common are municipal, industrial, and agricultural. Municipal wastewater is generated as input into a municipality's sewage collection system. Often miles of pipeline are used to collect this wastewater. Most of this pipeline system is gravity flow, but some components are pressurized to overcome negative hydraulic gradients and/or accelerate transport of 
wastewater to the treatment plant. Typically the average amount of wastewater volume produced within the US falls within the 100 to 200 gallons per day per person (per capita input basis). The biochemical oxidation demand (BOD) of these waters often found in the 200 to $600 \mathrm{mg} / \mathrm{l}$ range with a BOD to chemical oxidation demand (COD) in the 0.6 to 0.9 range (thus, indicating a highly biodegradable material). The bulk of the organics making up the carbon causing the BOD or COD is primarily human fecal matter, kitchen wastes, and rinse-waters (aka. grey waters) from washing. Grease and oils are common components of this carbon - often found in the $100 \mathrm{mg} / \mathrm{l}$ range as measured using separations-based, gravimetric methods. Hence, influents can input quantities of significant lipids into wastewater plants.

While per capita inputs are most often the most significant input into municipal wastewaters, industrial inputs can also be significant. Both the hydraulic and chemical composition of these wastewater influents can vary quite dramatically depending on the industrial activity on-going within the industry generating the input stream. However, with food processing and petroleum-based industrial inputs, the introduction of lipids and/or recoverable hydrocarbons can be significant. One interesting aspect of the petroleum-based hydrocarbons would be the impact of these chemicals on subsequent lipid extraction activities. Initially, there does not appear to be concern, but it is worthy of further consideration.

\section{$\underline{\text { Wastewater Treatment Plant Hydraulic Capacities }}$}

The flow rate of influent (incoming water requiring treatment) into wastewater treatment plants can vary dramatically depending on the population of the municipality, production capacity of the factory, or the population of animals serviced at the farm. 
From a municipality standpoint, small plants fall in the less than $5 \mathrm{Mgal} / \mathrm{day}$ or MGD; medium tend to be less than 100 MGD; and large systems can be as large as 500 MGD. Most industries will have an influent flow rate less than 5 MGD with many being less than 1 MGD. Confined animal feeding operations or CAFOs typically utilize intermittent flows with equalized flow rates ranging in the less than 5 MGD range.

\section{Overview of the Activated Sludge Process}

Once wastewater influents are collected and transferred to the wastewater plant, the influents enter the "Headworks" of the plant. Here the influent may be divided up into within redundant plant process lines and/or passed through an equalization stage. Equalization basins or holding tanks are used to provide increased hydraulic handling during storm events and/or with smaller plants provide a more consistent flow through the plant.

The first actual active processing step into the plant is "Screening". Within this process large objects are physically removed via passage of the influent through a bar screen or grate. These captured items are usually disposed of within a landfill without any further treatment. The lipid or petroleum content of these solids is not reported to be very high.

The next processing step is "Degritting" which is a processing step which remove inert solids, such as sand, gravel, and other heavy residuals (typically none of these have a high organic composition). The collected solids or grit typically do not go further treatment and are then disposed within a landfill. Grit will likely not have appreciable lipid or oil content to warrant any consideration as a potential feedstock source for biofuels production. 
After degritting, the liquid influent enters the "Primary Treatment" stage. During primary clarification settling is used to remove the organic solids from the liquid influent - typically separated as insoluble BOD and soluble BOD. Separation is accomplished via the use of clarifiers (both round and rectangular are used). The clarifiers are often equipped with "slimmer" which collects floating materials off the surface of the clarifier volume. The primary components of the skim or scum are non-aqueous floating hydrocarbons (such as fats, oils, and grease [aka. FOG]), small floating inert materials, and light foam. The insoluble BOD or primary solids are then sent to the plant's sludge digestion facility. Note that not all plants use primary treatment - many smaller operations are starting to by-pass this option (however, by-passing primary treatment is still not a popular choice among plant designers). The Starkville, MS plant is an example of a facility that skips primary treatment.

After primary treatment, the influent, containing at this point water and soluble BOD, undergoes "Secondary Treatment". Within secondary treatment, the influent enters the aeration chambers or tanks. Within the aeration tank, aerobic microorganisms degrade the soluble BOD resulting in the conversion of the BOD into either new microorganisms (catabolism) or conversion into cell maintenance energy (anabolism). The microorganism population within the aeration tank is so large (typically ranging from 2,000 to $5,000 \mathrm{mg} / \mathrm{l}$ ) that this "living" biomass is often called "Activated Sludge" hence, the name of the process. From the aeration tank, the water containing the activated sludge (often referred to as "Mixed Liquor") enters the "Secondary Clarification" stage. Here the thickened mixed liquor is recirculated back to the head of 
the aeration tank. The pipes used to accomplish this transfer are called the sludge return lines.

Since the aeration tank is operated at steady-state conditions in terms of biomass concentrations within the tank, then the amount of new cells produced is "wasted" periodically (often daily). The activated sludge wasted is referred to as "Waste Sludge". At this point in treatment, the waste sludge is almost completely composed of active bacteria and a small portion of inert solids and not raw sewage. Wasting is done by redirecting a portion of the sludge return to the waste sludge line often to a sludge thickener which concentrates the sludge to a solids concentration of about $3 \%(w / w)$. After thickening, the sludge is transferred to the digestion stage where either aerobic or anaerobic microorganisms degrade the sludge (achieve about $60 \%$ degradation). After digestion, the residuals are dewatered to about $25 \%$ solids then are disposed off.

\section{$\underline{\text { System Management }}$}

The MSU Process will be dependent on the ability to access the sludges generated at wastewater treatment plants. It is critical that some understanding of how these systems are managed be gained prior to attempting to approach these facilities requesting access to their sludges. The management strategies used for each of the three-wastewater treatment plants are briefly detailed below:

Municipal Treatment Plants - Cities and towns tend to utilize a separate wastewater division or department within their governments. Often the head of this unit is an engineer with actual plant operations performed by highly trained operators. Over the past 20 years, some municipalities have contracted operations via a private contractor (referred to as "privatization"). However, it is expected that any agreements with a 
municipality will have to be approved by the major and/or council after a positive approval from the wastewater engineer. It is interesting to note that among the several challenges facing cities today with regard to wastewater treatment that sludges disposal and conversion of the sludges to Class A is among the most pressing. The MSU Process may actually greatly assist the city with these issues - yet, it is expected that getting approval from a municipality will be fairly more difficult than with the other two sources (industrial and agricultural) due to the bureaucracies associated with municipalities.

Industrial Treatment Plants - These facilities are usually run by their environmental departments. Often an engineer(s) oversees highly trained operators. However, any contact or decisions made will likely have to be done via corporate headquarters; however, negotiations should be easier than with a municipality. Liability associated with releasing their waste and any danger that this waste could later cause either personal or environmental damage will likely be a key issue.

Agricultural Treatment Plants - With these facilities there is not the layers of administrative levels that must be addressed. Typically, a farmer is the owner, operator, and manager of the facility. Therefore, negotiations involve only one person with that person used to dealing with commodities generated on-site. Unfortunately, unless treatment systems other than lagoons are used, the amount of bacterial-based sludge generated will be minor.

\section{Lipid Origins in Wastewater Treatment Facilities}

It has always been known that municipal, and even some industrial wastewater contains lipids. A cursory glance at wastewater entering a plant allows one to see oil and grease floating on top of the influent wastewater. This is due to the influent water 
bringing free lipids into the plant in the form of vegetable or animal wastes. An often overlooked source of lipids, however, is the microorganisms which inhabit the treatment plant. Like all animal cells, the microbes in a MWWTF are surrounded by a cell wall composed of lipids. Some of these cells also store energy in the form of lipids. Although some information was known about modeling of MWWTFs, the demand for a more complete operational picture called for increased model complexity. For example, it was found that long-chain fatty acids produce various toxic effects during anaerobic digestion [6,7]. Anaerobic digestion refers to the reduction of sludge mass through bacterial metabolism in the absence of oxygen. Bacteria produce methane gas as a metabolic waste product, which leaves the digester in the gas phase. Due to this and other pressing reasons there have been several attempts to document the amount and composition of lipids in the entire treatment process.

A typical MWWTF consists of several different sections working in sequence to take large amounts of organic waste and reduce it to manageable levels for release back into the environment. The standard measure of how much effect wastewater will have if released into the environment is the Biochemical Oxygen Demand (BOD). This is the amount of oxygen needed by organisms to degrade organics in the water. Figure 1 shows a standard MWWTF. Raw influent wastewater typically enters at the headworks, where large debris is removed to avoid clogging the system. The water then travels to primary clarification, where the majority of influent Biochemical Oxygen Demand (BOD) is removed through settling out of solids from the water. The primary solids are then thickened and dewatered for anaerobic digestion. The clarified water enters the activated sludge process, where aerobic microorganisms degrade organics in the water. These 
organisms conglomerate to form clusters of microbial mass which remove the organic load, converting it to lipids and other cellular material [8]. They are not a single species, but rather a consortium of different microbes. A delicate balance must be maintained between types filamentous organisms and those which remove nitrogen and phosphorous $[9,10]$. 


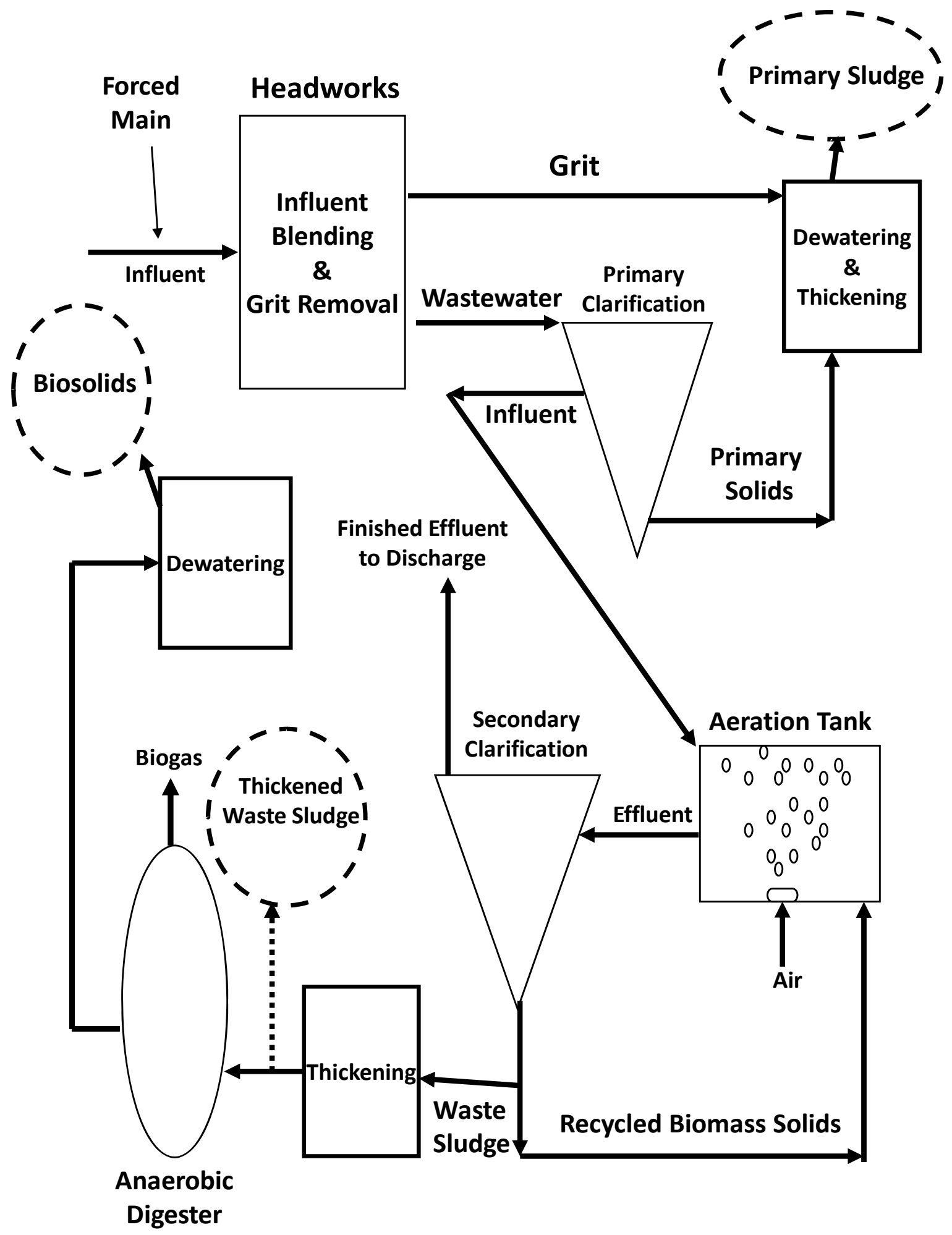

Figure 1. Standard Municipal Wastewater Treatment Plant. 
The water is passed through a secondary clarifier to remove the microbial cells, with the clarified water being clean enough for discharge in most cases. Part of the settled material is recycled back into the activated sludge process to maintain a steady state concentration of microorganisms, while the remainder is either disposed of or digested anaerobically. Both primary and secondary sludge are often digested anaerobically to reduce the mass of sludge which must be disposed of. In the aerobic process of activated sludge treatment, organisms remove BOD and convert it to energy and cellular material, as well as residual solids. This generates a large amount of biomass. In the anaerobic digestion process organisms convert waste microbial cells to energy and small molecules such as methane and hydrogen. This has the effect of reducing the mass of sludge left after digestion. Any remaining sludge is then dewatered for disposal.

It has been reported by Barttelbort and others that MWWTF influent is over 50\% organic material, and composed of 20 to $25 \%$ lipids by mass [11,12]. Of these, kitchen waste is responsible for 14 to $36 \%$ of the total [13]. Feces themselves contain between 4 to $23 \%$ lipids by mass [14]. In an average plant $45 \%$ of the total influent lipid content is derived from feces, while $55 \%$ is from kitchen wastes [15]. The overall goal of a treatment plant is to reduce the organic load exiting after treatment. This removal process takes place at several stages throughout the treatment plant, where organisms consume the lipids and other organic matter for energy [16].

The types of lipids, or lipid profile, also changes as influent material travels through the treatment plant. Lipids in raw wastewater are composed mainly of triglycerides, the dominant lipid type in animal and plant oils. This composition 
continues into the primary clarification step. As the treatment process moves toward the activated sludge tank, the lipid profile changes to include more phospholipids, glycolipids, and sterols [17]. This reflects the change from free lipids in solution to cellular lipids which were created by microorganisms feeding on organic matter in the waste. A major part of cells within the activated sludge system is the extracellular polymeric system (EPS). The EPS helps to bind organisms together and form flocs, to increase settling of the sludge. EPS varies between species of microorganisms, but normally contains carbohydrates, proteins, and lipids [8]. One significant difference is that pure bacterial cultures produced an EPS high in carbohydrates, while samples take in MWWTFs are higher in protein [18]. Martinez analyzed variations of carbohydrate, protein, and lipids over long periods; finding that while protein fluctuated from $7-40 \%$, the levels of carbohydrate and lipids remained constant at $40 \%$ by weight for lipids [19]. A byproduct of the activated sludge process is foam created by the microorganisms. This foam was also found to be a source of lipids, with some plants showing a concentration of up to $29 \%$ [20]. The wastewater lipid profile changes once again when aerobic microorganisms are replaced with anaerobic in the digester. The digester contains lower amounts of lipids than other parts of the process, but the lipids present have a much different composition than those found elsewhere in the plant [21]. Bacteria which inhabit an anaerobic digester contain specialized fatty acids, such as branched-chain fatty acids, which are not found in aerobic processes such as that of the activated sludge process. 


\section{Lipid Extraction and Analysis}

Most research on lipids in wastewater focus on extraction for laboratory work rather than commercial utilization. In microbiology, scientists often identify bacterial cultures by the types of fatty acids in their cells. The procedure required to prepare lipids for analysis, however, is the same chemical reaction used to produce crude biodiesel from lipids. In this sense, researchers are creating biodiesel every time they analyze a sample. The standard method consists of lysing the cells through physical or mechanical means $[22,23]$. The extraction of lipids is then performed through use of a solvent, followed by conversion to fatty acid methyl esters (FAMEs). Solvent used can range from hexane to toluene, isopropyl alcohol, methanol, and benzene [24-26]. In an experiment performed by Casado [23], the cells were mechanically lysed using sonication and extracted with methylene chloride. Others use the method of Bligh and Dier which involves extracting lipids in a single-phase system, then separating it into two phases $[25,27,28]$. The extracted lipids were transesterified with a solution of $\mathrm{BF}_{3}$ in methanol and analyzed through mass spectrometry [23]. One can substitute sulfuric acid or sodium hydroxide for $\mathrm{BF}_{3}$ without significant changes in lipid profiles or conversion efficiencies, but the chromatograms obtained have larger amounts of byproducts [29]. It is also possible to use other alcohols besides methanol in deriving lipids, although the products will not be methyl esters. A common alternative is isopropyl alcohol (IPA). Werker analyzed microbial communities in MWWTFs using sulfuric acid and IPA [30]. Dried cells were lysed in IPA with sulfuric acid, and then extracted with hexane for analysis. Table 1 shows common values for lipid composition in sewage sludge as reported in literature. 
In a sample without large numbers of microorganisms the lipids can be extracted from the sample without any lysing steps. When analyzing lipid concentrations in foam produced from the activated sludge process, Fahmy extracted free lipids with a combination of water washing and solvent extraction [20]. Work has also been performed on extracting lipids and other chemicals from biomass using supercritical fluids [31]. The use of supercritical fluids allows for easily tuning the extraction to maximize the yield of desired products.

Table 1. Comparison of Fatty Acid Distribution of Wastewater vs. Microalgae.

\begin{tabular}{llc}
\hline Fatty Acid & \multicolumn{2}{l}{ Percent Total Lipid Fraction } \\
& Wastewater & Microalgae \\
\hline C14 & 9.3 & 10.1 \\
C16 & 22.1 & 41.7 \\
C18 & 46.3 & 11.4 \\
C20 & 1.2 & 22.6 \\
C22 & 1.2 & 8.4 \\
Others & 19.9 & 5.8 \\
\hline \multicolumn{3}{r}{ Wastewater Data from Casado [23] } \\
\multicolumn{3}{r}{ Microalgae Data from Grima [32] }
\end{tabular}

\section{Lipids in Other Microorganisms}

There are other sources of microbial lipids than just sewage sludge. Algae, for example, have often been harvested for their oil production; although it was not always for fuel use. From 1978 to 1996 the U.S. Department of Energy conducted a study on obtaining microbial oil from various algal species with the intent of biodiesel production 
[2]. This study spawned a 328 page report detailing advances made in algae to fuel conversion over two decades of research. Researchers worked on over 3,000 different algae species, trying to find oil producers able to thrive in various conditions. The final organisms showed high growth rates and oil levels of up to $50 \%$ by weight [2]. Unlike organisms in a MWWTF, modifying the amounts of available nitrogen did not seem to have a significant effect on increasing the amount of oil produced. Although great breakthroughs were made in the large-scale production of oil from algae, including the use of $\mathrm{CO}_{2}$ as a carbon source, the cost of production remains too high for fuel use. Even using assumptions of photosynthetic efficiency near the theoretical limit, the projected cost of oil is twice that of petroleum derived fuel. Most of the cost was attributed to maintaining the organisms and pond systems required for large-scale production. The county of San Francisco conducted its own research into the problem, growing algae on municipal wastewater. This removed the requirement of feeding the algae expensive feedstock to produce oil. While oil production was favorable problems were still encountered with environmental conditions [33]. In both cases, the amount of land required to produce significant amounts of oil is still prohibitive to national replacement of petroleum fuel.

Other companies have grown algae for oil harvesting purposes other than fuel production. Martek Biosciences Corp. is a commercial company which grows algae for the purpose of extracting nutritional fatty acids such as docosahexaenoic acid (DHA) and arachidonic acid (ARA) [34]. Their organisms produce around 20\% lipids by weight, only $25 \%$ of which are nutritional fatty acids of commercial interest for their market. When using corn syrup as the carbon source in industrial fermenters, the operating cost 
are high. However, the market for DHA and ARA is so strong that the company is consistently meeting profit goals. This is partly due to the FDA announcing in 2004 that adding omega-3 fatty acids to one's diet may reduce the risk of coronary heart disease [35]. Interestingly enough, after extracting DHA and ARA Martek disposes of most remaining oil, which may be suitable for fuel production.

Extraction of lipids is often carried out through simultaneous saponification and extraction of the oil using ethanol, with some researchers adding hexane as a co solvent [36]. Purities of up to $97 \%$ have been reported using this method when combined with urea fractionation [37]. Chloroform can also be used alone or in a Bligh-Dyer extraction, but chlorinated solvents are not regularly used in industry [32,38]. Lysing the algae cells through sonication or grinding increases extraction yield of lipids, as it does for sewage sludge [39]. Care must be taken, however, to keep lipid degradation to a minimum.

To date, research in alternative oil production is fairly active. However, the involvement of commercial backers and large-scale production plants for lipid-based renewable fuels will not occur until fundamental problems with production are solved. These include production of the lipid containing material, plants or microorganisms, as well as extraction and transportation of the final lipid product.

\section{MSU Research on Southeast Oil Crops}

Twelve plant species with potential for oil production were tested at Mississippi

State, MS Selection of the species was based on potential and actual yield, potential economic return, and ability to fit into existing crop rotation programs. A predominance of warm winters with few cold fronts makes the production of winter annuals an attractive option in the Southeast. Black mustard, birdseed rape, canola, Camelina, 
Crambe, flax, and Hesperis were tested. Date of planting studies indicated that regardless of planting date and irrigation, these species were cued to germinate when soil temperatures dropped below $20^{\circ} \mathrm{C}$. Of the species tested, canola, rapeseed and birdseed rape appear to have potential in Mississippi as winter annual crops because of yield. Flax may also be possible if markets could be secured for the linen. Focusing on oil yield per acre, winter-grown canola has the potential to yield three times the oil of soybeans grown during the summer on the same acreage. None of the winter annual species tolerate water logged soil (a common occurrence in the South during the winter), with the exception of birdseed rape. The other high yielding species would have to be planted on beds to allow drainage. Crambe contains especially desirable erusic acic (C22) in its seed. However, crambe only tolerates temperatures of negative $8^{\circ} \mathrm{C}$. A selection and breeding program were begun to screen for cold hardy genotypes from 'Meyer' crambe.

To grow summer annual species in the South, an existing crop would have to be displaced. With corn and soy at near record prices, that is unlikely. However, castor, sunflower and okra appear to be possible oilseed crops. Castor is a full-season crop and would be the one summer crop that would, in order to achieve production, displace existing crops like cotton, corn, or soy. The percentage oil in its seed (55-60\%) makes it hard to ignore as a potential oil feedstock crop. Mean yields of $2000 \mathrm{~kg} / \mathrm{ha}$ of castor seed were achieved at locations at, or north of Starkville. However, the presence of ricin in the extracted meal raises substantial safety concerns. Sunflower and okra were investigated as short season "catch" crops. These two species would be planted after a winter annual was harvested (June) to utilize the land for the balance of the summer growing season (June to October). Both these species have short cycle/determinate 
cultivars. Bird damage on sunflower is location dependent and caused as much as $70 \%$ reduction in yield at some locations. Okra only had a single years' data, but yields due to close planting density make it worthy of additional research.

Two perennial crops were investigated, Chinese tallow tree and tung tree. High seed yields from these species are possible because, there stature allows for a third dimension in yield (up). Tung has been in Mississippi for decades and has gone feral since hurricane Camille. Oil percentage of tung is $20 \%$, but tonnage yield is rough 8,000 $\mathrm{kg} / \mathrm{ha}$. Harvest regimes have already been worked out with tung, and the large seed makes shedding of the seed with tree shakers possible. While tallow tree seed yields can be mind boggling $(12,000 \mathrm{~kg}$ seed $/ \mathrm{ha}$ at $40 \%$ oil), genotypes that shed seed easily are currently not known. The trees noticed in the landscape are those that retain their seed late into the season. This characteristic is not desirable for a domestic crop. Add to that, the current "noxious weed" classification of tallow tree, getting this species into the main stream of production will be a challenge.

Of the species investigated, canola, sunflower, and okra have the greatest potential. However, it should be noted that even record yields of all the crops mentioned above won't come close to fully replacing the U.S. need for oil/petroleum.

\section{MSU Research on Genetics of Oil Bearing Plants}

At the onset of this project much research was devoted toward identifying critical enzymes and proteins necessary for lipid biosynthesis. The first objective was to data mine the corresponding gene sequences if available as a means to develop primers for the amplification of gene sequences which were to be subsequently cloned into a vector. A database of the enzymes essential for lipid biosynthesis was created by querying NCBI 
for genes having to do with lipid biosynthesis (see Table 2 below). This task was accomplished by constructing an automatic query algorithm using the Perl programming language. When the entire set of useful genes had been assembled it was necessary to sort them so that redundant entries and incomplete sequences could be eliminated. The organization was handled by a separate Perl script that sorted entries based on which gene they represent as well as the organism that the sequence came from. These sequences were assembled in order to generate a consensus sequence of all of the genes so that PCR primers could be constructed and used in many different species. The purpose of this was to find the organism that would provide the best gene for the desired enzyme. The longer range goal was to insert the amplified genes into a vector under the control of specific promoters. This way the proper set of genes and promoters could be found that would increase the oil yield from a plant without compromising the plant's viability or integrity.

Sample specimens of Brassica napus, Riccinus communis, and Simmondsia chinensis seeds were germinated to provide tissue for RNA extraction. These three species were chosen because according to the literature they produce high quantities oils and the oil produced has unique characteristics. RNA isolation procedures were optimized for each separate organism to provide the best quality and highest yield of RNA for additional procedures. First-strand cDNA was then synthesized for use as template for PCR. Both one-step and two-step cDNA synthesis procedures were implemented in order to find the optimal protocol for cDNA production. Validation primers were generated for genes of interest and PCR was used to amplify the desired gene fragments using the cDNA as template. The wax synthase and oleic 12-hydorxylase 
genes were the first fragments to be amplified. These genes were chosen first because of their unique qualities.

Unfortunately the progress of the project was severely hindered early on due to issues involving a material transfer agreement (MTA) for a vector that was to be used for this project. This setback resulted in the reduction of efforts to isolate and extract the genes of interest and a shift to searching for an alternative source for another suitable vector which could be attained commercially or through collaboration. The intended expression vector was designed for inserting the genes into a host plant with proper temporal expression, and since no suitable alternative could be found the project was further shifted toward constructing a suitable vector from scratch. The new vector was designed to have a reporter element that would be constitutively expressed in the host for simple selection of transform individuals. Seed specific promoters would control the gene of interest so that the gene would only be expressed in the seed, where the oil is concentrated. Two seed specific promoters (napin and phaseolin) were researched and amplified by PCR. The cauliflower mosaic virus $35 \mathrm{~S}$ promoter was chosen for constitutive expression and a reporter gene was obtained from a collaborator. Restriction enzyme digestions and subsequent ligation protocols underwent extensive optimization in order to ensure that the vector was being properly assembled. Troubles with the ligation of certain elements further hindered the project.

The objective of finding a suitable host organism was accomplished. Dr. Brian Baldwin concluded from his concurrent evaluation of suitable oil seed crops for the Southeastern US that Ricinus communis (common name: castor) would be the best host crop for the over-expression of lipid biosynthesis genes. The reasoning for this is that 
castor seed is intrinsically high in oil content and the oil produced by castor has unique properties that make it a good candidate for biodiesel production. Beginning with a naturally high oil seed crop indicated that it could then be further improved by the addition of the over-expressed lipid biosynthesis genes. This would provide a crop that a maximum amount of usable oil per acre of land.

The goals of this research have identified plausible metabolic pathways to enhance oil seed yield and have been designed to remain flexible to adapt to a variety of hosts. This work has carried over to a separately funded project as part of the South Eastern Renewable Energy Center at Mississippi State University. 
Table 2. Lipid Biosynthesis Genes of Interest Names, Sequence Source Species, and Functions.

\begin{tabular}{|c|c|c|}
\hline Gene & Species & Function \\
\hline Acetyl-CoA Carboxylase (ACCase) & $\begin{array}{l}\text { A. thaliana } \\
\text { B. napus } \\
\text { H. sapiens } \\
\text { L. multiflorum }\end{array}$ & Carboxylation of acetyl-CoA in malonyl-CoA \\
\hline ACP-desaturase & $\begin{array}{l}\text { A. thaliana } \\
\text { B. napus } \\
\text { B. oleracea } \\
\text { L. usitatissimum } \\
\text { L. luteus } \\
\text { S. chinensis } \\
\text { T. majus } \\
\end{array}$ & Desaturation of fatty acids \\
\hline Acyl-CoA Reductase & S. chinensis & Coverts acyl-CoA to fatty alcohol \\
\hline Acyl-ACP Thioesterase & $\begin{array}{l}\text { A. thaliana } \\
\text { H. sapiens }\end{array}$ & Releases the acyl-ACP from the FAS complex \\
\hline Carnitine Palmitoyl Transferase (CPT) & $\begin{array}{l}\text { C. familiaris } \\
\text { M. lucifugus } \\
\text { S. scrofa }\end{array}$ & $\begin{array}{l}\text { Movement of fatty acids from cytosol into } \\
\text { mitochondria }\end{array}$ \\
\hline Fatty acid Elongase (FAE) & $\begin{array}{l}\text { A. thaliana } \\
\text { B. campestris } \\
\text { B. juncea } \\
\text { B. napus } \\
\text { B. oleracea } \\
\text { B. rapa }\end{array}$ & Elongates $\mathrm{C} 18$ fatty acids to $\mathrm{C} 20$ and $\mathrm{C} 22$ \\
\hline Fatty acid Synthase (FAS) & H. sapiens & $\begin{array}{l}\text { Synthesis of palmitate from acetyl- and malonyl- } \\
\text { CoA (multifunctional enzyme) }\end{array}$ \\
\hline Beta-ketoacyl-ACP synthetase $1 \& 2(\mathrm{~K}$ & $\begin{array}{l}\text { AS } 1 \& 2) \\
\text { A. thaliana } \\
\text { H. vulgare } \\
\text { B. napus } \\
\text { R. communis } \\
\text { G. max } \\
\text { P. frutescens }\end{array}$ & Condenses acyl group with malonyl group \\
\hline Lysophosphatidic acid Acyltransferase & $\begin{array}{l}\text { LPAAT) } \\
\text { B. taurus } \\
\text { H. sapiens } \\
\text { M. musculus } \\
\text { R. norvegicus }\end{array}$ & $\begin{array}{l}\text { Converts lysophosphatidic acid to phosphatidic acid } \\
\text { for phosopolipid synthesis }\end{array}$ \\
\hline Wax Synthase & S. chinensis & $\begin{array}{l}\text { Esterifies fatty alcohol to acyl CoA to form wax } \\
\text { ester }\end{array}$ \\
\hline
\end{tabular}




\section{Research on Sludge Oil Extraction and Biodiesel Production}

In light of the rapidly expanding biofuels market, it is imperative that new sources of renewable feedstock be discovered and commercialized. One overlooked source of renewable feedstock is lipid extraction from microorganisms. It is hypothesized that microorganisms present in sewage sludge will provide a ready source of lipids from which biofuels, such as biodiesel could be produced.

The objective of this phase of the project is to:

- Evaluate the ability of microbial lipid sources to produce a quality biofuel. This includes yield of extractable oil and economics relating to feedstock generation for green diesel production.

\section{Materials and Methods}

\section{Extraction of Lipids from Sewage Sludge}

Several different methods were used to collect and process sludge used in this study, depending on origin and type of material.

\section{Chemicals}

Methanol, acetone, 1,3-dichlorobenzene, sulfuric acid, sodium chloride, and $n$ hexane were purchased from Fisher Scientific, Atlanta, GA. Industrial grade carbon dioxide was provided by NexAir, Memphis, TN. These chemicals were used as received. Sewage Sludge

Secondary sewage sludge was collected from a municipal wastewater treatment plant (MWWTP) located in Tuscaloosa, AL. It was collected from the aerobic waste sludge line, which fed into the anaerobic digester.

\section{Sample Preparation}


Upon collection at the facility, the sludge flocks were allowed to gravity settle. Separation of the clarified water resulted in a sludge containing $2 \%$ solids. This sludge was dewatered by centrifugation or pressure filtration. Centrifugation was performed with a Marathon 3000 centrifuge, manufactured by Fisher Scientific, and operated at $3000 \mathrm{rpm}$ for 20 minutes. Removal of the free water resulting from this step gave a sludge containing 7-8\% solids. Pressure filtration was conducted with a Millipore $1.5 \mathrm{~L}$ pressure filter pressurized in $69 \mathrm{kPa}$ increments from 103-517 $\mathrm{kPa}$. Sludge was first filtered using an $80 \mu \mathrm{m}$ nylon filter with the filter cake collected for later use. The filtrate was then filtered again with a $20 \mu \mathrm{m}$ nylon filter and the cake combined with that from the $80 \mu \mathrm{m}$ run. The remaining sludge cake contained $12-14 \%$ solids.

\section{Organic Solvent Extraction}

Prior to organic solvent extraction, dewatered sludge was mixed with Hydromatrix (manufactured by Varian, Inc., Palo Alto, CA) and loaded into a steel sample vessel. The Hydromatrix absorbed residual free water in the sample and competed for bound water during extraction. Hydromatrix was added until the sample formed small pellets and flowed freely. Solvent extraction was conducted using a 200 Series Accelerated Solvent Extraction system (ASE) (manufactured by Dionex, Sunnyvale, CA), which included a multi-solvent control system. The system was operated at 10.3 $\mathrm{MPa}$ and $100^{\circ} \mathrm{C}$ for 1 hour per extraction. Single or sequential (2 or 3 times) extractions were examined using the following solvent mixtures (\% by volume) or pure solvents:

1. $60 \%$ hexane $/ 20 \%$ methanol $/ 20 \%$ acetone (HMA) (same mixture 3 times)

2. Pure methanol followed by pure hexane (MH)

3. Pure hexane (single extraction) 


\section{Pure methanol (single extraction)}

After extraction, the sample vessel was drained into a glass collection vial followed by a solvent flush equal to $50 \%$ of the sample vessel's volume. The lipid-containing solvent vial was then stored at $-15^{\circ} \mathrm{C}$ until further analysis. Each experiment was performed in duplicate except for extraction with pure hexane, which was a singlet.

\section{In Situ Transesterification}

A fluidized bed drier was used in the same manner as the supercritical $\mathrm{CO}_{2}$ extraction unit to achieve a sample with 5\% moisture content. The dried sludge was then ground in a mortar and pestle until a fine powder was obtained. A screw-top vial was then charged with $1 \mathrm{~mL}$ of $1 \%$ sulfuric acid in methanol and $200 \mathrm{mg}$ of powdered sample. The vial was then capped and heated overnight at $50^{\circ} \mathrm{C}$. Then, a $5 \mathrm{~mL}$ aliquot of $5 \% \mathrm{NaCl}(\mathrm{w} / \mathrm{v})$ in water was added and the FAMEs were extracted with hexane $(2 \times 5$ $\mathrm{mL}$ ), vortexing the vial between extractions to provide efficient mixing. The hexane phase was washed with $2 \%$ sodium bicarbonate and dried over sodium sulfate. The experiment was performed in duplicate.

\section{Analysis of Fatty Acid Methyl Esters}

After extraction, the lipid-containing solvent phase was removed under vacuum in a Büchi R205 Rotary Evaporator (rotovap) at $40^{\circ} \mathrm{C}$ and $15-30 \mathrm{kPa}$ of vacuum. The resulting liquid oil was weighed using an Ohaus analytical balance. The yield of extracted material was then determined and expressed as grams of extractable lipid per gram of dry solid.

Conversion of the lipids to FAMEs for extraction with organic solvents was carried out through acid catalysis using a modified version of Christie's method [40]. 20 
$\mathrm{mg}$ of lipids were dissolved in $1 \mathrm{~mL}$ of hexane containing 1,3-dichlorobenzene as an internal standard and added to a vial with $2 \mathrm{~mL}$ of $1 \%$ sulfuric acid in methanol. The vial was then capped and heated overnight at $50^{\circ} \mathrm{C}$. Then, a $5 \mathrm{~mL}$ aliquot of $5 \% \mathrm{NaCl}$ in water was added and the FAMEs were extracted with hexane $(2 \times 5 \mathrm{~mL})$, vortexing the vial between extractions to provide efficient mixing. The hexane phase was washed with $2 \%$ sodium bicarbonate and dried over sodium sulfate.

Transesterification of lipids from $\mathrm{SC}-\mathrm{CO}_{2}$ extractions was performed in an Erlenmeyer flask. The flask was charged with 0.1-0.2 $\mathrm{g}$ of lipid and $10.0 \mathrm{~mL}$ of $n$-hexane. $4.0 \mathrm{~mL}$ of $0.5 \mathrm{~N}$ sodium methoxide was then added and the mixture refluxed for 10 minutes. The flask was allowed to cool and $5.0 \mathrm{~mL}$ of $14.0 \% \mathrm{BCl}_{3}$ was added. The mixture was refluxed for 10 minutes and was dried by filtering through sodium sulfate.

The FAMEs produced by transesterification were analyzed on an Agilent gas chromatograph (Model 6890; Palo Alto, CA) with a flame-ionization detector. Helium was used as the carrier gas. The separation was achieved with a fused silica capillary column composed of stabilized $90 \%$ polybiscyanopropyl $/ 10 \%$ cyanopropylphenyl siloxane (SP-2380; Supelco, Bellefonte, PA). The dimensions of the column were $100 \mathrm{~m}$ x $0.25 \mathrm{~mm}$ with a phase thickness of $0.2 \mu \mathrm{m}$. A calibration curve was prepared by injecting known concentrations of an external standard mixture comprised of 37 fatty acid methyl esters (47885-U, 37 Component FAME Mix, Supelco, Bellefonte, PA). All calibration curves were linear with a correlation coefficient of 0.99 or better. 1,3Dichlorobenzene was used as an internal standard. The method consisted of injecting $1 \mu 1$ of sample into the GC with a split ratio of 100:1. The temperature program began at $110^{\circ} \mathrm{C}$, holding for 2 minutes. It then increased by $10^{\circ} \mathrm{C}$ per minute to $140^{\circ} \mathrm{C}$, where it 
was held for 4 minutes. After 9 minutes of total run time, the temperature increased $2^{\circ} \mathrm{C}$ per minute until reaching $240^{\circ} \mathrm{C}$. The temperature was then held constant until a total run time of 99 minutes was achieved. Concentration data obtained from GC runs were used to calculate the amount of saponifiable material in extracted lipids. Only compounds with a concentration greater than $1 \%$ were counted toward the total FAME. Software bundled with the instrument was used to analyze the data.

\section{Results}

One overlooked source for renewable oils is the harvesting of bacteria from municipal wastewater treatment facilities (MWWTF). MWWTF facilities in the USA produce $6.2 \times 10^{6} \mathrm{t}$ (dry basis) of sludge annually [3]. This sludge is composed of a variety of organisms which consume organic matter in wastewater. The content of phospholipids in these cells have been estimated at $24 \%$ to $25 \%$ of dry mass $[4,5]$. This phosphorous may need to be removed before production of green diesel due to poisoning effects on the catalyst. The most common type of treatment at a MWWTF is the activated sludge process. Activated sludge is the solid or semi-solid produced during biological treatment of industrial and municipal wastewaters. It contains a variety of microorganisms, which utilize the organic and inorganic compounds in the water as a source of energy, carbon, and nutrients. A reactor, settling tank, solid recycle and sludge wasting line comprise the unit operations of the activated sludge process. The waste sludge containing $1 \%$ to $2 \%$ solids is usually concentrated via gravity thickening or air floatation to approximately $10 \%$ solids. In many cases, the concentrated sludge is introduced into an aerobic or anaerobic digester to reduce the level of pathogens and odors (stabilization). 
In a wastewater treatment facility, activities associated with sludge treatment represent from $30-80 \%$ of electrical power consumed at the plant [3]. Prior to or after stabilization, the sludge may be dewatered and disposed of via incineration, land application, or placement in landfills. However, several environmental health and safety concerns restrict the feasibility of these options.

Research has recently indicated that the lipids of microorganisms contained in sewage sludge are a potential feedstock for lipid based fuels. Literature indicates that sewage sludge contains approximately $20 \%$ ether soluble grease and fats [21]. Additionally the cell membrane of microorganisms, a main component of sewage sludge, is composed mostly of phospholipids [41]. Both sources could be converted to renewable fuels. Assuming that cells are $2 \%$ phosphorous by dry weight with $50 \%$ of phosphorous in the cell membrane, calculations on the estimated mass of phospholipids in cells place them at $24 \%$ by dry mass of the cell. This is in agreement with literature values of $25 \%$ for E. Coli [4].

In this work, lipids were extracted using organic solvents with different polarities or supercritical carbon dioxide. The following text provides results on the lipid and fatty acid methyl ester yields obtained with several extraction strategies.

\section{Solvent Effects}

The amounts of oil, saponifiable material, and the overall yield obtained through different extraction methods can be found in Table 3. Different solvents were used during extraction to determine which system gave the best yield. An explanation of the difference in extraction yield by solvent can be rationalized through use of the Hildebrand Solubility Parameter ( $\delta$ ), which is a measure of the "strength" of the solvent 
[42]. This can be thought of as the energy required to create a "hole" in the solvent for another molecule to fit in. It can be broken into three parts called the Hansen parameters, which describe forces acting on a molecule. The dispersion force is a measure of London dispersion forces, or non-polar interaction, given by $\delta_{\mathrm{d}}$.

Table 3. Extraction and Transesterification Yield of Waste Activated Sludge .

\begin{tabular}{|c|c|c|c|c|c|c|c|c|}
\hline \multicolumn{3}{|c|}{ Extraction Medium } & \multicolumn{2}{|c|}{$\%$ Oil Yield $f$} & \multicolumn{2}{|c|}{$\begin{array}{c}\% \text { of Oil } \\
\text { Saponifiable }^{g}\end{array}$} & \multicolumn{2}{|c|}{$\%$ FAME Yield $^{h}$} \\
\hline \multicolumn{3}{|l|}{$100 \%$ Hexane $^{b}$} & & 1.94 & & 19.7 & & 0.38 \\
\hline \multicolumn{3}{|l|}{$100 \%$ Methanol $^{b}$} & & $19.39 \pm 3.20$ & & $14.25 \pm 1.66$ & & $2.76 \pm 0.39$ \\
\hline $60 \%$ Hexane $^{c}$ & & Extraction 1 & \multicolumn{2}{|l|}{21.20} & \multicolumn{2}{|l|}{16.22} & \multicolumn{2}{|l|}{3.44} \\
\hline $20 \%$ Methanol & & Extraction 2 & 5.37 & \multirow[t]{2}{*}{$27.43 \pm 0.98$} & 15.57 & $16.18 \pm 3.21$ & 0.84 & \multirow[t]{2}{*}{$4.41 \pm 0.63$} \\
\hline $20 \%$ Acetone & & Extraction 3 & 0.86 & & \multicolumn{2}{|l|}{15.92} & 0.14 & \\
\hline $100 \%$ Methanol $^{d}$ & - & Extraction 1 & 19.39 & \multirow{2}{*}{$921.96 \pm 2.28$} & 14.25 & \multirow{2}{*}{$14.21 \pm 1.53$} & 2.76 & \multirow{2}{*}{$3.07 \pm 0.33$} \\
\hline $100 \%$ Hexane & - & Extraction 2 & 2.57 & & 12.03 & & 0.31 & \\
\hline \multicolumn{3}{|c|}{ In Situ Transesterification ${ }^{e}$} & \multicolumn{2}{|r|}{-} & \multicolumn{2}{|r|}{-} & \multicolumn{2}{|r|}{$6.23 \pm 0.11$} \\
\hline
\end{tabular}

${ }^{a}$ All extractions carried out at $100^{\circ} \mathrm{C}$ for 1 hour, solvent to solids ratio $40: 1$ (wt.)

${ }^{b}$ Sample extracted once

${ }^{c}$ Solvent mixture extracted three times

${ }^{d}$ Sequential extraction using Methanol followed by Hexane

${ }^{e}$ Dried to 95 weight percent solids. Solvent was Methanol with $1 \%$ Sulfuric Acid

${ }^{f}$ Gravimetric yield of oil in grams of oil per gram of dry sludge

${ }^{g}$ Percent of extracted oil saponifiable on a mass basis.

${ }^{h}$ Grams of FAME produced per 100 grams of dry sludge

${ }^{g, h}$ Values on left indicate individual extraction yields. Values on the right indicate total yield. 
Table 4. Solvent Solubility Parameters for Extraction Systems.

\begin{tabular}{lllll}
\hline Solvent & $\begin{array}{l}\delta_{\mathrm{d}}{ }^{a} \\
\mathrm{MPa}^{1 / 2}\end{array}$ & $\begin{array}{l}\delta_{\mathrm{p}}{ }^{b} \\
\mathrm{MPa}^{1 / 2}\end{array}$ & $\begin{array}{l}\delta_{\mathrm{h}}{ }^{c} \\
\mathrm{MPa}^{1 / 2}\end{array}$ & $\begin{array}{l}\delta^{d} \\
\mathrm{MPa}^{1 / 2}\end{array}$ \\
\hline Acetone $^{e}$ & 15.5 & 10.4 & 7.0 & 20.0 \\
Methanol $^{e}$ & 15.1 & 12.3 & 22.3 & 29.6 \\
$n$-Hexane $^{e}$ & 14.9 & 0.0 & 0.0 & 14.9 \\
HMA $^{e}$ & 15.1 & 7.1 & 10.6 & 19.8 \\
\hline
\end{tabular}

${ }^{a}$ Magnitude of London Dispersion Forces

${ }^{b}$ Magnitude of Dipole Moment Contribution

${ }^{c}$ Magnitude of Hydrogen Bonding Contribution

${ }^{d}$ Combined Solubility Parameter

${ }^{e}$ Calculated using values from Hansen, C. [100]

The magnitude of the dipole moment contribution is given by $\delta_{\mathrm{p}}$, and the hydrogen bonding contribution is represented as $\delta_{\mathrm{h}}$. The summed squares of these parameters are equal to the square of the total Hildebrand solubility parameter, $\delta^{2}=\delta_{d}^{2}+\delta_{p}^{2}+\delta_{h}^{2}$. Solvents with similar Hildebrand parameters are usually miscible with each other, although the individual Hansen parameters must also be taken into account. The behavior of solutes can also be predicted in the same way [42]. Table 4 gives values for the solvents used in extraction of lipids from sludge.

As Table 4 shows, all of the solvents have roughly equal contributions from dispersion forces with the exception of $\mathrm{SC}-\mathrm{CO}_{2}$. It is also evident that acetone and methanol are almost equal in strength regarding polarity while $n$-hexane has no polar force at all. The degree of hydrogen bonding is greatest for methanol and is less for acetone. The difference in solvents can thus be summed up as follows. $n$-Hexane contains only dispersion forces and may be considered a standard solvent used for comparison. Acetone and methanol are used to examine the effect of highly polar solvents on extraction and low and high hydrogen bonding strengths. $\mathrm{SC}-\mathrm{CO}_{2}$ has the 
smallest dispersion value with a polarity around half that of acetone and methanol and hydrogen bonding near acetone.

Table 3 shows that when used in a single solvent extraction, hexane achieves an oil yield of $1.94 \%$. However, the addition of a polar co-solvent results in an increase of extracted oil. Compared to pure hexane, a single extraction using a mixture of hexane, methanol, and acetone increased the oil yield from $1.94 \%$ to $21.20 \%$. In addition, the sequential extraction experiment of a hexane, methanol, and acetone mix shows that a significant amount of material is left behind after the first extraction. However, the amount of extractable oil decreases sharply with each subsequent extraction. The increase in yield due to addition of polar co-solvents could be due to high phospholipid levels in the sample. Phospholipids have a polar head and non-polar tail. Secondary sludge is mainly composed of microorganisms whose cell membranes contain phospholipids. Addition of the methanol/acetone mix would expose phospholipids to a solvent with high Hansen values for polarity and hydrogen bonding. It is hypothesized that the solvent mixture helps to disrupt the lipid membrane, which is held together through hydrophobic interactions and is protected by polar head groups. Samples analyzed through thin-layer chromatography indicated the presence of phospholipids but could not give quantitative amounts.

If one extracts with a pure polar solvent instead of non-polar the oil yield is much larger. An extraction with pure methanol gives $19.39 \%$ yield compared to the $1.94 \%$ of pure hexane. This reinforces the idea of polar lipids being extracted more easily with a polar solvent. Following the pure methanol extraction with pure hexane gives a yield for hexane of $2.57 \%$, which is slightly higher than extraction with hexane on a virgin sample. 
This is intuitive if one considers that hexane extracts mainly non-polar lipids with low values of $\delta_{\mathrm{p}}$ and $\delta_{\mathrm{h}}$, while methanol prefers polar lipids with larger values of $\delta_{\mathrm{p}}$ and $\delta_{\mathrm{h}}$. Extraction with a polar solvent first may help destroy the cellular membrane and allow a subsequent non-polar extraction access to previously unreachable lipids within the cell.

While polar solvents show a large increase in extractable oil yield, the percent of saponifiable material is lower. Conversion of a pure hexane extract to FAMEs gives $19.70 \%$ saponification by weight of the material extracted, while pure methanol only gives $14.25 \%$. Extracting with a mixture of solvents such as the HMA system results in a transesterification yield of $16.22 \%$ of material extracted, lower than pure hexane but higher than pure methanol. Repeated extraction with the HMA system shows that the percentage of saponifiable material in extracted oil does not change much with subsequent extractions. The percentage of saponifiable material extracted in the $\mathrm{MH}$ system is greater for methanol than for hexane. However, the percent of saponifiable material for hexane on a sample already extracted with methanol is lower than a virgin hexane extraction. This suggests that treatment with a polar solvent will help disrupt cell walls, releasing more extractable material than just non-polar lipids. The trend of decreasing transesterification yield with increasing amounts of polar solvent can also be rationalized through use of the Hildebrand solubility parameters. Hexane has no Hansen components for polarity or hydrogen bonding, and a low total Hildebrand value. This gives hexane the ability to extract compounds with similar Hildebrand parameters, including non-polar lipids such as triglycerides. In contrast, methanol is highly polar and has a high degree of hydrogen bonding. This allows for extraction of polar groups such as those found on phospholipids and non-lipid compounds found throughout the bacterial 
cell. The more polar solvents extract larger amounts of non-lipid material causing a sharp increase in oil yield, which is measured on a weight basis. This is accompanied by a decrease in the percentage of saponifiable material.

\section{Lipid Extraction}

Calculations based on the amount of oil extracted and the percent of saponifiable material in the oil gives an overall yield of saponifiable material extracted from the sludge. This is represented as the mass of biodiesel produced per mass of dry sludge. Although the percent of saponifiable material in a pure hexane extraction was higher than that of a pure methanol extraction, the methanol has a higher overall yield due a much larger amount of oil extracted. This shows that while an extraction with polar solvent will produce oil heavily contaminated with non-saponifiable material, the total amount of saponifiable material is larger. The increase can be contributed to greater extraction of phospholipids with methanol than with hexane. Since phospholipids contain a maximum of two fatty acid groups per molecule the yield of biodiesel is reduced. A comparison of the HMA extraction with MH shows that the first HMA extraction gives a slightly higher overall yield than the MH. Combining the last two HMA extractions gives the system a significantly larger yield than $\mathrm{MH}$.

The last row in Table 3 refers to In Situ transesterification of dried sludge. This is a method in which the lipids are converted to FAMEs without extracting them from the sludge. Since the reagents have access to all oil in the sludge instead of just what was extracted the yield should be higher than the other methods. Indeed, the yield of $6.23 \%$ is the highest of all methods tried. 
An analysis of the fatty acid profile in Figure 2 shows differences in lipid composition as a function of various extraction methods. The profile for hexane and methanol shows that hexane extracts a larger ratio of unsaturated fatty acids than methanol for all compounds except the C16s.

Comparison of sludge fatty acid profiles by various extraction methods to a standard soybean sample shows that all sewage sludge samples have a much larger concentration of saturated fatty acids, as seen in Figure 3. Although the higher levels of saturated fatty acids may present a problem in cold weather due to gelling, the higher saturated content will produce a better fluidized catalytic cracking feedstock. Feedstocks high in saturated compounds produce less coke and slurry products during the cracking reaction. They are therefore preferred as reactants. 


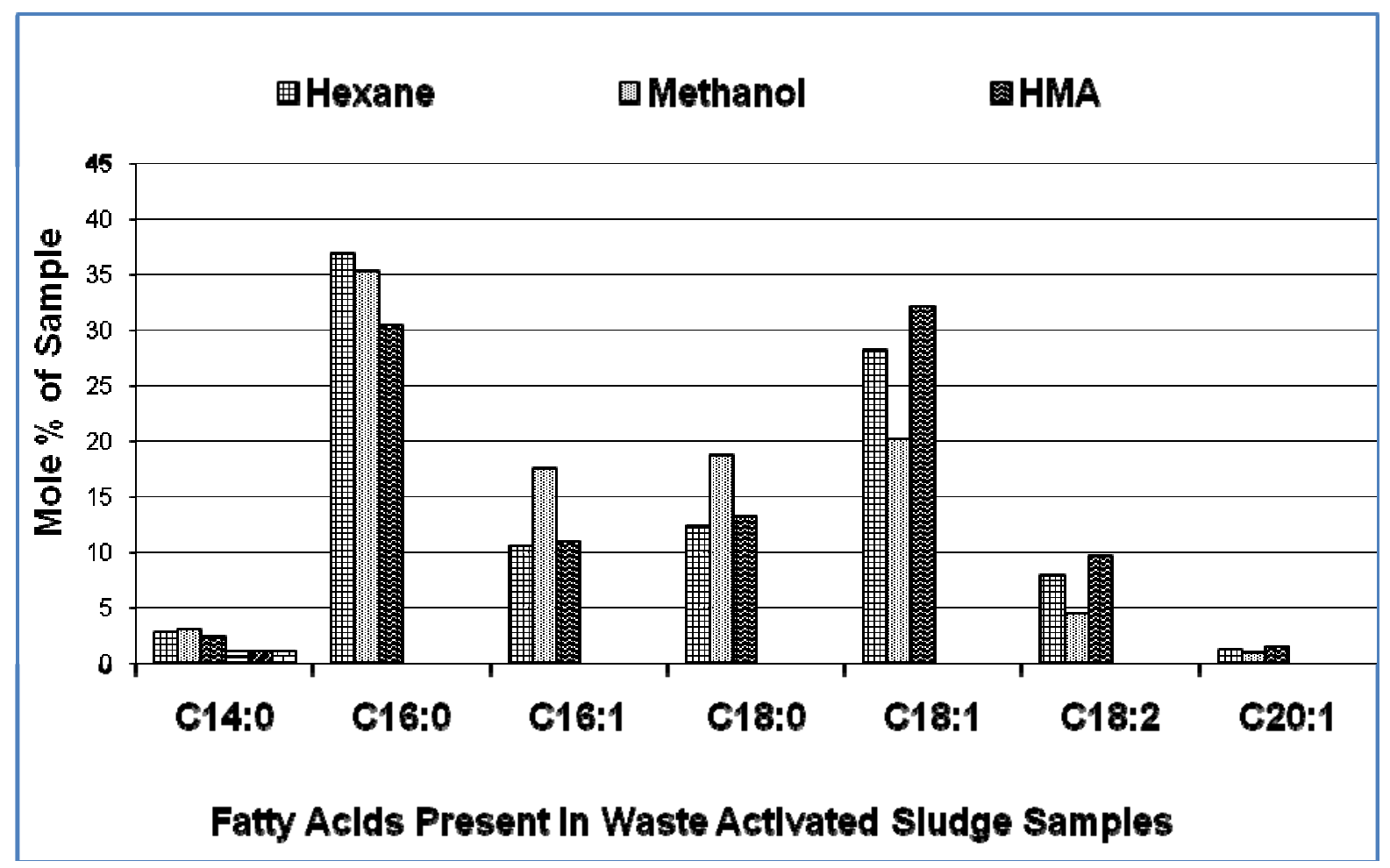

Figure 2. Impact of Extraction Medium on Fatty Acid Composition of Oil. 


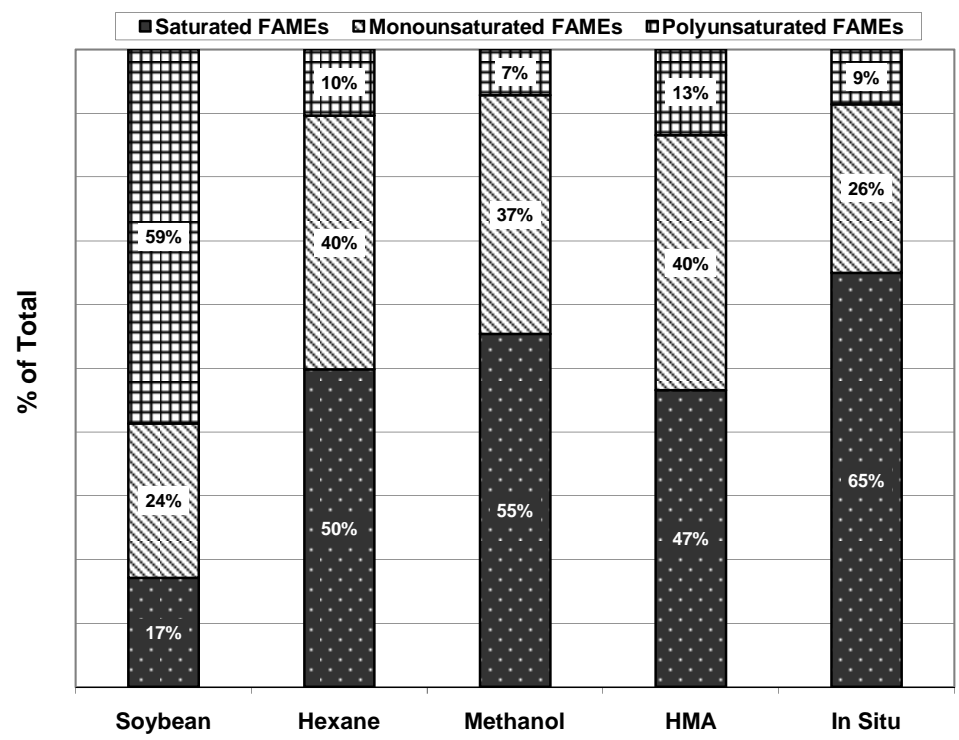

Figure 3. Comparison of Saturated vs. Unsaturated Fatty Acids Present in Waste Activated Sludge Samples. 
Examination of the various transesterification methods shows that in situ conversion of lipids to FAMEs provides the highest overall yield of biodiesel. A breakdown of processing cost is shown in Table 5. It is assumed that sludge will be centrifuged to $35 \%$ solid content, then dried to $95 \%$ solids content via an indirect heat paddle drum. If one then assumes a $7.0 \%$ overall yield of FAMEs from dry sewage sludge on a weight basis, the cost per gallon of extracted lipid would be $\$ 3.11$. Since the lipid is converted to FAMEs, also known as biodiesel, in the in Situ extraction process, the product can be used as is for renewable fuel. As transesterification efficiency increases the cost per gallon drops quickly, hitting $\$ 2.01$ at $15.0 \%$ overall yield. An overall yield of $10.0 \%$ is required to obtain biodiesel at $\$ 2.50$ per gallon, allowing it to compete with soybean oil in the marketplace. The extraction of lipids from sewage sludge is possible without a transesterification reaction. This would reduce the overall cost of extraction, although at a tradeoff to total lipid extracted. The use of in situ conversion, however, may be beneficial in that phospholipids would be converted to FAMEs. The phosphate head group could then be removed through a water wash process, rendering the feedstock safe for cracking in an industrial catalytic cracker.

Table 5. Production Cost Estimate for Sludge Lipids ${ }^{a}$

\begin{tabular}{ll}
\hline Centrifuge O\&M & $\$ 0.43 / \mathrm{gal}$ \\
Drying O\&M & $\$ 1.29 / \mathrm{gal}$ \\
Extraction O\&M & $\$ 0.34 / \mathrm{gal}$ \\
Lipid Processing O\&M & $\$ 0.60 / \mathrm{gal}$ \\
Labor & $\$ 0.10 / \mathrm{gal}$ \\
Insurance & $\$ 0.03 / \mathrm{gal}$ \\
Tax & $\$ 0.02 / \mathrm{gal}$ \\
Depreciation & $\$ 0.12 / \mathrm{gal}$ \\
Capital P\&I Service & $\$ 0.18 / \mathrm{gal}$ \\
\hline Total Cost & $\$ 3.11 / \mathrm{gal}$ \\
\hline
\end{tabular}

${ }^{a}$ Assuming $7.0 \%$ overall transesterification yield 


\section{Research on Extraction of Nutritional Components from Biodiesel}

The goal of this phase of the project was the extraction and separation of novel secondary products, such as polyunsaturated fatty acid methyl esters (including DHA and EPA) from bio-diesel (and bio oils).

Efficient methods were developed to isolate polyunsaturated fatty acid methyl esters from bio-diesel. Additionally, a method was developed to isolate another value added product, Vitamin E, from bio-oils, which was not in the original proposed statement of work.

Part 1: Extractive separation of polyunsaturated fatty acid methyl esters including omega-3 fatty acid eicosapentaenoic acid (EPA) and docosahexaenoic acid (DHA).

The hypothesis to isolate this class of fatty acids, which are used as popular dietary supplements and prescription medicine (OMACOR), was that they bind transition metal ions much stronger than their harmful saturated analogs. To solve the solubility problem associated with these metal ions, a biphasic extraction system involving novel ionic liquids was devised. In the procedure, fatty acid methyl esters dissolved in hexanes are extracted with transition metal ions dissolved in ionic liquids. Because of the binding between polyunsaturated fatty acid methyl esters and the transition metal ions, the polyunsaturated fatty acids methyl esters are extracted selectively into ionic liquids, thus separated from the saturated fatty acid methyl esters which stayed in hexanes. After layer separation, polyunsaturated fatty acid methyl esters could be back extracted with 1hexene. 
The first experiment was done using silver salt $(\mathrm{Ag}+)$ as the transition metal ion. Ionic liquid proved essential in this extraction, as other solvents worked poorly (Figure 4).

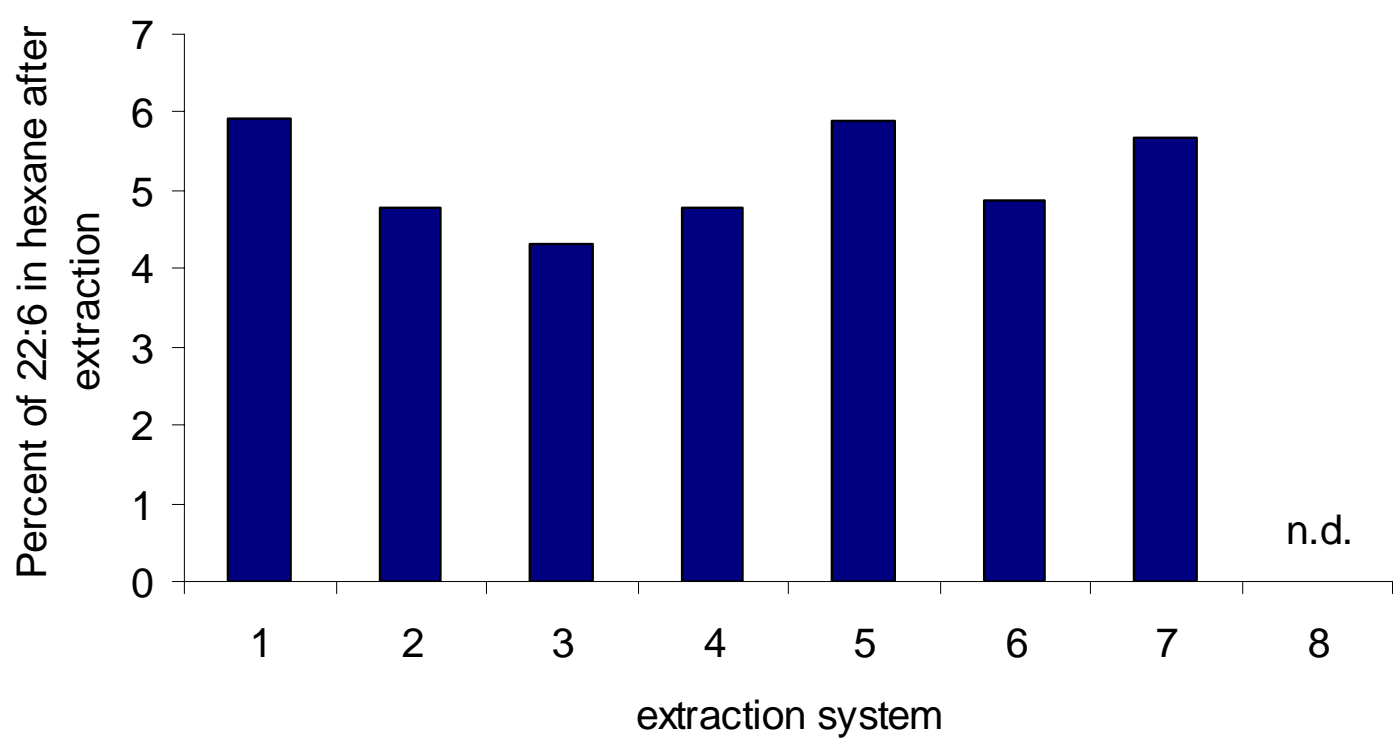

Figure 4. Comparison of Various Extraction Systems. Column 1, percent of DHA in hexane before extraction; 2, pure [hmim] $\left[\mathrm{PF}_{6}\right]$ (no silver salt); $3, \mathrm{AgBF}_{4} /$ water; 4, $\mathrm{AgBF}_{4} /$ ethylene glycol; $5, \mathrm{AgNO}_{3} /$ water; $6, \mathrm{AgNO}_{3} /$ (water: methanol=1:4); 7, $\mathrm{AgBF}_{4} /\left(\right.$ water: methanol=1:4); $8, \mathrm{AgBF}_{4} /[\mathrm{hmim}]\left[\mathrm{PF}_{6}\right]$. Initial fatty acid methyl ester compositions in hexane: 16:0 $=21.70 \%, 18: 0=22.66 \%$, $18: 1=25.50 \%, 18: 2=24.25 \%$, DHA $(22: 6)=5.95 \%$. $10 \mathrm{mg}$ of silver salt $(0.05$ mmol) was used.

Different metal ions were also evaluated for the extraction of omega-3 fatty acid methyl esters (Figure 5), since it is known that other transition metals could also exhibit some coordination ability with the double bond. Seven metal complexes in ionic liquids were selected to extract unsaturated fatty acid methyl esters in hexane solvent. The extraction ability of the metal complex was assayed by the EPA (20:5) concentration in hexane. The stronger the extraction ability, the lower the concentration of EPA in hexane becomes. $\mathrm{PdCl}_{2}, \mathrm{NiCl}_{2}$ and $\mathrm{CuCl}$ showed low extraction ability for $\mathrm{EPA}$ in ionic liquids $[\mathrm{hmim}]\left[\mathrm{PF}_{6}\right]$. The latter transition metal complex, $\mathrm{H}_{2} \mathrm{PtCl}_{6}, \mathrm{PdCl}_{2}(\mathrm{TPP})_{3}$ and $\mathrm{RhCl}(\mathrm{TPP})_{3}$ 
exhibited moderate extraction for EPA in [hmim][PF6]. $\mathrm{AgBF}_{4}$ in $[\mathrm{hmim}][\mathrm{PF} 6]$ showed very high extraction for EPA. It is apparent that $\mathrm{AgBF}_{4}$ has the highest extraction ability among all the metal ions tested.

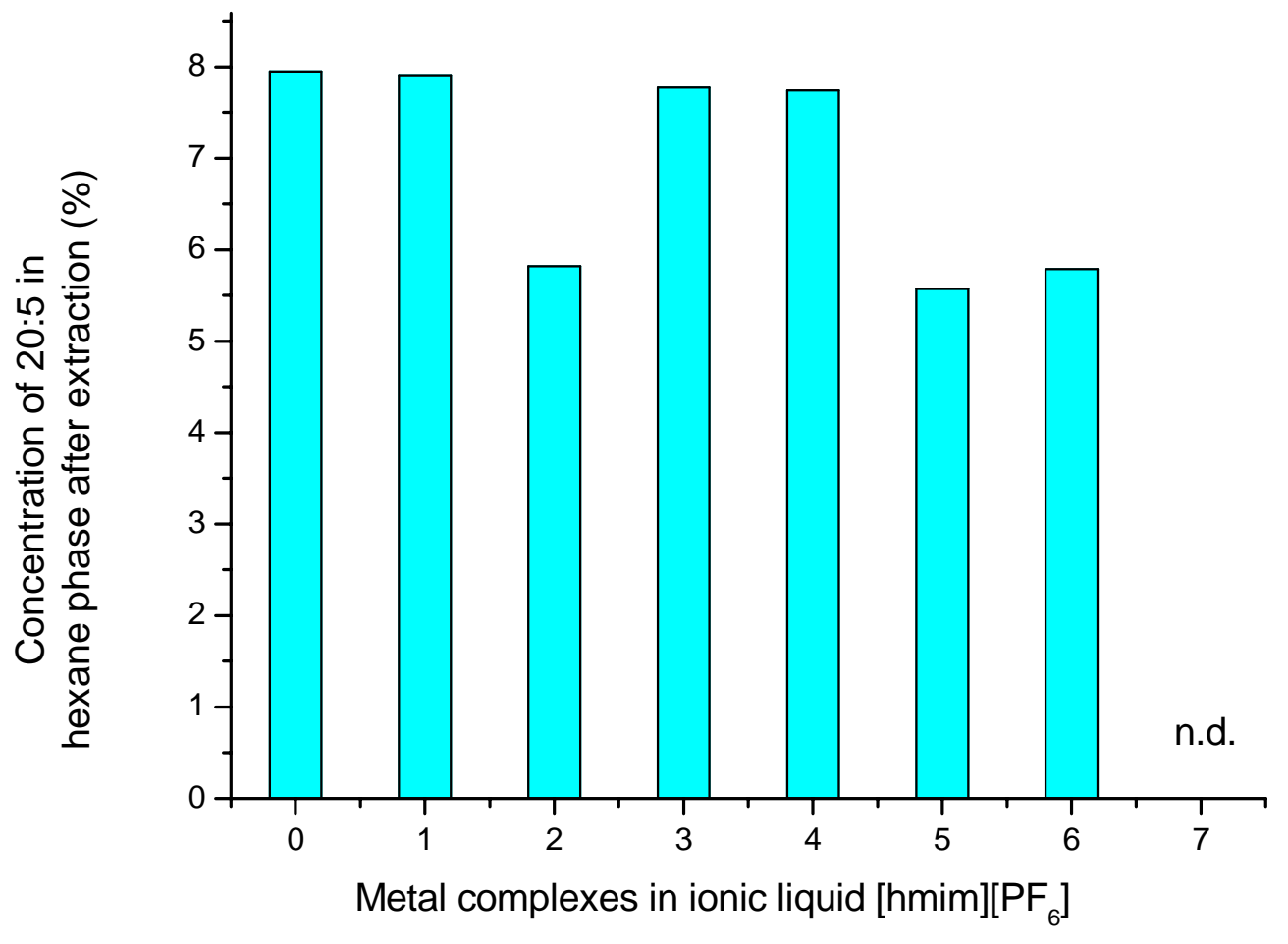

Figure 5. Comparison of extraction of EPA (20:5) in hexane with metal ions in ionic liquids. 0, no metal, control experiment; $1, \mathrm{PdCl}_{2} ; 2, \mathrm{H}_{2} \mathrm{PtCl}_{6} ; 3, \mathrm{NiCl}_{2}$; 4,CuCl; 5, $\mathrm{PdCl}_{2}(\mathrm{TPP})_{3} ; 6, \mathrm{RhCl}(\mathrm{TPP})_{3} ; 7, \mathrm{AgBF}_{4}$. n.d, not determinable.

The isolation of EPA and DHA was studied by covalently immobilizing ionic liquids (ILs) onto silica gel and then coating this silica-supported ILs with silver salts. These sorbents were successfully applied to extract and enrich polyunsaturated fatty acid methyl esters (PUFAMEs) including EPA and DHA with both high selectivity and high capacity. The enrichment of PUFAMEs was investigated using a simple three-step procedure consisting of (1) sorbent pretreatment, (2) sample extraction onto the sorbent 
and (3) stripping the sorbent by 1-hexene. Only $5 \mathrm{mg}$ of the sorbent $\left(\mathrm{AgBF} 4 / \mathrm{SiO} 2 \bullet \mathrm{Im}+\bullet \mathrm{PF}^{-}\right)$completely adsorbed $0.33 \mathrm{mg}$ of EPA (20:5) in $5 \mathrm{~min}$ from the feed mixture solution. The saturated extraction capacity for EPA by using this $\mathrm{AgBF} 4 / \mathrm{SiO} 2 \bullet \mathrm{Im}+\bullet \mathrm{PF}^{-}$sorbent was $120.0 \mathrm{mg} / \mathrm{g}$ as determined by its adsorption isotherm. After a consecutive two-step stripping by ethyl ether and then 1-hexene, the concentration of EPA increased from $7 \%$ in the feed stock solution to about $90 \%$ in the 1 hexene stripping solvent. After five recycles, the sorbent is still usable.

To further increase the extraction capacity, mesoporous silica gel complexing sorbents were studied. For this purpose, mesoporous silica gel was prepared and characterized. Compared with similar experiment described in the last paragraph, much higher extraction capacities were obtained.

Part 2. Separation of Vitamin E from soybean oil

Ordered mesoporous adsorbents were prepared by physically coating functionalized ionic liquids onto mesoporous silica gel. These adsorbents were successfully applied to the selective extraction and separation of vitamin E from a model mixture of soybean oil deoderizer distillate. Various parameters affecting the adsorption process, such as adsorption time, ionic liquid structures and loadings, the adsorption isotherm, and adsorbent reusability were investigated using liquid-solid extraction. $\alpha$ Tocopherol capacities as high as $211 \mathrm{mg} / \mathrm{g}$ adsorbent were obtained through the adsorption isotherm tests using $[\mathrm{emim}][\mathrm{Gly}] / \mathrm{SBA}-15$ as the adsorbent. The anion of glycine was employed as the counteranion to 1-ethyl-3methyl-imidazolium ([emim]). When this functionalized ionic liquid was coated on traditional microporous silica gel, the extraction capacity of the $[\mathrm{emim}][\mathrm{Gly}] / \mathrm{SiO} 2$ dropped to $105 \mathrm{mg} / \mathrm{g}$ adsorbent. The 
substantial extraction capacity enhancement of [emim][Gly]/SBA-15 adsorbent was ascribed to its larger pore size and surface area versus traditional silica gel. [emim][Gly]/SBA-15 also exhibited a very high adsorption selectivity for $\alpha$-tocopherol. The ratio of distribution coefficients between $\alpha$-tocopherol and the major interfering component glyceryl triundecanate $(\operatorname{Kd}(\alpha$-tocopherol) $/ \operatorname{Kd}$ (triglyceride $))$ was 10.5 . The concentration of $\alpha$-tocopherol was significantly increased from $15.6(w t \%)$ in original feedstock solution to $73.0 \%$ after stripping the adsorbed product with diethyl ether. The original feedstock solution also contained fatty acid methyl esters, triglyceride and $\alpha$ tocopherol. Five adsorbent recycle tests showed good reusability of this ionic liquidmodified mesoporous adsorbent. The distribution coefficient for $\alpha$-tocopherol, $\operatorname{Kd}(\alpha-$ tocopherol), went down from $199 \mathrm{~mL} / \mathrm{g}$ in the first cycle to $148 \mathrm{~mL} / \mathrm{g}$ in the fifth cycle.

\section{Research on Glycerol Fermentation}

Due to the world's decreasing supply of fossil fuels, alternative fuel sources must be found. Biodiesel fuel is steadily becoming a viable alternative to petroleum diesel. Glycerol is a key product from the production of biodiesel. It is produced during the transesterification process by cleaving the fatty acids from the glycerol backbone (the fatty acids are used as part of the biodiesel, which is a fatty acid methyl ester). Glycerol is a non-toxic compound with many uses; however, if a surplus exists in the future, more uses for the produced glycerol needs to be found. Also, for biodiesel production processes that incorporate animal wastes, the glycerol byproduct could negatively impact the quality of the glycerol and require expensive cleaning steps. As a consequence the crude glycerol form these feedstocks would not be desirable for use in many of its current 
applications in foods, cosmetics, pharmaceuticals, etc. These limitations again illustrate the need for new, more profitable uses of glycerol to be discovered.

The goal of this phase of the project was to find an add-on process to the biodiesel production process that will convert the glycerol by-product into more valuable substances for end uses other than food or cosmetics, focusing at present on 1,3propanediol and lactic acid. Experiments using bacteria that are known to ferment glycerol into these compounds has been performed in order to establish a benchmark for comparison against other types of bacteria. For this work the three benchmark cultures (Clostridium acetobutylicum, Clostridium beijerinckii, and Clostridium pasteurianium) were utilize as benchmark organisms to compare to MSU isolates producing these compounds. Some of the isolates tested from MSU's Chemical Engineering culture collection were isolated during a US DOE EPSCoR project whose focus was to find a microorganism capable of economically converting syngas to ethanol. During the EPSCoR project $>20$ cultures were isolated from various environments ranging from manure to sewage treatment plants. In addition to these microorganisms as potential glycerol-fermenting microorganisms, attempts were made to isolate glycerol-fermenting microorganisms from Winogradsky columns. Winogradsky columns are an old technique of developing microbial biofilms that allows microorganisms to develop in their native state thereby encouraging the growth of larger variety of microorganisms. Reported here are the findings of those experiments.

\section{Materials and Methods}

Glycerol-Fermenting Cultures: Clostridium acetobutylicum ATCC 824, Clostridium beijerinckii ATCC 14823, and Clostridium pasteurianium ATCC 6013 were purchased 
from the American Type Culture Collection and cultivated on ATCC 1500 culture medium. Isolates from the previous EPSCoR work were removed from storage at $0^{\circ} \mathrm{C}$ on slants and placed into fresh ATCC 1500 medium and incubated at $35^{\circ} \mathrm{C}$ and $100 \mathrm{rpm}$. In order to increase the genetic pool of glycerol-fermenting microorganisms other microorganisms with this ability were also screened. The sources of these microorganisms were the biofilms that had formed in the Winogradsky columns that MSU had been developing for several years (Figure 6). These cultures were isolated by first selecting a Winogradsky column that distinctly developed biofilms (this is an indication of fully developed column). Based on the known the development of colors in the columns samples were selected from a zone in the columns known to be anaerobic. Since this was the early phase little efforts were placed on identification of the isolates. Emphasis was placed on the ability of each organism to convert glycerol into industrial products and the efficiencies of these conversions.

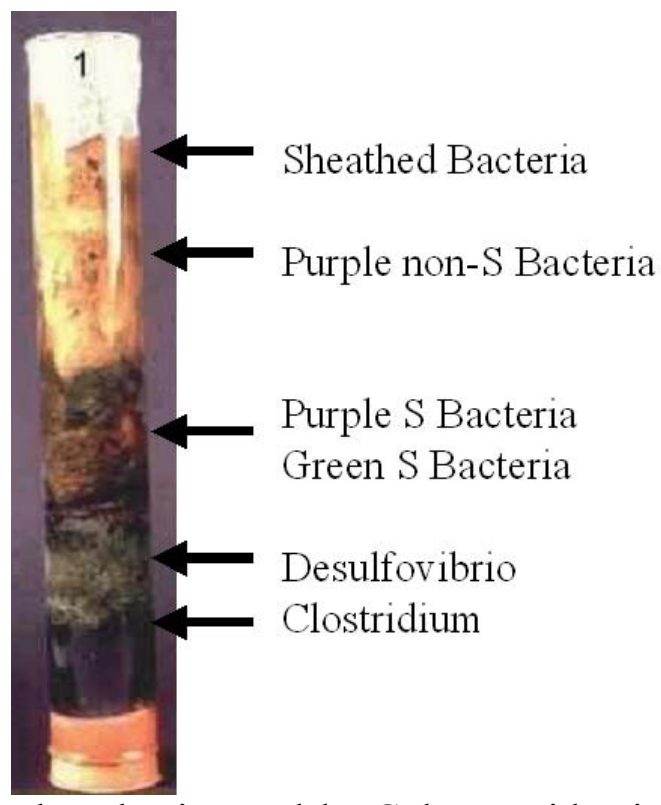

Figure 6. Fully Developed Winogradsky Column with Distinct Biofilm Layers and Glycerol-Fermenting Microorganisms Label Clostridium. 
Isolation of Glycerol-Fermenting Cultures: Traditional enrichment techniques were utilized to isolate candidate cultures. Using a modified ATCC 1500 medium (glycerol as the carbon source instead of corn starch) either $1 \mathrm{~mL}$ of inoculum or $1 \mathrm{~g}$ of soil was initially added to $30 \mathrm{~mL}$ of the sterile medium contained in $40 \mathrm{~mL}$ volatile organic acid (VOA) vials under anaerobic conditions. Vials were initially allowed to incubate for 5 days before the first enrichment transfer was made. Enrichments of this culture were made by transferring $1 \mathrm{~mL}$ of the fluid to sterile ATCC 1500 glycerol medium under anaerobic conditions followed by a 3 day incubation period. Anaerobic conditions were maintain via the use of a Coy Flexible Anaerobic Chamber that was equipped with an automatic airlock system and 4 sets of arm ports (Figure 7). The chamber contains an atmosphere of $95 \% \mathrm{~N}_{2}$ and $5 \% \mathrm{H}_{2}$. Workers were able to transfer cultures into fresh medium via pipette inside the anaerobic chamber and avoid the cultures from being exposed to oxygen for which they are very sensitive to it. 


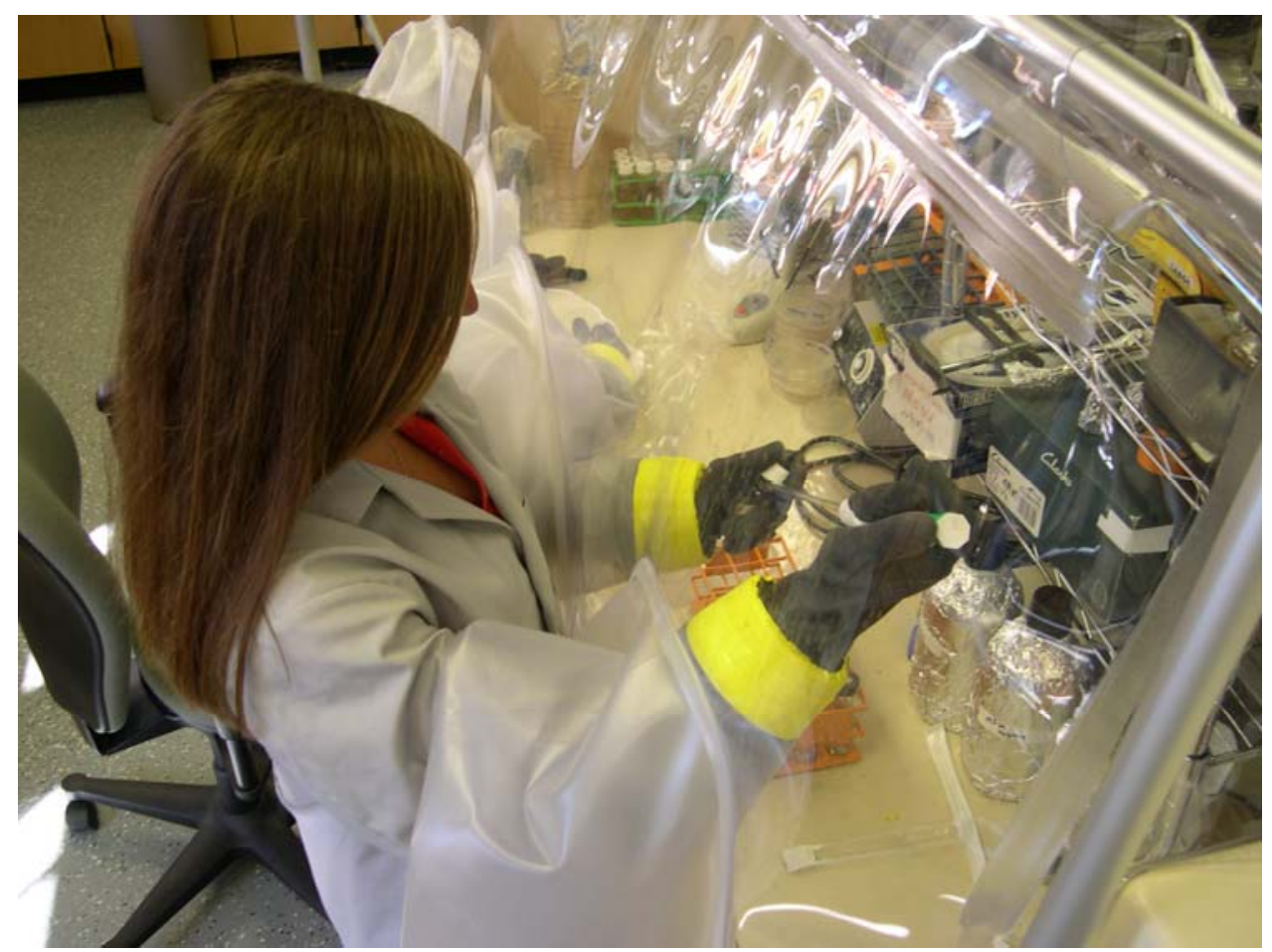

Figure 7. Worker Transferring Cultures in the Coy Flexible Anaerobic Chamber.

Following three enrichments, an aliquot of the cell suspension was transferred to $100 \mathrm{~mm}$ diameter Petri plates containing $25 \mathrm{~mL}$ of ATCC 1500 medium solidified with $18 \mathrm{~g} / \mathrm{L}$ bacto agar. Using traditional streak plate techniques the individual cultures were isolated from members of their consortium. These cultures were incubated in the glove bag to ensure anaerobic conditions for a minimum of five days. Using an inoculation loop individual colonies from the surface of the solidified medium were transferred to liquid $40 \mathrm{~mL}$ VOA vials containing $30 \mathrm{~mL}$ of fresh sterile ATCC 1500 glycerol medium. These cultures were incubated for 3 days before being transferred to fresh ATCC 1500 glycerol medium. After the third transfer cultures were tested for the presences of lactic acid and/or 1,3-propanediol. 
Glycerol GC-FID Analytical Method: These samples were shot in triplicates for GCFID analysis. An Agilent 6890 gas chromatography (GC) system with a Flame Ionization Detector (FID) and autosampler (Agilent Inc., Palo Alto, CA) was used. The system was controlled by the Agilent GC Chemstation software; version B.01.03. The system was operated with Ultra High Purity hydrogen gas (NexAir LLC, Columbus, MS) and compressed air (NexAir) at flow rate of $40 \mathrm{~mL} / \mathrm{min}$ and $400 \mathrm{~mL} / \mathrm{min}$ respectively. Ultra High Purity hydrogen gas was used as makeup gas on the system. The final combined flow was regulated to $35.0 \mathrm{~mL} / \mathrm{min}$. A Restek Stabilwax-DA capillary column (30 m length, 250 um inner diameter, 0.25 um film thickness, and maximum temperature of $260^{\circ} \mathrm{C}$ ) was used for separation of the compounds. During the injection cycle, the syringe was washed twice with a $50 \%$ Acetonitrile solvent, and injections of $1 \mu 1$ were made with a $10 \mu \mathrm{l}$ syringe. Post injection, the syringe was washed again twice with the solvent. The inlet was run in split mode in a 40:1 ratio with an initial temperature of $255^{\circ} \mathrm{C}$. The oven was programmed to hold the initial temperature of $50^{\circ} \mathrm{C}$ for 2 minutes and then ramp with $22^{\circ} \mathrm{C} / \mathrm{min}$ to the final temperature of $250^{\circ} \mathrm{C}$ and hold for 7 minutes. The total runtime was 18.09 minutes.

Lactic Acid and 1,3-Propanediol Analysis with HPLC: Lactic acid and 1,3-propanediol in the liquid phase was quantified using a Waters HPLC System (Milford, Massachusetts). The Waters System consisted of a 515 Pump, a 717-Plus Autosampler, and a 2487 Dual $\lambda$ Absorbance Detector. The HPLC used a Waters YMC ODS-AQ S-5 $120 \AA$ column $(150 \times 4$ 4.6 I.D., S-5 $\mu \mathrm{m}, 12 \mathrm{~nm})$, and the corresponding Waters YMC ODS-AQ S-5 $120 \AA \AA$ guard column ( $4.0 \times 23 \mathrm{~mm}$ threaded guard). The mobile phase for the $\mathrm{HPLC}$ was $20 \mathrm{mM} \mathrm{NaH}_{2} \mathrm{PO}_{4}$ with a pH of 3.5. 
Correlating Cell Mass to Optical Density: Cultures were inoculated for growth into 200 $\mathrm{mL}$ of ATCC 1500 glycerol medium under anaerobic conditions. These cultures were grown for three weeks to achieve a large amount of cell mass. After this period the cultures were placed in a centrifuge at $2000 \mathrm{rpm}$ for 20 minutes. This sample was resuspended in $50 \mathrm{~mL}$ of medium without glycerol. At this point a serial dilution was made by placing volumes of the cell suspension into blank medium to achieve dilutions of $1: 1,1: 2,1: 5$, and $1: 10$. Ten $\mathrm{mL}$ of the resuspend cell pellet was placed on aluminum weigh dishes and dried overnight at $60^{\circ} \mathrm{C}$. Dilutions were examined for optical density using a Genesys 20 spectrophotometer at $546 \mathrm{~nm}$ wavelength. A curve was generated by plotting optical density measurements vs cell mass concentrations for all three of the ATCC purchased cultures. These curves are presented in Figures 8-10.

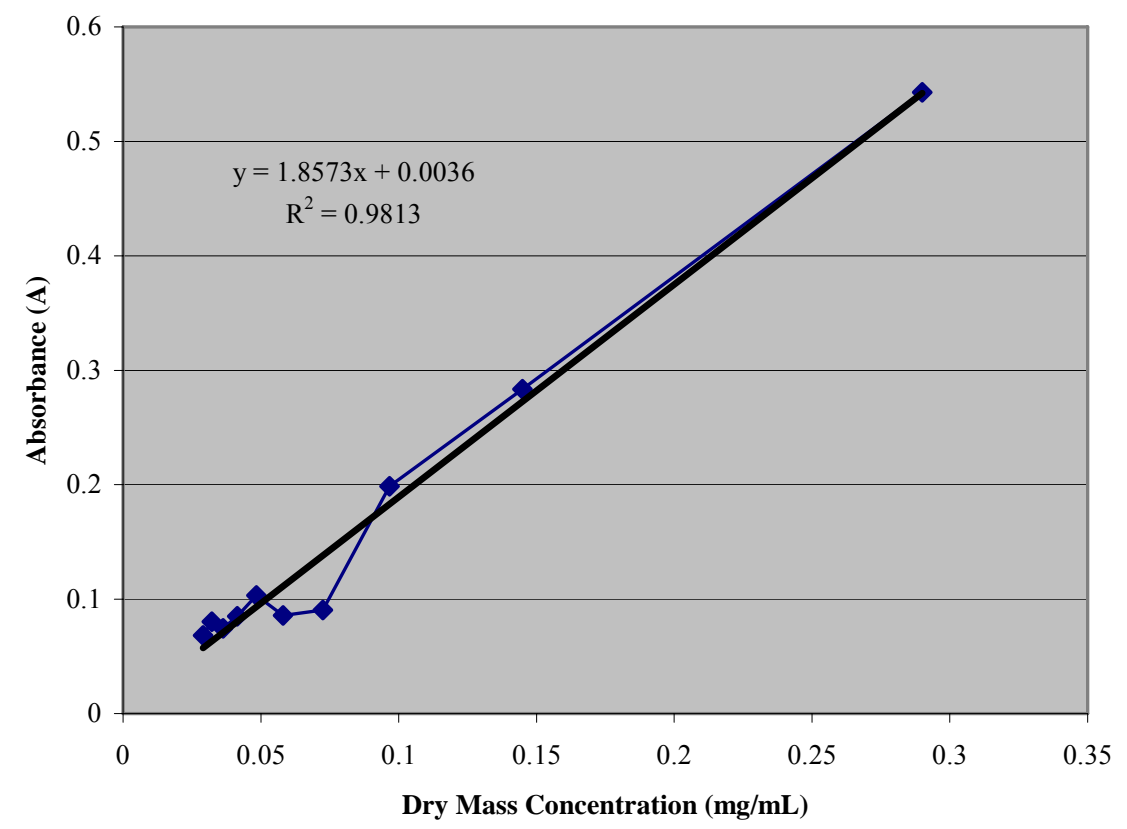

Figure 8. Correlation of Absorbance to Dry Mass Concentrations for Clostridium acetobutylicum. 


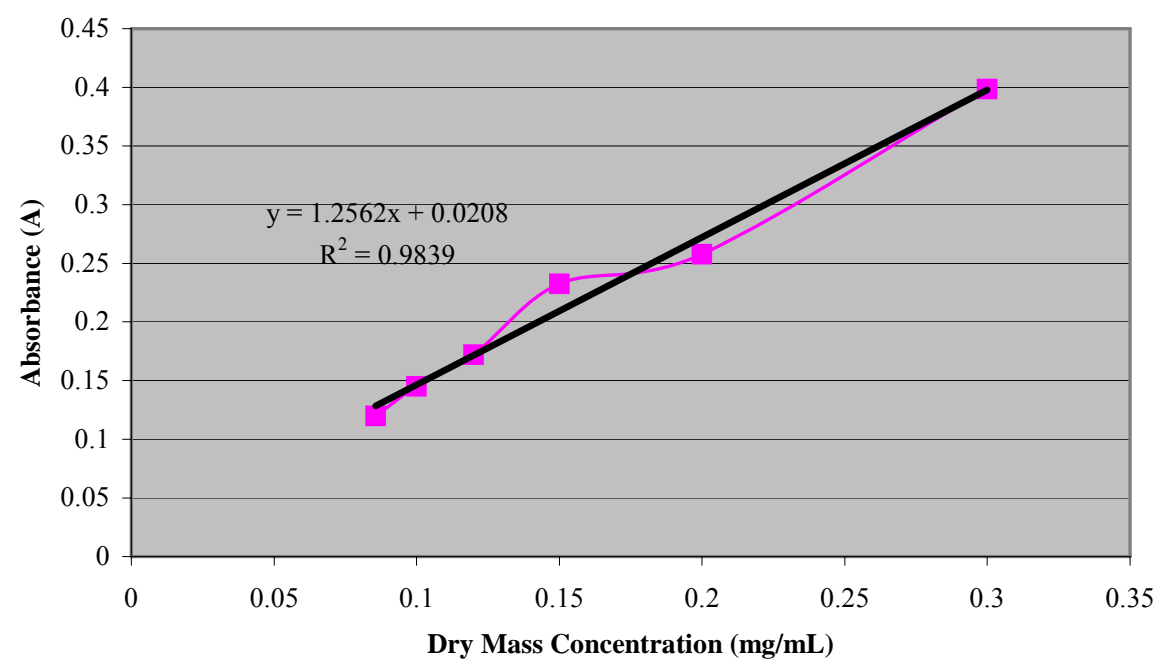

Figure 9. Correlation of Absorbance to Dry Mass Concentrations for Clostridium beijerinckii.

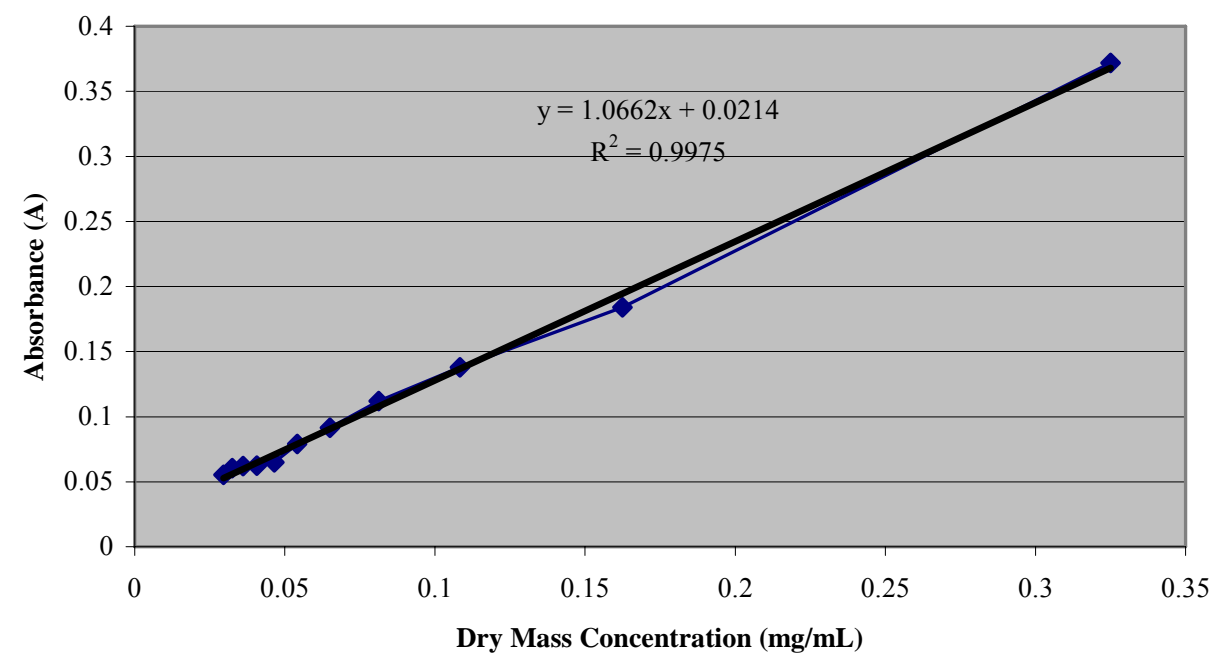

Figure 10. Correlation of Absorbance to Dry Mass Concentrations for Clostridium pasteurianium.

\section{Results}

Glycerol Conversion by C. acetobutylicum, C. beijerinckii, and C. pasteurianium: The results of these experiments are given in Table 6 below. These assays were conducted in $40 \mathrm{~mL}$ VOA vials containing $30 \mathrm{~mL}$ of ATCC glycerol medium. The concentration of 
glycerol used in this study was $2.5 \mathrm{~g} / \mathrm{L}$. The results of these experiments demonstrate the ability of $C$. acetobutylicum and $C$. beijerinckii to convert glycerol into lactic acid at concentration greater than $100 \mathrm{mg} / \mathrm{L}$. However C. beijerinckii was capable of simultaneously producing 1,3-propanediol from the fermentation of glycerol. With a more fundamental understanding of the genetic regulations this microorganism offers the potential to produce either product depending on the market price. C. pasteurianum by far produced the largest concentration of 1,3-propanediol of all the microbes purchased from ATCC or isolated by MSU. C. pasteurianum failed to produce any detectable amounts of lactic acid during the time tested.

Table 6. Final Concentration of 1,3-Propanediol and Lactic Acid in the Fermentation Medium When the ATCC Cultures Were Offered ATCC 1500 Glycerol Medium (2.5 g/L glycerol).

\begin{tabular}{|l|l|l|}
\hline \multicolumn{1}{|c|}{ BACTERIA } & \multicolumn{1}{|c|}{$\begin{array}{c}\text { 1,3-PROPANEDIOL } \\
\text { PRODUCED (ppm) }\end{array}$} & \multicolumn{1}{c|}{$\begin{array}{c}\text { LACTIC ACID } \\
\text { PRODUCED (ppm) }\end{array}$} \\
\hline Clostridium \\
acetobutylicum & none & 145.35 \\
\hline Clostridium beijerinckii & 43.32 & 179.31 \\
\hline Clostridium pasteurianum & 545.58 & none \\
\hline
\end{tabular}

The yield of product per mole of glycerol also demonstrated that $C$. pasteurianum was much more efficient at converting glycerol to 1,3-propanediol than was $C$. acetobutylicum or C. beijerinckii at converting glycerol to either product. $C$. pasteurianum yielded $0.27 \mathrm{~mol}$ of 1,3-propanediol per mol of glycerol. Where $C$. acetobutylicum only yielded $0.06 \mathrm{~mol}$ of lactic acid per mol of glycerol and $C$. 
beijerinckii yielded $0.08 \mathrm{~mol}$ and 0.02 of lactic acid and 1,3-propanediol respectively per mol of glycerol. Of these three tested C. pasteurianum produced the highest yield and final concentration of product when offered $2.5 \mathrm{~g} / \mathrm{L}$ glycerol.

Glycerol Conversion by MSU Isolates: Of the $>20$ cultures tested only 8 showed any measurable amounts of either lactic acid or 1,3-propanediol in the fermentation broth. These cultures were designated $\mathrm{J} 1, \mathrm{~J} 2, \mathrm{~J} 6, \mathrm{~J} 7, \mathrm{~J} 8, \mathrm{~J} 9, \mathrm{~J} 10$, and $\mathrm{J} 13$ and the concentration of either lactic acid or 1,3-propanediol is given in Table 7. It is very apparent that the cultures isolated were very well suited for the conversion of glycerol to lactic acid as all but 2 of the MSU isolates produced the compound. Three cultures (J6, J1, and J13) produced more lactic acid than the benchmark organisms. With yields greater than 20 mol lactic acid per mol of glycerol for all three microorganisms. Three cultures (J6, J7, and J9) demonstrated the ability to produce 1,3-propanediol during glycerol fermentation. However all three MSU cultures produced products at concentrations below that of the benchmark microorganisms. There was one notable isolate the caught the eye of the investigators and that was culture $\mathrm{J} 6$ due to the ability of this microorganism to coproduce both products and one in particularly high concentrations. This culture with more understanding of its metabolic pathways could prove a useful biological agent for the conversion of glycerol.

These results demonstrate the potential for undiscovered microorganisms to carryout significant biochemical pathways. It also demonstrates the importance of being able to culture the microorganisms from its environment as was demonstrated using the Winogradsky columns. The metabolic ability of the microbial community is vast and could have tremendous potential. 
All of the cultures isolated during this study were placed in the freezer in glycerol medium for use in subsequent experiments.

Table 7. Final Concentration of 1,3-Propanediol and Lactic Acid in the Fermentation Medium When Offered ATCC 1500 Glycerol Medium (2.5 g/L glycerol) to the MSU Isolates.

\begin{tabular}{|l|l|l|}
\hline BACTERIA & $\begin{array}{l}\text { 1,3-PROPANEDIOL } \\
\text { PRODUCED (ppm) }\end{array}$ & $\begin{array}{l}\text { LACTIC ACID } \\
\text { PRODUCED (ppm) }\end{array}$ \\
\hline $\mathrm{J} 6$ & 78.89 & 509.56 \\
\hline $\mathrm{J} 7$ & 214.22 & none \\
\hline $\mathrm{J} 9$ & 50.89 & none \\
\hline $\mathrm{J} 1$ & none & 476.43 \\
\hline $\mathrm{J} 2$ & none & 131.12 \\
\hline $\mathrm{J} 8$ & none & 148.41 \\
\hline $\mathrm{J} 10$ & none & 119.78 \\
\hline $\mathrm{J} 13$ & none & 794.44 \\
\hline
\end{tabular}




\section{Research on Reaction Kinetics of Soybean Oil Transesterification Using Heterogeneous Metal Oxide Catalysts.}

Biodiesel is generally produced by the transesterification of a triglyceride (vegetable oil, animal fat etc.) with alcohol in the presence of a catalyst (basic, acidic, enzymatic etc). The products are fatty acid alkyl esters (biodiesel) and glycerol. The stoichiometric reaction requires $1 \mathrm{~mol}$ of a triglyceride and 3 moles of alcohol. However, excess alcohol is used in order to drive the reaction forward (since the transesterification is a reversible reaction) to increase the yields of the alkyl esters and to allow phase separation from the glycerol formed. Figure 11 depicts a generalized reaction for the transesterification reaction.

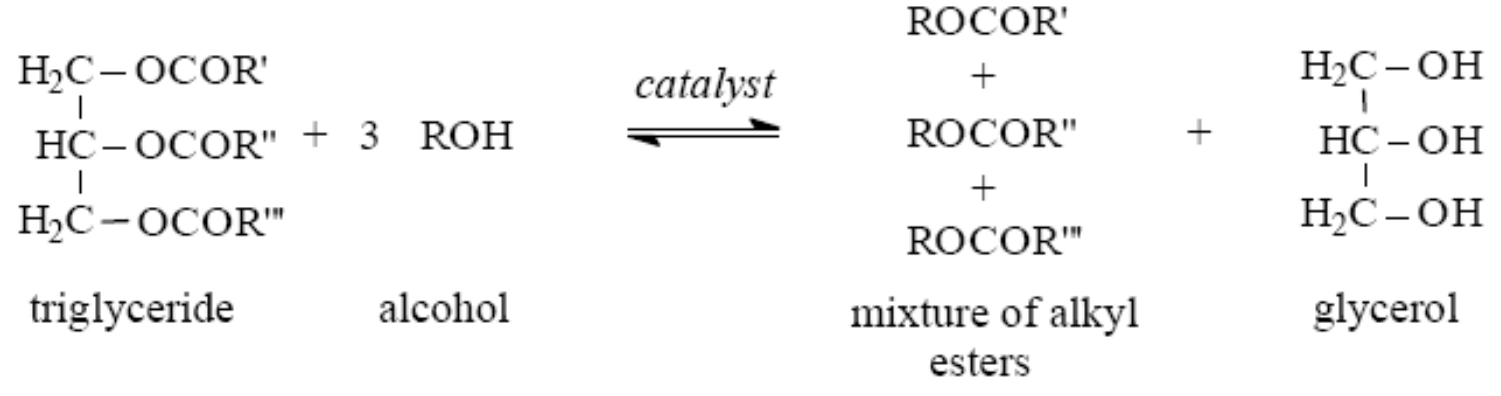

Figure 11. Transesterification of soybean oil into biodiesel.

In transesterification, the selection of catalyst depends on the amount of free fatty acid present in the source oil. When the free fatty acid content is less than approximately $1 \%$, an alkali catalyzed reaction is preferred due to better conversion rates. For higher amounts of free fatty acid content, acid catalyzed esterification followed by transesterification is better suited. Conventionally homogeneous catalysts (like $\mathrm{NaOH}$, $\mathrm{KOH}$ etc.) are used for the transesterification. However, there are drawbacks associated with homogeneously catalyzed processes. The catalyst dissolves fully in the glycerin layer and partially in the FAME layer. As a result, biodiesel should be cleaned through a slow, tedious and environmentally unfriendly water washing process. Catalyst 
contaminated glycerin has little value in today's market and is increasingly becoming a disposal issue. Another negative aspect of the homogeneously catalyzed process is that the catalysts are not re-usable. Heterogeneous catalysts, on the other hand, makes product separation easier and makes catalysts re-usable. Also, heterogeneous catalysts have the potential to simplify the production process by enabling usage of continuous packed bed reactors.

In most of the solid catalyzed experiments, the reaction proceeded at a relatively slow rate [43]. The presence of heterogeneous catalysts makes the reaction mixture a three-phase system, oil-methanol-catalyst, which for mass transfer reasons, protracts the reaction. At the same time, heterogeneous catalysis requires relatively harsher reaction conditions, i.e., high pressures and high temperatures. For example, some experiments have been carried out at temperatures as low as $78 \mathrm{~K}$ and as high as $1000 \mathrm{~K}$ and high pressures, with high pressure and temperature favoring better conversion [44]. The overall goal of this study was to identify a heterogeneous oxide catalyst that gives satisfactory FAME yields at intermediate conditions compared to above.

\section{Biodiesel Production Using Solid Catalysts}

There have been several studies on the transesterification of vegetable oils using

heterogeneous catalysts. In one study, rapeseed oil was transesterified by methanol using basic alkaline-earth metal compounds: calcium oxide, calcium methoxide and barium hydroxide [43]. It was found that these were effective in the transesterification reaction and the reaction rate could be enhanced by ultrasound as well as by introducing an appropriate reagent into a reactor to promote methanol solubility in the triglyceride [43]. 
Biodiesel from jatropha curcas oil was produced with a heterogeneous solid super base catalyst, calcium oxide [45]. The results showed that the base strength, $\mathrm{pK}_{\mathrm{B}}$, of calcium oxide was more than 26.5 after calcination, following immersion in an ammonium carbonate solution. Optimization of reaction conditions were studied for the transesterification of jatropha curcas oil. It was found that under the optimum conditions for catalyst calcinations, i.e. a temperature of $900^{\circ} \mathrm{C}$, reaction temperature of $70^{\circ} \mathrm{C}$, reaction time of $2.5 \mathrm{~h}$, catalyst loading of $1.5 \%$, and a methanol/oil molar ratio of 9 , the oil conversion was $93 \%$. However, a different study [46] concluded that using calcium oxide calcined in air only resulted in a $10 \%$ methyl esters yield after $4 \mathrm{~h}$. The catalyst samples were prepared by calcination of the precipitated calcium carbonate at $900^{\circ} \mathrm{C}$ in the prescribed atmosphere, an ambient air or helium gas flow. Calcination in a helium gas flow markedly intensified the activity of calcium oxide yielding acceptable ester yields in $2 \mathrm{~h}$.

In a different study, biodiesel was produced by transesterification of soybean oil with methanol using $\mathrm{ZnO}$ loaded with $\mathrm{KF}$ as a solid base catalyst [47]. The catalyst with $15 \%$ KF loading and calcined at $873^{\circ} \mathrm{K}$ showed the best activity. The results also showed that the activity of the catalysts correlated with their basicity. The transesterification of soybean oil using alumina loaded with potassium iodide $(35 \% \mathrm{w} / \mathrm{w})$ as a solid base catalyst [48] showed that after calcination at $773 \mathrm{~K}$ for $3 \mathrm{~h}$, the catalyst gave the highest basicity and the best catalytic selectivity for this reaction. The conversion was found to be $96 \%$ under the optimum reaction conditions. In other work, a heterogeneous base catalyst, $\mathrm{Na} / \mathrm{NaOH} / \gamma-\mathrm{Al}_{2} \mathrm{O}_{3}$, showed comparable results to a homogenously catalyzed $\mathrm{NaOH}$ process [49]. Although screening studies have been carried out on potential 
heterogeneous catalysts, the kinetics of the heterogeneously catalyzed process has not yet been analyzed in depth. This study is an attempt to fill this gap in knowledge to a selected group of solid oxide catalysts.

\section{Reaction Kinetics of Transesterification Reaction}

Although the importance of biodiesel as an alternative fuel has grown during the last twenty years, the chemical kinetics of transesterification, very important for process design, remain controversial. Kinetics describes the rate of chemical reactions. Rate equations are typically written in terms of the concentration of the reactants. In the past, it has been observed that the base catalyzed transesterification is a second order reaction [50]. This has been confirmed in a different work for the transesterification of soybean oil with methanol using sodium hydroxide a homogeneous catalyst [51]. In this work, it was assumed that transesterification is a three-step, reversible process, and the reaction rate constants and activation energies were determined for all the forward and reverse reactions.

In a different work, the rate constants and the reaction order were determined for each of the steps in the presence of a catalyst with a computerized kinetics program [52]. It was found that the forward reactions appear to be pseudo-1st order or 2nd order depending upon conditions used. Reverse reactions appeared to be 2 nd order. At a $\mathrm{MeOH} / \mathrm{oil}$ molar ratio of $6: 1$, a shunt reaction was observed. Activation energies were determined for all forward and reverse reactions under a variety of experimental conditions for plots of $\log k$ vs. $1 / T$ (where $k=$ rate constant and $T=$ temperature).

In the present work, the fatty acid methyl esters yields from the transesterification of soybean oil with methanol in the presence of different solid catalysts were determined. 
The reaction kinetics (rate constant and reaction order) of the transesterification reactions was proposed.

\section{Materials and Methods}

\section{Reagents}

Solvent-extracted degummed soybean oil donated by Bungi Corporation Marks, MS, USA, was used as the triglyceride. The basic catalysts $\left(\mathrm{PbO}, \mathrm{MgO}, \mathrm{MnO}_{2}, \mathrm{BaO} \&\right.$ $\mathrm{CaO})$ and methanol $(99.9 \%)$ used in the study was purchased from Fisher Scientific, USA.

\section{Equipment}

The transesterification was carried in a fully automated high-pressure hightemperature batch reactor (PARR Instrument, 4843). The equipment consists of a high pressure cylindrical chamber, a heater, a water line (in order to control the temperature) and a stirrer.

\section{Soybean oil and Methanol solution}

A mixture of $30 \mathrm{~mL}$ methanol and $100 \mathrm{~mL}$ of soybean oil and $2 \mathrm{~g}$ of solid catalyst was used in each experimental unit.

\section{Transesterification}

Two different methods of transesterification were followed. For the first three catalysts, $\left(\mathrm{PbO}, \mathrm{MgO} \& \mathrm{MnO}_{2}\right)$, the mixture (oil, methanol and catalyst) was first heated to $215^{\circ} \mathrm{C}$ (it was found that there was a very little conversion of 3 to $4 \%$ in the ramping period). Then the reaction was carried out for 2 hours in the high-pressure reactor. Samples were taken out in 15-minute intervals and the fatty acid methyl esters yield was measured with gas chromatography. For the last two catalysts, $(\mathrm{CaO}, \mathrm{BaO})$, it was 
observed that significant conversions took place during the first few minutes of the reaction ( $46 \%$ and $20 \%$ respectively) while ramping up the temperature to $215^{\circ} \mathrm{C}$. Accordingly, the method was changed for these two, in this case the oil was first heated with the catalyst to $215^{\circ} \mathrm{C}$, then $30 \mathrm{~mL}$ of methanol was injected using a HPLC pump at a flow rate of $10 \mathrm{~mL} / \mathrm{min}$ for 3 minutes. Then the experiments were carried out for the next 14 minutes at a sampling interval of 2 minutes. The product (a mixture of fatty acid methyl esters and glycerol) was separated and then was transferred to a freezer before being sent for gas chromatography (GC) analysis.

\section{Gas Chromatography Analysis}

The top layer of each sample, after stabilization, was analyzed for FAME composition at the Mississippi State Chemical Laboratory, Mississippi State University, with gas chromatography.

\section{Determination of Reaction Kinetics}

The transesterification reaction is a reversible reaction and therefore, excess methanol is used to drive the reaction forward. Equation 1 shows the generalized transesterification reaction, where A is the triglyceride, B is methanol, C is FAME and D is glycerol. The equation also shows the stoichiometric relationship between the reactants and the products.

$$
A+3 B \Leftrightarrow C+D
$$

The general rate equation for the Equation 1 will be,

$$
-\frac{\mathrm{d} C_{A}}{\mathrm{~d} t}=k C_{A}^{\alpha} C_{B}^{\beta}
$$

Where, 


$$
\begin{aligned}
-\frac{\mathrm{d} C_{A}}{\mathrm{~d} t} & =\text { the consumption of reactant A per unit time } \\
k & =\text { rate constant } \\
C_{A} & =\text { concentration of } \mathrm{A} \text { after time } \mathrm{t} \\
C_{B} & =\text { concentration of } \mathrm{B} \text { after time } \mathrm{t} \\
\alpha & =\text { reaction order of reactant } \mathrm{A} \\
\beta & =\text { reaction order of reactant } \mathrm{B}
\end{aligned}
$$

Also,

$$
\begin{aligned}
& C_{A}=C_{A 0}(1-X) \\
& C_{B}=C_{A 0}\left(\theta_{B}-3 X\right) \\
& \theta_{B}=C_{B 0} / C_{A 0}
\end{aligned}
$$

Where,

$$
\begin{aligned}
& C_{A 0}=\text { initial concentration of } \mathrm{A} \\
& C_{B 0}=\text { initial concentration of } \mathrm{B} \\
& X=\text { conversion } \\
& \theta_{B}=\text { the ratio of } \mathrm{C}_{\mathrm{B} 0} \text { to } \mathrm{C}_{\mathrm{A} 0}
\end{aligned}
$$

Equation 2 can be written as

$$
\frac{\mathrm{d} X}{\mathrm{~d} t}=k C_{A 0}^{(\alpha+\beta-1)}(1-X)^{\alpha}\left(\theta_{B}-3 X\right)^{\beta}
$$

In the present work, 8 different cases were analyzed in order to get the reaction order. These case were,

$$
\begin{aligned}
& (\alpha=0, \beta=0) ;(\alpha=1, \beta=0) ;(\alpha=0, \beta=1) ;(\alpha=1, \beta=1) ;(\alpha=2, \beta=0) ; \\
& (\alpha=0, \beta=2) ;(\alpha=2, \beta=1) ;(\alpha=1, \beta=2) .
\end{aligned}
$$


For each case, definite integrals of Equation 6 were calculated from a conversion of $X=0$ to a conversion of $X=X$ in the time span of $t=0$ to $t=t$. Then the calculated equation for each case was transferred into a linier equation passing through origin $(y=m x)$. The transferred equations for all the 8 cases are as follows:

Case 1: $(\alpha=0, \beta=0)$

$$
C_{A 0} X=k t
$$

Case 2: $(\alpha=1, \beta=0)$

$$
\ln \left(\frac{1}{1-X}\right)=k t
$$

Case 3: $(\alpha=0, \beta=1)$

$$
-\frac{1}{3}\left[\ln \frac{\left(\theta_{B}-3 X\right)}{\theta_{B}}\right]=k t
$$

Case 4: $(\alpha=1, \beta=1)$

$$
\frac{1}{\left(\theta_{B}-3\right)} \ln \left[\frac{\left(\theta_{B}-3 X\right)}{(1-X) \theta_{B}}\right]=k C_{A 0} t
$$

Case 5: $(\alpha=2, \beta=0)$

$$
\frac{X}{(1-X)}=k C_{A 0} t
$$

Case 6: $(\alpha=0, \beta=2)$

$$
\frac{X}{\left(\theta_{B}-3 X\right) \theta_{B}}=k C_{A 0} t
$$

Case 7: $(\alpha=2, \beta=1)$

$$
\frac{1}{\left(\theta_{B}-3\right)}\left\{\frac{X}{(1-X)}-\frac{3}{\left(\theta_{B}-3\right)} \ln \left[\frac{\left(\theta_{B}-3 X\right)}{(1-X) \theta_{B}}\right]\right\}=k C_{A 0}{ }^{2} t
$$


Case 8: $(\alpha=1, \beta=2)$

$$
\frac{1}{\left(3-\theta_{B}\right)}\left\{\frac{3 X}{\left(\theta_{B}-3 X\right) \theta_{B}}-\frac{1}{\left(3-\theta_{B}\right)} \ln \left[\frac{(1-X) \theta_{B}}{\left(\theta_{B}-3 X\right)}\right]\right\}=k C_{A 0}{ }^{2} t
$$

For Equations 7 through 14, if it is assumed that the left side component is an ordinate (y variable) and $t$ (for Eq. 7 to 9), $C_{A 0}$ (for Eq. 10 to 12) and $C_{A 0}{ }^{2} t$ (for Eq. 13 to 14) are abscissas ( $\mathrm{x}$ variable) respectively, the equations are in the form of $y=m x$ (a straight line passing through origin). For all 8 cases, the y variable was plotted against the corresponding $\mathrm{x}$ variable and the coefficient of determination was determined. In all the cases (Eq. 7 to 14), the slope of the straight line is the rate constant (k) for the reaction. The highest correlation coefficient $\left(\mathrm{R}^{2}\right)$ for each case was observed and the case that gave the highest correlation coefficient was used to determine the reaction order.

\section{Determination of Surface Area of the Catalysts}

Surface area is an attribute that is used by catalyst manufacturers and users to monitor the activity and stability of catalysts. There are different methods used to measure surface area, most methods are based on the isothermal adsorption of nitrogen. Either a single point or multipoint method can be used to calculate the surface area. In our case the multipoint Brunauer, Emmett and Teller (BET) method was used to measure total surface area of these metal oxides by the use of nitrogen adsorption/desorption isotherms at liquid nitrogen temperature and relative pressures $(\mathrm{P} / \mathrm{Po})$ ranging from $0.04-$ 0.4 .

\section{Results}

\section{Biodiesel Yield}

The biodiesel yield (FAME \%) from gas chromatography analysis showed a large variation among different solid catalysts. Figure 12 shows the biodiesel yield (FAME) 
for all the catalysts, $\mathrm{PbO}, \mathrm{MgO}, \mathrm{MnO}_{2}, \mathrm{BaO}$ and $\mathrm{CaO}$, over 2 hours of transesterification. For $\mathrm{PbO}$ the yield was found to be more than $84 \%$ after 1 hour, for $\mathrm{MgO}$ the maximum yield was found to be approximately $66 \%$ after 2 hours and for $\mathrm{MnO}_{2}$ the yield surpassed $80 \%$ after 2 hours.

For $\mathrm{BaO}$ and $\mathrm{CaO}$, the biodiesel yield was found to be more than $95 \%$ and $75 \%$ within 15 and 30 minutes respectively. Cracking of the methyl esters was observed subsequent to these time periods. The initiation of reduction of methyl esters yield could be attributed to the pretense that the rate of cracking exceeded the rate of transesterification for $\mathrm{BaO}$ and $\mathrm{CaO}$ after 15 and 30 minutes respectively under the provided reaction conditions. As a result, only 2 data points for $\mathrm{BaO}$ and 3 data points for $\mathrm{CaO}$ were at hand to calculate the reaction order and rate constant - which was not sufficient (Figure 12). Consequently, in order to capture the trend, the method was modified for these two catalysts. The data was collected in 2 min intervals for 14 minutes after attaining a temperature of $215^{\circ} \mathrm{C}$. It could be noted that according to Figure 13, the FAME yield for the $\mathrm{BaO}$ catalyst surpassed $85 \%$ after 14 minutes and for catalyst $\mathrm{CaO}$, the yield was found to be approximately $78 \%$ after 2 minutes. 


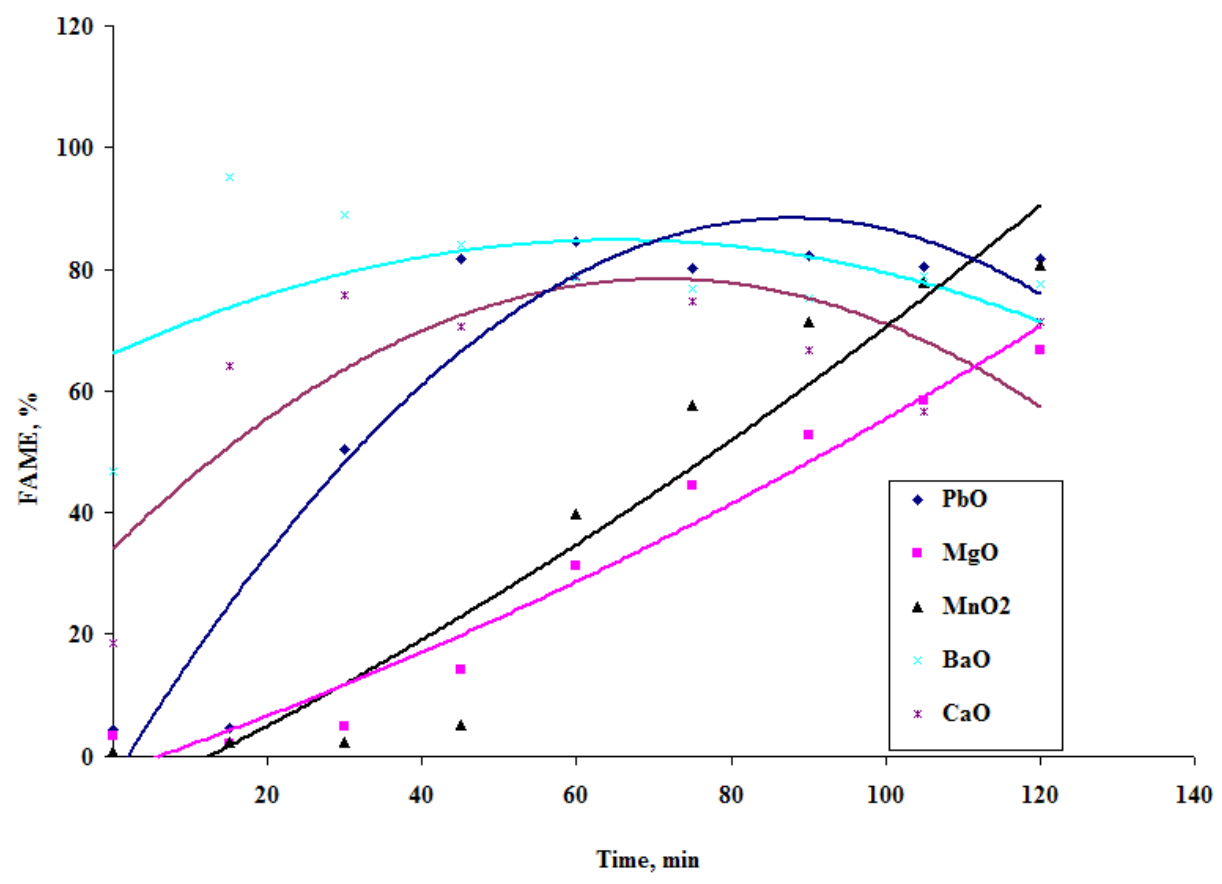

Figure 12. FAME Yield for $\mathrm{PbO}, \mathrm{MgO}, \mathrm{MnO}_{2}, \mathrm{BaO}$ and $\mathrm{CaO}$ (reaction times denoted represent time after reactants reached $215^{\circ} \mathrm{C}$ ).

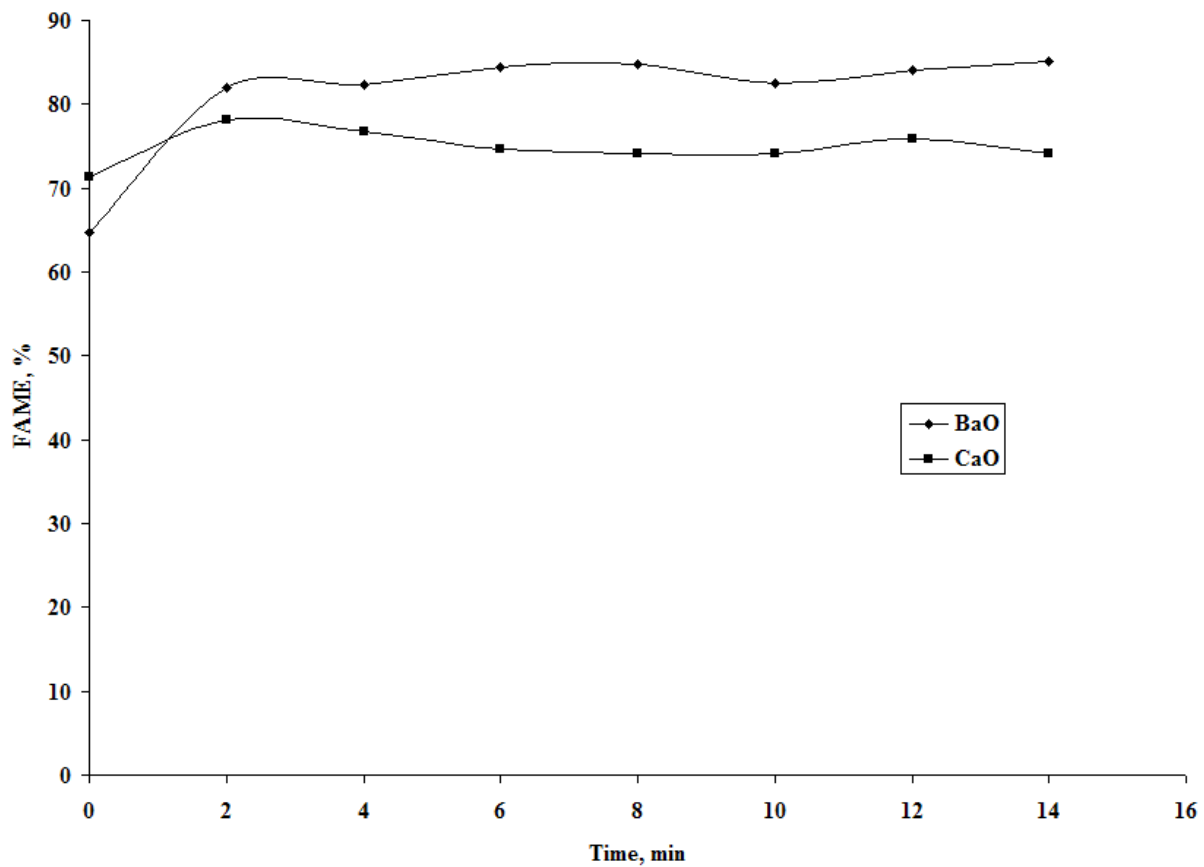

Figure 13. FAME Yield for $\mathrm{BaO}$ and $\mathrm{CaO}$ (reaction times denoted represent time after reactants reached $215^{\circ} \mathrm{C}$ ). 


\section{Reaction Kinetics}

Based on the principle discussed above, all eight cases for each catalyst were plotted and the coefficient of correlation $\left(\mathrm{R}^{2}\right)$ was determined for each case. Finally the case with the highest coefficient of correlation $\left(\mathrm{R}^{2}\right)$ was selected for the determination of rate constant and reaction order. Table 8 gives the $\mathrm{R}^{2}$ values of all eight cases for each of the 5 catalysts.

For some experimental units, Table 8 renders an array of $\mathrm{R}^{2}$ values because the data has been transferred in the form of $y=m x$ in order to model the reaction order based on Equation 7 to 14 . For each catalyst, the highest $\mathrm{R}^{2}$ value is selected out of the 8 cases and the corresponding values of slope were determined. Table 9 gives the reaction order of the transesterification w.r.t. each of the reactants, as well as the overall reaction order and the value of rate constant for each of the 5 catalysts.

\section{Surface Area of the Catalysts}

Table 10 shows the surface area of the catalysts based on the nitrogen adsorption /desorption method (multipoint BET), and it was found that $\mathrm{MgO}$ had the largest area of $157.4 \mathrm{~m}^{2} / \mathrm{g}$ whereas the $\mathrm{PbO}$ had the minimum of $0.55 \mathrm{~m}^{2} / \mathrm{g}$.

\section{Conclusions}

The base catalyzed transesterification of soybean oil using solid catalysts produces biodiesel under high pressure and high temperature conditions. A maximum biodiesel yield of $85 \%$ was obtained by $\mathrm{BaO}$ in 14 minutes, whereas, $\mathrm{PbO}, \mathrm{MnO}_{2}, \mathrm{CaO}$ and $\mathrm{MgO}$ gave a maximum yields of $84 \%, 80 \%, 78 \%$ and $66 \%$ respectively at $215^{\circ} \mathrm{C}$. The overall reaction order of $\mathrm{PbO}, \mathrm{MnO}_{2}, \mathrm{BaO}, \mathrm{CaO}$ and $\mathrm{MgO}$ was found to be $1,1,3,1$ 
and 1 respectively. The highest rate constant was observed for $\mathrm{BaO}$ which was 0.0085 $\mathrm{g}^{2} \cdot \mathrm{mole}^{-2} \cdot \mathrm{min}^{-1}$.

Table 8. The Value of Coefficient of Correlation $\left(\mathrm{R}^{2}\right)$ of All Eight Cases for Each Catalyst.

\begin{tabular}{|l|l|l|l|l|l|}
\hline $\begin{array}{l}\text { Catalysts } \rightarrow \\
\text { Cases } \\
\downarrow\end{array}$ & $\mathrm{PbO}$ & $\mathrm{MgO}$ & $\mathrm{MnO} 2$ & $\mathrm{BaO}$ & $\mathrm{CaO}$ \\
\hline 1 & 0.90 & 0.91 & 0.87 & 0.39 & 0.48 \\
\hline 2 & 0.89 & 0.90 & 0.85 & 0.49 & 0.45 \\
\hline 3 & 0.91 & 0.93 & 0.88 & 0.41 & 0.49 \\
\hline 4 & 0.88 & 0.88 & 0.83 & 0.51 & 0.44 \\
\hline 5 & 0.83 & 0.83 & 0.77 & 0.61 & 0.41 \\
\hline 6 & 0.90 & 0.91 & 0.86 & 0.42 & 0.46 \\
\hline 7 & 0.81 & 0.80 & 0.74 & 0.63 & 0.41 \\
\hline 8 & 0.86 & 0.85 & 0.80 & 0.53 & 0.44 \\
\hline
\end{tabular}

Table 9. Reaction Order of the Transesterification w.r.t. Each of the Reactant as well as Overall and the Rate Constant.

\begin{tabular}{|l|l|l|l|l|}
\hline Catalyst & $\begin{array}{l}\text { Order w.r.t. } \\
\text { Triglyceride }\end{array}$ & $\begin{array}{l}\text { Order w.r.t. } \\
\text { Methanol }\end{array}$ & $\begin{array}{l}\text { Overall } \\
\text { Order }\end{array}$ & Rate Constant \\
\hline $\mathrm{PbO}$ & 0 & 1 & 1 & $0.0032, \mathrm{~min}^{-1}$ \\
\hline $\mathrm{MgO}$ & 0 & 1 & 1 & $0.0011, \mathrm{~min}^{-1}$ \\
\hline $\mathrm{MnO}_{2}$ & 0 & 1 & 1 & $0.0014, \mathrm{~min}^{-1}$ \\
\hline $\mathrm{BaO}$ & 2 & 1 & 3 & $0.0085, \mathrm{~g}^{2} \cdot \mathrm{mole}^{-2} \cdot \mathrm{min}^{-}$ \\
\hline $\mathrm{CaO}$ & 0 & 1 & 1 & $0.0046, \mathrm{~min}^{-1}$ \\
\hline
\end{tabular}


Table 10. Surface Area of the Metal Oxides

\begin{tabular}{|c|c|}
\hline Catalyst & $\begin{array}{c}\text { Surface area, } \\
\mathrm{m}^{2} / \mathrm{g}\end{array}$ \\
\hline $\mathrm{PbO}$ & 0.55 \\
\hline $\mathrm{MgO}$ & 157.4 \\
\hline $\mathrm{MnO}_{2}$ & 50.55 \\
\hline $\mathrm{BaO}$ & 0.76 \\
\hline $\mathrm{CaO}$ & 61.39 \\
\hline
\end{tabular}

\section{Research on Flame Temperature Analysis of Biodiesel Blends and Components}

Meeting the growing energy demand without adversely affecting the environment is a great challenge. Alternatives to petroleum-derived fuels such as biodiesel, ethanol and hydrogen have the potential, at least in part, to satisfy these energy needs while coercing minimal impact to the environment. In particular, biodiesel reduces emissions such as life cycle $\mathrm{CO}_{2}$, particulate matter, $\mathrm{CO}, \mathrm{SO}_{\mathrm{x}}$, volatile organic compounds (VOCs), and unburned hydrocarbons significantly [53-55]. However, biodiesel has portended to increase oxides of nitrogen $\left(\mathrm{NO}_{\mathrm{x}}\right)$ emissions by as much as $10.3 \%$ for $\mathrm{B} 100$ fueling (100\% biodiesel) [56]. Biodiesel, in general, is an oxygenated fuel with inherently high cetane numbers. Although these properties suggest lower flame temperature and thus lower $\mathrm{NO}_{\mathrm{x}}$ emissions, the reality is the total antithesis. The effects of primary techniques for reducing $\mathrm{NO}_{\mathrm{x}}$ emissions from diesel engines are given by [57], [58] and [59]. Likewise reasons for the variation in the $\mathrm{NO}_{\mathrm{x}}$ emissions from these alternate fuels have 
been proposed [60] and [61]. However, none of previous work has adequately explained the enigma of increased $\mathrm{NO}_{\mathrm{x}}$ emissions from biodiesel fuels. This research is a preliminary approach to fundamentally understand the combustion characteristics of component methyl esters and a few selected oxygenates when combusted in open air conditions.

Thermal, fuel, and prompt NO are three pathways that contribute to the overall $\mathrm{NO}_{\mathrm{x}}$ emissions [62]. Thermal $\mathrm{NO}$ formation is the main contributor to $\mathrm{NO}_{\mathrm{x}}$ emissions formed in the combustion chamber [63]. This type of $\mathrm{NO}_{\mathrm{x}}$ is generally formed during fuel combustion such as gas or diesel [64]. The formation rate is primarily a function of temperature, oxygen availability, and the residence time of the air-fuel mixture at a particular temperature [65]. $\mathrm{NO}_{\mathrm{x}}$ from a direct-injection diesel engine is resulted via thermal NO that is described by Zeldovich mechanism [66]. Thus, studying temperature profiles of combustion flames can be helpful in diagnosing the formation of $\mathrm{NO}_{\mathrm{x}}$ during combustion of biodiesel and its blends. The thermal and chemical behavior of combustion flames depends on fuel properties; preheat temperature and oxygen concentration [67]. The combustion phenomena of diesel engines using combustion chamber visualization techniques have been widely studied $[68,69]$. However, flame analysis in open-air conditions is the easiest, cheapest and the most fundamental means of diagnosing the effect of fuel properties on flame temperature. Although combustion inside a diesel engine cylinder is quite different from what that occurs in atmospheric conditions, the present work will yield valuable benchmark insights to uncover complex mechanisms that occur in an engine environment. 
The main objective of this work is to study the open air flame temperature distribution of biodiesel components and blends (with diesel, ethanol and methyl acetate). The results of this study is expected to provide some insights into understanding the correlation between flame temperature and the fuel properties like volatility, chemically bound oxygen content, hydrocarbon chain length and degree of unsaturation. 


\section{Materials and Methods}

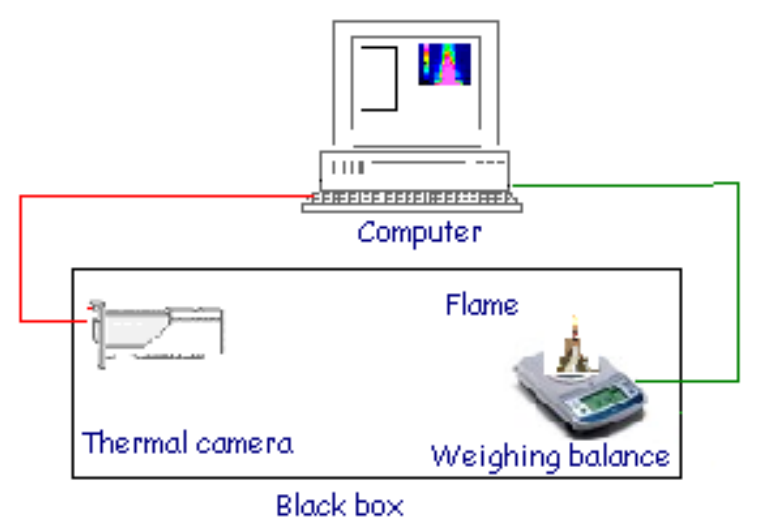

Figure 14. Schematic Diagram of Experimental Set-Up.

The experiments were carried out using fuel blends prepared by blending different proportions of soybean biodiesel in ethanol, methyl acetate and diesel (as shown in Table 11). Fuel blends were combusted using cotton wicks in atmospheric conditions. The combustion set-up was enclosed in a black colored chamber as shown in Figure 14 to reduce extraneous impacts from the surrounding environment. Wicks used for burning fuel components were of same length $(10 \mathrm{~cm})$ and same diameter $(7.5 \mathrm{~mm})$. A type-K thermocouple having a probe diameter of $1 \mathrm{~mm}$ was used to measure the flame temperature. Thermal images were taken using an infrared thermal camera (camera model DSC-S60). Fuel consumption rate was measured using a digital balance and was recorded using RS232 in a computer. The calorific value of each blend was measured using bomb calorimeter. Each experiment was replicated three times. 
Table 11. Calorific Values (kJ/kg) of Different Blends.

\begin{tabular}{|l|l|l|l|}
\hline $\begin{array}{l}\text { Blend } \\
\text { proportion }\end{array}$ & Ethanol:Biodiesel & $\begin{array}{l}\text { Methyl } \\
\text { Acetate:Biodiesel }\end{array}$ & Diesel:Biodiesel \\
\hline $100: 0$ & 28540 & 26670 & 42650 \\
\hline $80: 20$ & 30774 & 29278 & 42062 \\
\hline $60: 40$ & 33009 & 31887 & 41475 \\
\hline $40: 60$ & 35244 & 34496 & 40888 \\
\hline $20: 80$ & 37479 & 37105 & 40301 \\
\hline
\end{tabular}

The goal of this study was to uncover flame temperature trends of different blends and compositions with respect to soybean biodiesel. The temperature at $90 \%$ height of total flame was used to calibrate the thermal images. The two-dimensional thermal images, as given in Figure 15, depict the surface temperature of the flame body. The color scale beside the flame illustrates the variation of temperature on the flame surface. In order to reduce the error associated with temperature measurement using the thermocouple, the temperature difference was chosen for analysis instead of absolute temperatures. The thermal images of flames of different fuels were analyzed and compared as can be seen in Figure 15. A relationship between blend proportions and flame temperature was then obtained.

A separate analysis of flame temperatures of different component soybean methyl esters was performed. Methyl palmitate, methyl stearate, methyl oleate, methyl linoleate and methyl linolinate, the five methyl esters that are predominantly present in soybean oil, were tested in a similar manner to observe flame temperatures. In order to verify the 
effect of unsaturation on flame temperature, methyl linoleate (an unsaturated component) was mixed in different proportions with methyl palmitate (a saturated FAME) and methyl stearate (a saturated FAME) and the flame temperature was measured in a similar manner.
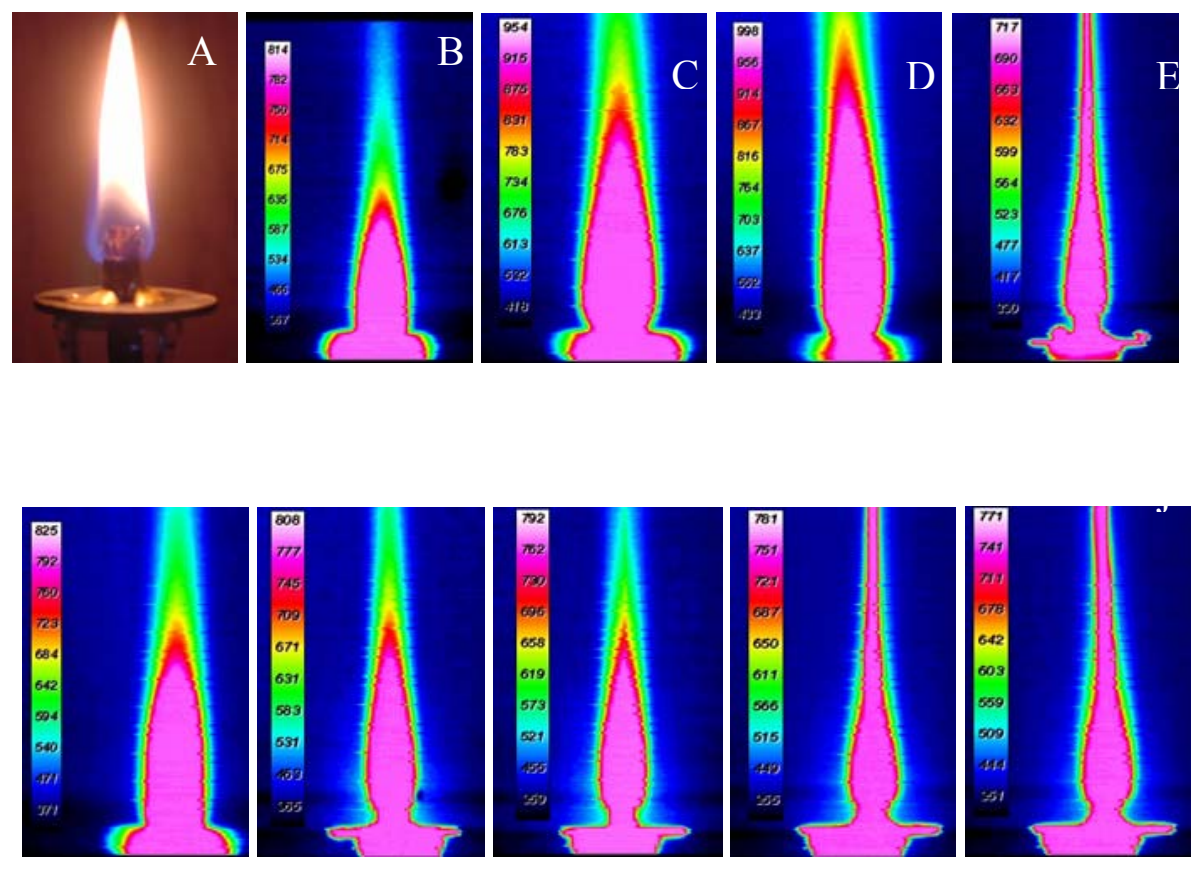

Figure 15. Thermal image of flames (A. Flame arrangement; B. Soybean biodiesel; C. Ethanol; D. Methyl Acetate; E. Diesel; F. Methyl Palmitate; G. Methyl Stearate; H. Methyl Oleate; I. Methyl Linoleate; and J. Methyl Linolinate).

\section{Thermodynamics of combustion using fatty acid methyl esters (FAMEs):}

Assuming a typical FAME has a general chemical formula $\mathrm{C}_{\mathrm{x}} \mathrm{H}_{2 \mathrm{y}} \mathrm{O}_{2 \mathrm{z}}$. The chemical equation for stoichiometric combustion can be written as follows:

$$
\mathrm{C}_{x} \mathrm{H}_{2 y} \mathrm{O}_{2 z}+a\left[\mathrm{O}_{2}+3.76 \mathrm{~N}_{2}\right] \rightarrow x \mathrm{CO}_{2}+y \mathrm{H}_{2} \mathrm{O}+(3.76 a) \mathrm{N}_{2}
$$


Conservation of atomic species gives the following equation for "a" in terms of $\mathrm{x}, \mathrm{y}$ and $\mathrm{z}:$

$$
a=x+\frac{y}{2}-z
$$

The stoichiometric air-fuel ratio ( $\mathrm{AF}_{\text {grav, }}$ on mass basis) can be written as follows:

$$
A F_{\text {grav }, s}=\frac{a[32+3.76(28)]}{12 x+2 y+32 z}=34.32\left(\frac{2 x+y-2 z}{6 x+y+16 z}\right)
$$

Air-fuel ratio for different FAMEs is depicted in Figure 16.

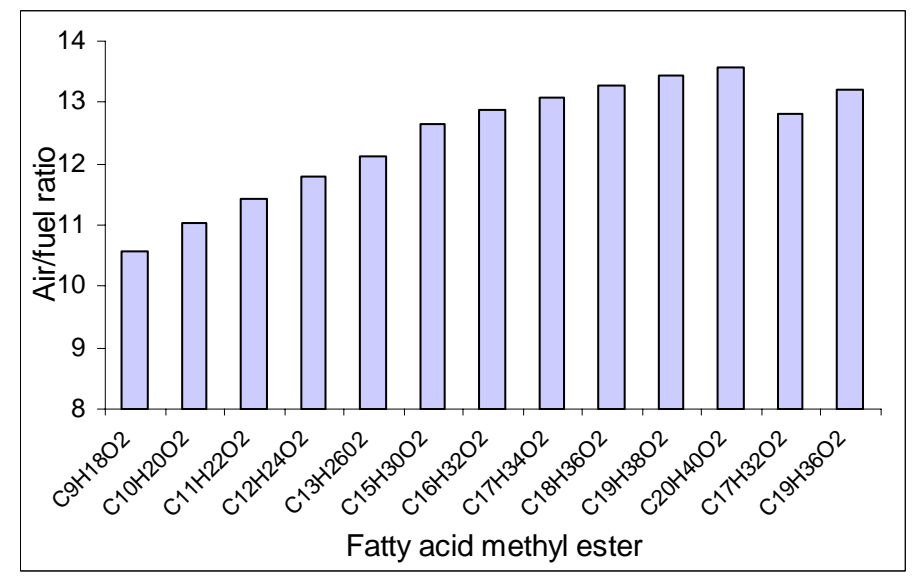

Figure 16. Estimates of Stoichiometric Air-Fuel Ratio for Different Fatty Acid Methyl Esters.

\section{Energy Flow Analysis}

The adiabatic flame temperature was obtained by equating the enthalpy of the reactants to the enthalpy of the products. On simplification, an approximation of the adiabatic flame temperature can be given by [70]:

$T_{P}=T_{0}+\frac{L H V}{\left(1+A F_{\text {grav }}\right) C_{p}}$

Where $T_{p}$ is adiabatic flame temperature, $T_{0}$ is ambient temperature, LHV is lower heating value of fuel and $\mathrm{C}_{\mathrm{p}}$ is the average specific heat of the products. Hence, when 
comparing one fuel with another, a higher stoichiometric flame temperature does not necessarily solely dependent on higher large heating value, but air-fuel ratio must also be considered. Using equation 18, adiabatic flame temperatures for stoichiometric combustion of the fuels are depicted in Figure 17.

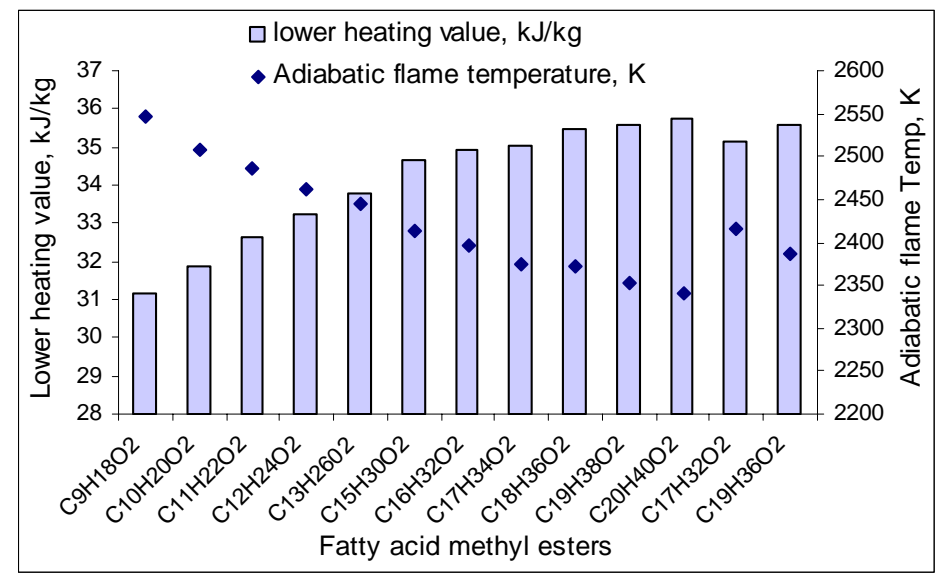

Figure 17. Lower heating value [71] and adiabatic flame temperature of FAMEs

\section{Sources of Error}

Despite repeated measurements, a significant difference was observed in recorded flame temperatures and the expected flame temperatures and could be attributed to the effect of the thermocouple probe on the flame. In this study, diameter of the thermocouple used was $1 \mathrm{~mm}$ where as the flame diameter varied in between 4-6 $\mathrm{mm}$. The diameter of the thermocouple probe is expected to change the flame profile while the probe was inserted to measure the flame temperature. This leads to the variation in aerodynamics and thermal properties of flame zone. Consequently, to obtain the trend associated with flame temperatures, relative flame temperature, $\Delta \mathrm{T}$ with respect to soybean biodiesel was calculated using actual point temperatures of blend ( $\left.\mathrm{T}_{\text {blend }}\right)$ and point temperature of biodiesel $\left(\mathrm{T}_{\mathrm{BD}}\right)$. 


$$
\Delta T_{\text {blend }}=T_{\text {blend }}-T_{B D}
$$

$$
\Delta T_{F A M E}=T_{F A M E}-T_{B D}
$$

Similarly, relative fuel consumption rate, $\Delta(d m / d t)$ was calculated as the flow consumption rate varied for each fuel combination.

$$
\begin{aligned}
& \Delta(d m / d t)_{\text {blend }}=(d m / d t)_{\text {blend }}-(d m / d t)_{B D} \\
& \Delta(d m / d t)_{\text {FAME }}=(d m / d t)_{F A M E}-(d m / d t)_{B D}
\end{aligned}
$$

Furthermore, we speculate that the difference in temperatures may have been due to radiation and conduction losses. These corrections can be estimated by making a balance between energy received by conduction from the gas and that lost by radiation and conduction along the supports. The radiation correction for the thermocouple lead was done by using the following equation [72]:

$$
T=\frac{\sigma \varepsilon}{h_{c}}\left(T_{t c}^{4}-T_{\infty}^{4}\right)+T_{t c}
$$

Where $\mathrm{T}$ is the corrected thermocouple temperature, $\sigma$ is the Stefan Boltzman constant, emissivity factor, $\varepsilon=0.21$ for $\mathrm{NiCr}-\mathrm{Ni}, \mathrm{T}_{\mathrm{tc}}$ is the recorded thermocouple temperature, $T_{\infty}$ is the ambient temperature and $\mathrm{h}_{\mathrm{c}}$ is determined by heat transfer correlations [73]: 
$N u=\frac{h_{c} d}{k_{\text {air }}}=2+\left(0.4 \mathrm{Re}^{1 / 2}+0.06 \operatorname{Re}^{2 / 3}\right) \operatorname{Pr}^{2 / 5}$

Where $\mathrm{Nu}$ is the nusselt number, $\mathrm{d}$ is the diameter of the thermocouple bead, $\mathrm{K}_{\mathrm{air}}$ is the thermal conductivity of air, $\operatorname{Pr}=.68$ for air and the Reynolds number, $\operatorname{Re}$ is:

$$
\operatorname{Re}=\frac{u d}{v_{a i r}}
$$

Where $v_{\text {air }}$ is the kinematic viscosity of air, and $u$ is the velocity of the plume [74].

$$
u=3.9\left(\frac{g \dot{Q}}{T_{\infty} c_{p} Z}\right)
$$

Where $c_{p}$ is the specific heat of air, $Q$ is the heat input, and $z$ is the height above the source.

\section{Results}

The theoretical analysis of fatty acid methyl esters shows that the required stoichiometric air-fuel ratio increases with increasing hydrocarbon chain length and FAMEs saturation level. Increasing hydrocarbon chain length in the FAMEs leads to increased lower heating value and a simultaneous decrease in the adiabatic flame temperature.

Figure 18 shows the relative trends of flame temperature with varying proportions of blends of soybean biodiesel. As mentioned earlier, flame temperatures were measured using a $\mathrm{K}$ type thermocouple and corrected for radiation losses. However, since the errors associated with these measurements were observed to be substantial, temperature differences with respect to straight soybean biodiesel flames are reported. It can be seen that as the proportion of ethanol and methyl acetate increased in the blends, the difference 
in flame temperature with respect to soybean biodiesel increased. The reason for this increase may be due to the more volatile nature of ethanol and methyl acetate in comparison to soybean biodiesel. On the contrary, blending diesel with soybean biodiesel showed a decrease in flame temperature difference (Figure 18). Pure diesel had a lower flame temperature than the pure soybean biodiesel. It should be noted that the oxygen content in ethanol and methyl acetate is greater than that of soybean biodiesel. Consequently, soybean biodiesel, having a more oxygen content than diesel, may have led to a more complete combustion and hence leading to a greater flame temperature. Accordingly, it could be speculated that the increase/decrease of flame temperature is associated more with oxygen content of the fuel being used than the calorific value of a fuel. An experimental error of 3-5\% was observed as can be seen in Figure 18 and Figure 19.

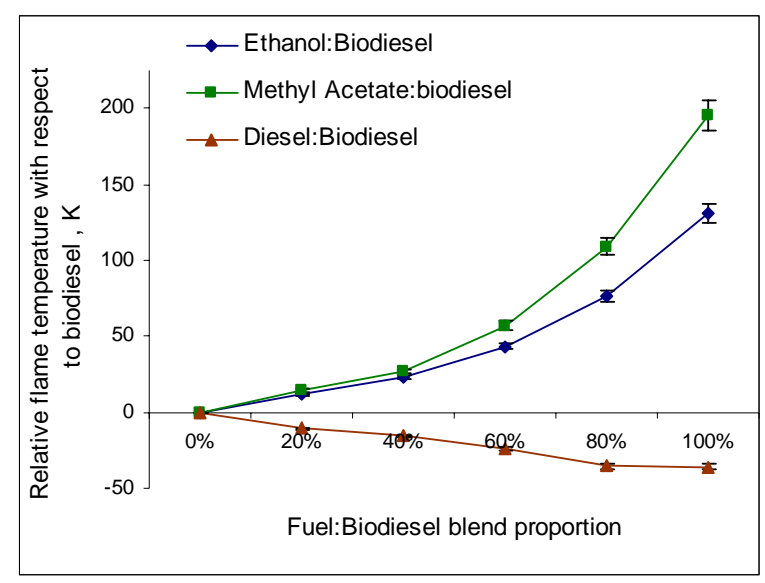

Figure 18. Effect of Blending Soybean Biodiesel with Ethanol, Methyl Acetate and Diesel on Flame Temperature. 


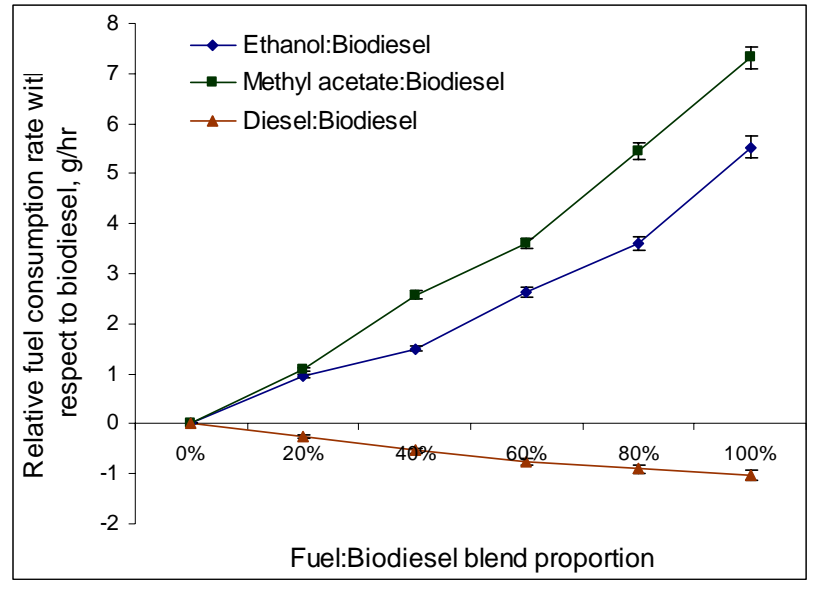

Figure 19. Comparative Fuel Consumption Rate of Soybean Biodiesel Blends with Ethanol, Methyl Acetate and Diesel with Respect to Pure Soybean Biodiesel.

The trend observed in maximum flame temperatures can be attributed to the fuel consumption rates of the fuel blends. Figure 19 shows the trend in difference of fuel consumption rates of biodiesel blends with ethanol, methyl acetate and diesel with respect to pure biodiesel.

It was observed that while combusting a fuel, the wick also burnt - although at a relatively insignificant rate. To circumvent the error associated with this phenomenon, the difference in fuel consumption rate was compared. It was observed that as the ethanol and methyl acetate percentage increased in the biodiesel blend, fuel consumption rate increased. The reason for this may be the distinct capillary flow rate due to lower density and viscosity of ethanol and methyl acetate in comparison to biodiesel causing better adsorption and capillary motion of fuel through the cotton wick. 


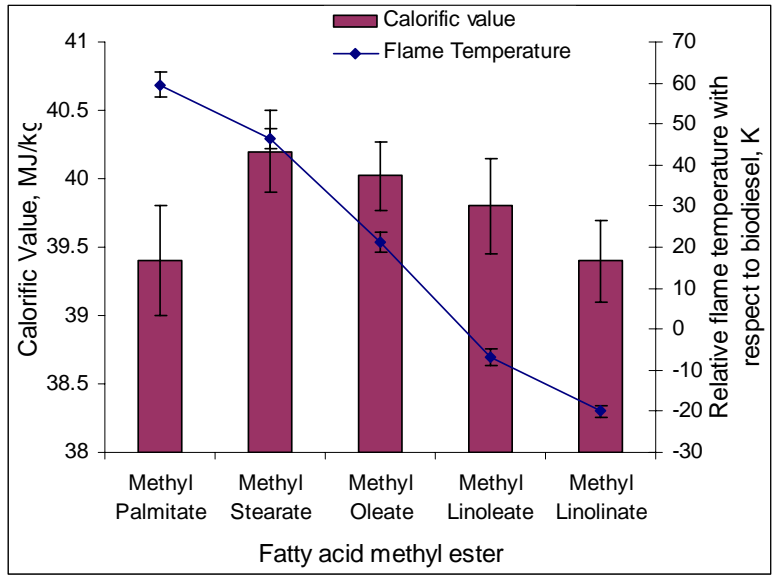

Figure 20. Flame Temperature and Calorific Value of Different Components of Biodiesel.

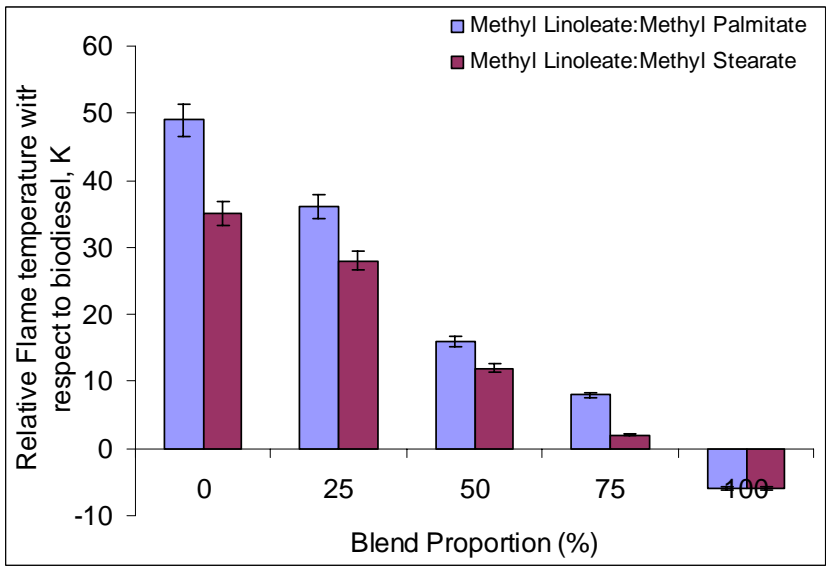

Figure 21. Effect of Change in Unsaturated Methyl Ester Proportion in Fatty Acid Methyl Ester Blends. 


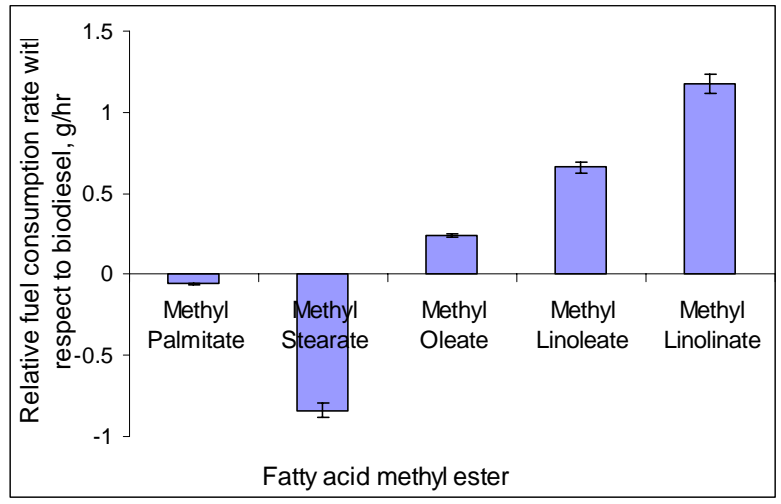

Figure 22. Comparative Fuel Consumption Rate of Biodiesel Components with Respect to Pure Soybean Biodiesel.

Figure 20 shows the variation of calorific value and the difference in flame temperature of different fatty acid methyl esters with respect to soybean biodiesel. An experimental error of $1-2 \%$ was observed for calorific value where as $3-5 \%$ error was observed for relative flame temperature values. The flame temperature obtained by component biodiesel FAMEs revealed that the saturated methyl esters resulted in higher flame temperatures than unsaturated FAMEs. In addition, it can be seen that as the degree of unsaturation increased, the flame temperature decreased. Likewise, it can be observed in Figure 21 that as the percentage of an unsaturated component increased, the flame temperature decreased. Thus, it shows that saturated methyl esters may be the main contributor to temperature increase in the combustion zone while using soybean biodiesel. Also, the shorter chained methyl ester, methyl palmitate, resulted in a higher temperature in comparison to the longer chained methyl stearate on mixing with unsaturated component methyl linoleate.

Figure 22 shows comparative fuel consumption rate of fatty acid methyl esters with respect to soybean biodiesel. It was found that the fuel consumption rate increased with increase in degree of unsaturation. This is evident from the difference in volumetric 
flow rate due to capillary motion through the wick due to decreasing density and viscosity of fatty acid methyl esters with increasing unsaturation [75].

A qualitative analysis on soot formation based on visual observation and verification from the thermal images indicated that the greater the proportion of ethanol and methyl acetate, lesser was the shoot formation. A similar trend was observed in the blends of soybean biodiesel with diesel. Soybean biodiesel being more oxygenated produced less soot than diesel. This can be related to incomplete combustion. Thus, a reduction in shoot formation was observed as the proportion of an oxygenated compound in the blend was increased. It was observed that soot formation and flame temperature had an inverse relationship (more the soot formation, lesser was the flame temperature). Soot formation also increased with the increase in the degree of unsaturation. It was also observed that as the unsaturation increased, the flame length increased.

Literature suggests a direct relationship between $\mathrm{NO}_{\mathrm{x}}$ release and flame temperature during combustion [66,76-78]. Thus it can be conferred from the observations of this study that saturated components like methyl palmitate and methyl stearate could be associated with a higher tendency to produce $\mathrm{NO}_{\mathrm{x}}$ than unsaturated components. Also lesser the carbon chain length more was the flame temperature and consequently it could be conjectured that smaller chained oxygenated hydrocarbons may lead to higher $\mathrm{NO}_{\mathrm{x}}$ formation. However, since this study was performed at atmospheric conditions, further studies are required in diesel engine environments to confirm this hypothesis and elucidate the effect of FAME chemistry on $\mathrm{NO}_{\mathrm{x}}$ behavior.

The presence of saturated components, the degree of unsaturation, volatility and the oxygen content in an oxygenated hydrocarbon fuel plays an important role in 
determining its open air flame temperature characteristics. It was observed that more the calorific value, lesser was the flame temperature of a particular fuel. Presence of saturated components and lower carbon chain length components led to increased flame temperatures suggesting an association with and a higher tendency for thermal $\mathrm{NO}_{\mathrm{x}}$ formation. With the increase in the degree of unsaturation, the fuel consumption rate increased. Insights obtained from this study coupled with an in-depth study in an engine environment will be helpful to underpin $\mathrm{NO}_{\mathrm{x}}$ emissions behavior of soybean biodiesel fuel blends.

\section{Research on Exhaust Emissions Using Diesel-Biodiesel-Ethanol Blends in New and Used Compression Ignition Engines}

The current scenario of rapidly increasing energy demand across the world has led many countries to search for renewable fuel sources other than fossil fuels. Also, the heightened awareness of harmful effects associated with ambient air pollution compels introduction of more stringent environmental regulations worldwide. Beginning in 2007, the United States, heavy-duty diesel engine emission regulations will be phased in with a $\mathrm{NO}_{\mathrm{x}}$ standard of $0.27 \mathrm{~g} / \mathrm{kW}-\mathrm{hr}(0.2 \mathrm{~g} / \mathrm{bhp}-\mathrm{hr})$ and a particulate standard of $0.01 \mathrm{~g} / \mathrm{kW}-\mathrm{hr}$ (0.01 g/bhp-hr). In Europe, the 2005 European Union (EU) 4 standard is $3.5 \mathrm{~g} / \mathrm{kW}-\mathrm{hr}(2.6$ $\mathrm{g} / \mathrm{bhp}$-hr) for $\mathrm{NO}_{\mathrm{x}}$ and $0.2 \mathrm{~g} / \mathrm{kW}$-hr $(0.15 \mathrm{~g} / \mathrm{bhp}$-hr) for particulate with a change (EU 5 standard) to $2 \mathrm{~g} / \mathrm{kW}-\mathrm{hr}(1.5 \mathrm{~g} / \mathrm{bhp}-\mathrm{hr})$ for $\mathrm{NO}_{\mathrm{x}}$ in $2008[79,80]$.

Although discrepancies exist, there is a general agreement in the research community that biodiesel reduces particulates, emissions of $\mathrm{CO}, \mathrm{SO}_{2}$ and $\mathrm{HC}$. However, it has been reported that biodiesel increases oxides of nitrogen $\left(\mathrm{NO}_{\mathrm{x}}\right)$ emissions by as much as $10.3 \%$ for $100 \%$ biodiesel [81]. McCormick stated that newer engines increase $\mathrm{NO}_{\mathrm{x}}$ emission in comparison to older engines, where the increase in the emissions level 
could be as high as $31 \%$ vs $10 \%$ [82]. $\mathrm{NO}_{\mathrm{x}}$ emissions in a Detroit Diesel 2-stroke engine increased with the addition of methyl soyester while particulate emissions decreased [83]. Using a 1991 6V-92TA DDEC II engine, $\mathrm{NO}_{\mathrm{x}}$ emissions were found to increase by $3.5 \%$, $5.5 \%, 13.4 \%$ and $15 \%$ respectively for $10 \%, 20 \%, 30 \%$ and $40 \%$ blends. Graboski and coworkers tested methyl soyate and diesel blends in a 1991 Detroit Diesel Series 60 (4stroke) engine. For $35 \%$ biodiesel, the composite $\mathrm{NO}_{\mathrm{x}}$ emissions increased by nearly $1 \%$, while the composite particulate emissions decreased by $26 \%$ relative to the reference diesel. For $100 \%$ biodiesel, the composite $\mathrm{NO}_{\mathrm{x}}$ increased by $11 \%$ while $\mathrm{PM}$ was decreased by $66 \%$ [84]. Signer and coworkers reported a 3 to $4 \%$ increase in $\mathrm{NO}_{\mathrm{x}}$ for a $3.5 \%$ increase in fuel density using the EEC 13-mode test cycle [85]. Cetane number and fuel aromatic content are well known to influence $\mathrm{NO}_{\mathrm{x}}$ and $\mathrm{PM}$ emissions from diesel engines [86].

There are various effective engine direct-emission control methods used in the past, but they are still inadequate to guarantee meeting the proposed emissions reduction regulations. Some catalytic devices have been devised to purify the exhaust from engines. Due to additional cost, they are not practical nor do they prove satisfactory for engine manufacturers to meet the 2007 emission standards. Changing the fuel properties of biodiesel using different blends of oxygenates is another approach which is found to be economic and efficient in reduction of emissions [87-89]. This study, attempted to understand the effect of adding ethanol as an oxygenate into biodiesel on the tailpipe emissions profile. Ethanol has a much lower cetane number and energy value (26.98 $\mathrm{MJ} / \mathrm{kg}$ ) than biodiesel, yet, it has beneficial fuel properties. One of the disadvantages of 
biodiesel is its high cloud point, which makes it unsuitable for cold weather conditions. Ethanol tends to reduce the cloud point when blended with biodiesel $[90,91]$.

Due to the low calorific value of ethanol, E-diesel blend is believed to reduce engine power. Interestingly, some studies have shown that not much variation is observed in brake horsepower, depending on blend concentrations. There was no significant power reduction in an engine operated on E-diesel blends up to 20\% [92]. Abu-Qudais and group found an increase of $3.6 \%$ in brake thermal efficiency and $43.3 \%, 34 \%$, and $32 \%$ reductions in $\mathrm{CO}, \mathrm{HC}$, and soot emissions, respectively at an optimum percentage of $15 \%$ E-diesel blends [93]. E-diesel yielded significant reductions in particulate matter (PM) $[94,95]$. Recent studies conducted on E-diesel confirmed substantial reductions in PM, at times up to $40 \%$, depending on the test methods, operating conditions, and ethanol concentrations [96-100]. Marek and Evanoff also found reductions in $\mathrm{NO}_{\mathrm{x}}$ emissions ranged from $0-5 \%$ and $0-4 \%$ for $15 \%$ and $10 \%$ ethanol blends respectively [98]. However, another engine test showed considerable variations in both $\mathrm{PM}$ and $\mathrm{NO}_{\mathrm{x}}$ over the load-speed range of the engine with reductions varying $22-75 \%$ and $60-84 \%$ respectively. Ajiv and coworkers observed a reduction in the carbon monoxide (CO) and nitrogen oxides $\left(\mathrm{NO}_{\mathrm{x}}\right)$ emissions when a $20 \%$ blend of E-diesel was used in a constantspeed stationary diesel engine as opposed to diesel fuel [101].

The major drawback of adding ethanol into diesel is its immiscibility in diesel over a wide range of temperatures. Additionally, the miscibility of ethanol in diesel depends on factors such as pressure, relative humidity, and ethanol concentration. Buchholz et al. reported that the limited solubility of ethanol in diesel fuel required either an emulsifier (Span 85) or co-solvent ( $n$-butanol) to prepare ethanol-in-diesel blends 
[102]. Commercially, various surfactants are used as emulsifiers to form an ethanoldiesel emulsion. Ali and Hanna determined the ratio of beef tallow (methyl tallowate) to ethanol that gave the same viscosity as No. 2 diesel fuel [103]. They found that tallow ester:ethanol:diesel should be $16.25: 8.75: 75$ to get a stable emulsion that had a viscosity similar to that of diesel fuel. Looking into the phase behavior of the biodiesel-ethanoldiesel ternary system, Fernando and Hanna suggested that biodiesel could be effectively used as an amphiphile in an ethanol-diesel blend [104]. Aforementioned work laid the foundation for investigating the concept of using ethanol to reduce $\mathrm{NO}_{\mathrm{x}}$ emissions.

The objective of this study is to evaluate the effect of neat biodiesel and blends of dieselbiodiesel-ethanol (DBE) emulsions on exhaust gas emissions

\section{Materials and Methods}

\section{Engine and Instrumentation}

The study was performed using the following three engines: Ford 4000, John Deere 5103 and John Deere 4039DF008 multi-fuel engine. The Ford was a 45 year old engine with less than 200 hours run time and the two John Deere engines were brand new. Each of the engines was a direct injection type. Specifications of the engines are presented in Table 12. The engines were coupled to a hydraulic dynamometer. Engine torque was adjusted and set using the dynamometer. Engine speed was controlled using the throttle. A NOVA Logger II analytical gas analyzer was used to investigate the emissions from the engines. 
Table 12. Engine Specifications.

\begin{tabular}{|l|l|l|l|}
\hline Specification & Ford 4000 & John Deere 5103 & John Deere 4039DF008 \\
\hline No. of Cylinder & 3 & 3 & 4 \\
\hline Bore, mm & 111.75 & 106.5 & 106.5 \\
\hline Stroke, mm & 111.76 & 110 & 110 \\
\hline Displacement, litre & 3.294 & 2.9 & 3.9 \\
\hline Compression ratio & $16.5: 1$ & $17.8: 1$ & $17.8: 1$ \\
\hline Rated HP & 42.7 & 38 & 41 \\
\hline Rated speed & 2200 & 2400 & 1800 \\
\hline Fuel Injection Pump & Distributor-type & Stanadyne K5 & Stanadyne K5 \\
\hline
\end{tabular}

\section{Fuel Blends}

The experiments were carried out using pure diesel, neat biodiesel, dieselbiodiesel (70:30) blend and three different DBE (Diesel-Biodiesel-Ethanol) blends in proportions of 70:25:5 (D70BD25E5), 70:20:10 (D70BD20E10) and 70:15:15 (D70BD15E15) respectively. The fuel properties tests such as flash point, kinematic viscosity, cloud point, carbon residue, copper corrosion, calorific value, density, cetane number, acid number and Reid vapor pressure of each fuel combination were performed. Specific blend compositions and their properties are given in Table 13.

The methyl soy ester employed was a commercially available biodiesel known as "Soygold" that conformed to the ASTM D 6751-03 biodiesel standard. The following tests were conducted at the Biodiesel Testing Facility in Swalm School of Chemical Engineering at Mississippi State University: Carbon Residue Test (ASTM D 4530), 
Cloud Point (ASTM D 2500), Copper Corrosion (ASTM D 130), Flash Point (ASTM D 93A) and Viscosity (ASTM D 445). Tests of other parameters like Cetane Number (ASTM D613), Acid Number (ASTM D664) and Reid Vapor pressure were conducted at Southwest Research Institute, San Antonio, TX.

Table 13. Fuel Properties of Diesel, Biodiesel, and Blends.

\begin{tabular}{|c|c|c|c|c|c|c|}
\hline Property & Diesel & Biodiesel & D70BD30 & D70BD25E5 & D70BD20E10 & D70BD15E15 \\
\hline $\begin{array}{l}\text { Calorific Value, } \\
\mathrm{kJ} / \mathrm{kg}\end{array}$ & 42026 & 33622 & 39364 & 39098 & 38827 & 38554 \\
\hline Cetane Number & 43.3 & 51.7 & 46.7 & 42.6 & 40.8 & 36.2 \\
\hline Flash point & 71 & 145 & 95 & 39 & 30 & 23 \\
\hline Acid Number & $<0.05$ & 0.21 & 0.08 & 0.11 & 0.07 & 0.06 \\
\hline Reid Vapor & 1.68 & 0.33 & 0.41 & 1.67 & 2.96 & 3.44 \\
\hline Pressure, $\mathrm{kPa}$ & & & & & & \\
\hline Density, g/litre & 846.2 & 915.0 & 866.84 & 861.24 & 854.74 & 848.69 \\
\hline $\begin{array}{l}\text { Kinematic } \\
\text { Viscosity, cSt }\end{array}$ & 2.677 & 4.127 & 3.04 & 2.767 & 2.42 & 2.29 \\
\hline $\begin{array}{l}\text { Carbon residue, } \\
\%\end{array}$ & 0.0759 & 0.185 & 0.076 & 0.0623 & 0.0487 & 0.0778 \\
\hline Cloud Point, ${ }^{\circ} \mathrm{C}$ & -29 & 1 & -9 & -11 & -12 & -14 \\
\hline $\begin{array}{l}\text { Copper } \\
\text { Corrosion }\end{array}$ & $1 \mathrm{~A}$ & $1 \mathrm{~A}$ & $1 \mathrm{~A}$ & $1 \mathrm{~A}$ & $1 \mathrm{~A}$ & $1 \mathrm{~A}$ \\
\hline
\end{tabular}

Several concerns have been raised regarding potential adverse effects of the use of ethanol on engine performance and durability. Ethanol has fuel properties that are different than both biodiesel and diesel fuel, and does not meet either ASTM D 6751-03 for biodiesel fuel or ASTM D975 specification for diesel fuel. Thus, addition of ethanol in diesel-biodiesel blends may fail to meet standard fuel specifications. The data in Table 13 show that flash point decreased significantly with the rise in ethanol proportions. Adding ethanol increased the Ried vapor pressure of the blend extensively, making the fuel blends more volatile and vapor lock can be a problem. This means that DBE has more stringent storage requirements than conventional diesel. In fact, DBE must be stored and handled more like gasoline. 
Biodiesel and ethanol, with low calorific values resulted in a reduction of blend calorific value. D70BD15E15 has lower cetane number than the diesel fuel specifications i.e. less than 40 . The kinematic viscosity of D70BD20E10 and D70BD15E15, while being slightly lower than that for a typical diesel, met both the diesel and biodiesel specifications. The corrosivity as measured by copper strip corrosion method for each

blends were the same as typical diesel, and also within specifications. The cloud points for the biodiesel and all the other blends were significantly higher than for typical diesel. However, it can be seen that addition of ethanol into diesel-biodiesel blends resulted in a decrease of the cloud point.

\section{Testing Procedures:}

The NOVA gas analyzer was turned on 10 minutes prior to collection of data to allow the instruments to stabilize. The engine was started and warmed-up, at low idle, long enough to establish correct oil pressure and was checked for any fuel, oil, water and air leaks.

The speed was then increased to chosen engine rpm and load was set using the dynamometer. Data were taken while the engine was at constant load for different speeds. For the John Deere 5103, the selected engine speeds were 1400, 1700, 2000 and 2400 rev/min. Engine rpm of 1600, 1800, 2000 and 2200 were selected for Ford 4000. For John Deere multi-fuel engine, there was an automatic engine rpm set at 1800 . The engine was run at the specified speeds and loads for a minimum of $15 \mathrm{~min}$ before data were collected during the last one hour of operation. The procedure was repeated for all the selected fuel types. The experiment was replicated three times and the average values 
were reported. The testing was done at the Mississippi State University Department of Agricultural and Biological Engineering.

\section{Results}

\section{CO Emissions}

Ethanol has the potential to significantly lower CO emissions from diesel engines due to the high oxygen content. This has not been systematically observed since ethanol simultaneously both increases oxygen content and decreases the cetane number of a fuel. In some cases, the adverse impacts of a lower cetane number outweigh the benefits of an increased oxygenate content. A comparison of emissions using different fuel combinations in the three engines is shown in Figure 23. Compared to diesel fuel, the CO emissions of the biodiesel-diesel-ethanol blends increased with the increase in blend ethanol proportions. The increase of $\mathrm{CO}$ emissions with the increase of ethanol percentage in the blend could be attributed to respective reduction of the cetane numbers. It can be seen that biodiesel causes significantly less $\mathrm{CO}$ emissions. These lower emission levels were likely due to the fact that biodiesel contains about ten percent oxygen by weight, and this ample availability of oxygen helps to completely oxidize hydrocarbons in the cylinder. Also as engine rpm increased at the same load level, the CO emission level increased significantly. 


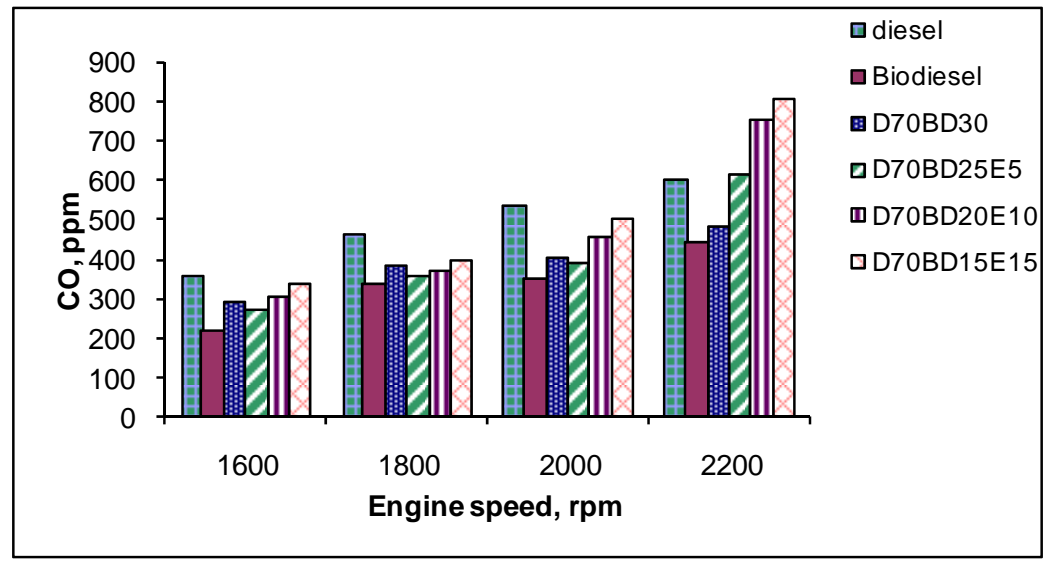

a. Ford 4000 Tractor Engine

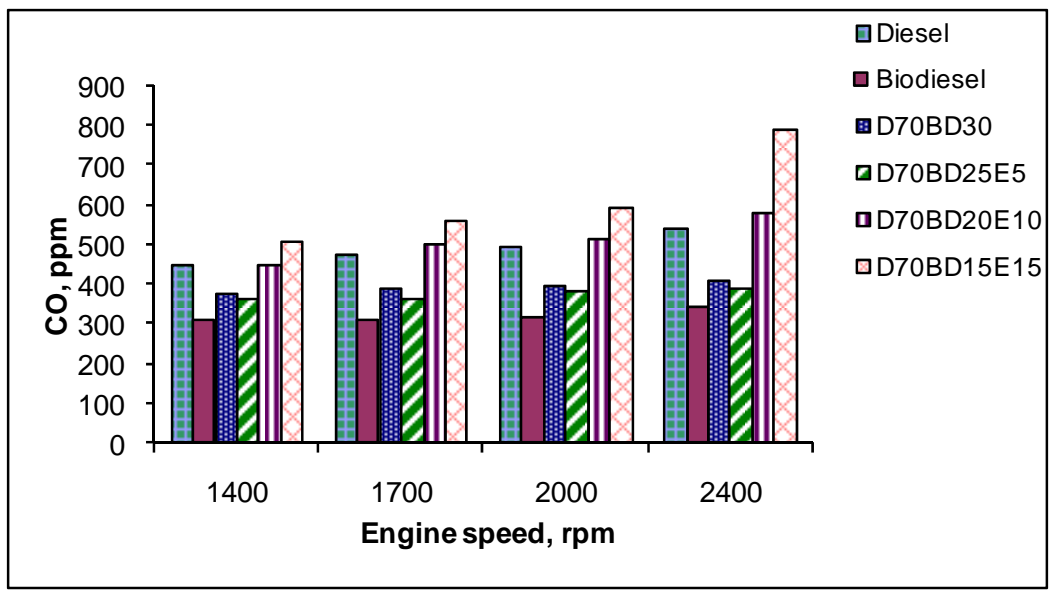

b. John Deere 5103 Tractor Engine

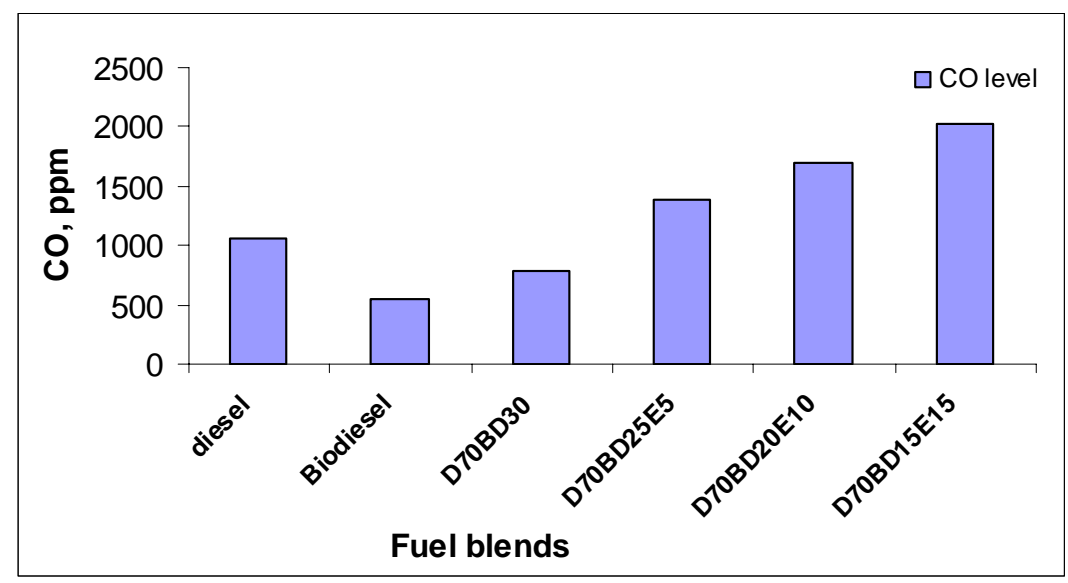

c. John Deere multi-fuel gen-set engine

Figure 23. Comparison of the Carbon Monoxide Level. 


\section{$\mathrm{CO}_{2}$ Emissions}

Figure 24 shows the variation of engine-out $\mathrm{CO}_{2}$ emissions caused by the differences in fuel compositions in the presence of ethanol and biodiesel. $\mathrm{CO}_{2}$ emissions

increased with the increase in engine speed. It was found that the $\mathrm{CO}_{2}$ emissions among different fuel combinations were not significantly different. 


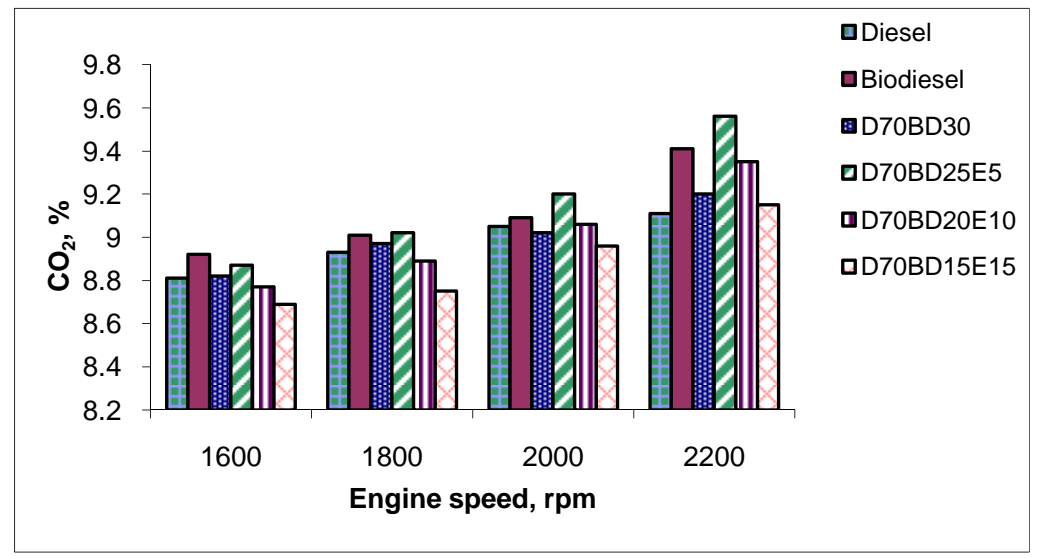

a. Ford 4000 Tractor Engine

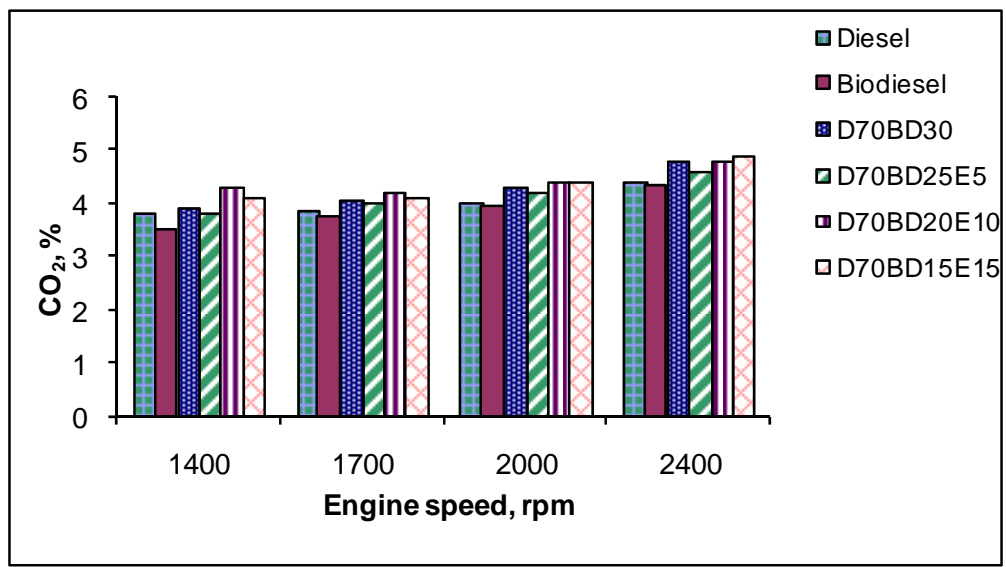

b. John Deere 5103 Tractor Engine

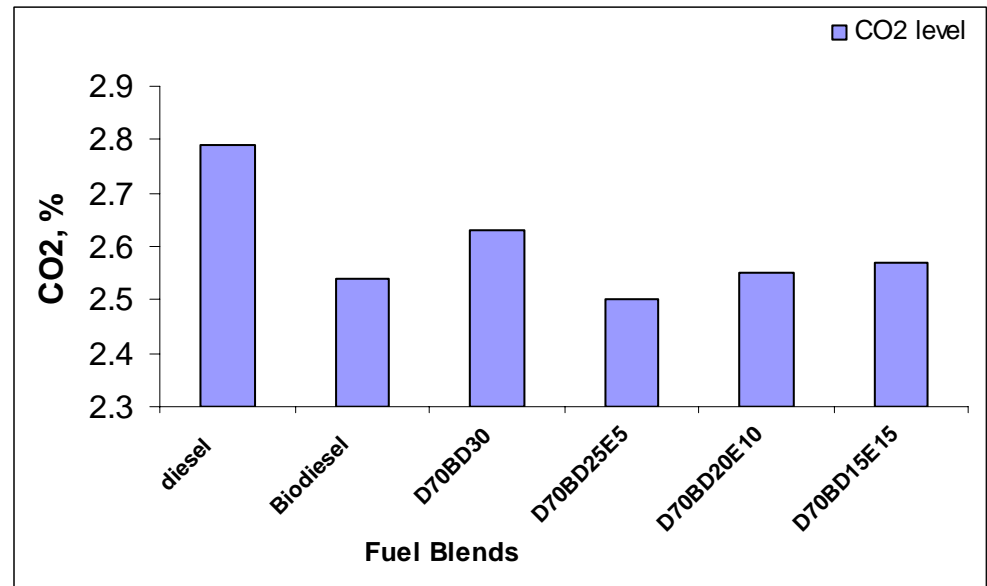

c. John Deere multi-fuel gen-set engine

Figure 24. Comparison of the Carbon Dioxide Level. 


\section{Oxides of Nitrogen}

Nitrogen oxides $\left(\mathrm{NO}_{\mathrm{x}}\right)$ collectively refer to both $\mathrm{NO}$ and $\mathrm{NO}_{2}$. Nitrogen oxides formation generally increases with the increase in flame temperature and slower flame speed. Nitrogen oxide emissions also increase with reduced engine speed. While high temperatures and pressures are desirable for high efficiency operation of a diesel engine, they are also the prime cause for the formation of $\mathrm{NO}_{\mathrm{x}}$ gasses. According to literature, the $\mathrm{NO}_{\mathrm{x}}$ emissions behavior of biodiesel in unmodified diesel engines varies widely. Several reports show $\mathrm{NO}_{\mathrm{x}}$ is increased with biodiesel. However, in chassis dynamometer tests with the Cummins B 5.9 L, a reduction in $\mathrm{NO}_{\mathrm{x}}$ with a corresponding increase in $\mathrm{PM}$ was found $[105,106]$. The variability in $\mathrm{NO}_{\mathrm{x}}$ response for biodiesel may be due to individual variables in the engines themselves. Sharp and co-workers stated that there is "a strong link between increasing cetane numbers and reducing $\mathrm{NO}_{\mathrm{x}}$ emissions, but the response varies from engine to engine [107,108]."

The $\mathrm{NO}_{\mathrm{x}}$ exhaust emissions are shown in Figure 25. The $\mathrm{NO}_{\mathrm{x}}$ emissions were higher for biodiesel and DBE blends in respect to diesel fuel in old ford 4000 engine. The increased $\mathrm{NO}_{\mathrm{x}}$ emissions could be associated with the oxygen content of the methyl esters, since the fuel oxygen may provide additional oxygen for $\mathrm{NO}_{\mathrm{x}}$ formation. Mittelbach and Tritthart tested used frying oil methyl ester and they found increased $\mathrm{NO}_{\mathrm{x}}$ emissions compared to No. 2 diesel fuel [109]. Rickeard and Thompson [110] and Monyem [111] stated that the $\mathrm{NO}_{\mathrm{x}}$ emissions increased for the biodiesel fuels.

Increasing ethanol fraction increased both $\mathrm{NO}$ and $\mathrm{NO}_{2}$ emission and simultaneously raised $\mathrm{NO}_{2} / \mathrm{NO}$ in the old Ford 4000 engine. $\mathrm{NO}_{\mathrm{x}}$ emission and $\mathrm{NO}_{2} / \mathrm{NO}$ reduced with increase in rpm. When compared with D70BD30, the D70BD25E5 blend 
showed an average increase in $\mathrm{NO}_{\mathrm{x}}$ emission of $16 \%$. On similar comparison, D70BD20E10 indicated an average increase of $21 \%$ and a $24 \%$ rise using D70BD15E15.

In contrast to the old Ford 4000 engine, the new John Deere 5103 tractor engine showed a reduction in $\mathrm{NO}$ and $\mathrm{NO}_{2}$ emissions with increasing ethanol proportions in the fuel blend. An increment in $\mathrm{NO}_{2} / \mathrm{NO}$ was observed in this case. $\mathrm{NO}_{\mathrm{x}}$ level and $\mathrm{NO}_{2} / \mathrm{NO}$ ratio declined with increase in engine speed. There was an average reduction of $12 \%$ of $\mathrm{NO}_{\mathrm{x}}$ emission using D70BD25E5 in comparison to D70BD30. Similarly, a drop of 16\% $\mathrm{NO}_{\mathrm{x}}$ emission was observed using D70BD20E10 while a decrease of $22 \%$ was found using D70BD15E15. This clearly indicates that within the ranges tested, increased ethanol concentrations favor a reduction in $\mathrm{NO}_{\mathrm{x}}$ emissions.

The John Deere multi-fuel engine also showed a similar trend - increased ethanol concentrations resulted in a reduction of levels of $\mathrm{NO}_{\mathrm{x}}$ and $\mathrm{NO}_{2} / \mathrm{NO}$. When compared with D70BD30, 12\%, 21\% and 29\% reduction in $\mathrm{NO}_{\mathrm{x}}$ was observed using D70BD25E5, D70BD20E10 and D70BD15E15 respectively.

The three engines were obtained at different times and therefore it is not statistically accurate to compare results between the engines. However, the difference can be attributed to different engine specifications in three different engines. Dissimilar Compression ratios and fuel injection systems can be the vital explanations for the dissimilar trend in different engines. The increase in $\mathrm{NO}_{2} / \mathrm{NO}$ level with addition of ethanol can be accredited to the fact that on addition of ethanol, a greater amount of NO was oxidized to $\mathrm{NO}_{2}$. This may be due to the better oxidizing ability of ethanol. Moreover, it was noted that an increase in engine rpm at the same load level reduced the $\mathrm{NO}_{\mathrm{x}}$ emission level significantly. This may be due to reduced air:fuel mixture at a higher 
speed. A super-lean mixture at low rpm burns very hot and produces a lot of $\mathrm{NO}_{\mathrm{x}}$. The richer the mix, the cooler the combustion zone and hence, lower $\mathrm{NO}_{\mathrm{x}}$ at higher rpm. Also, this could be the reason behind the reduced $\mathrm{NO}_{2} / \mathrm{NO}$ level with increase in engine $\mathrm{rpm}$. 


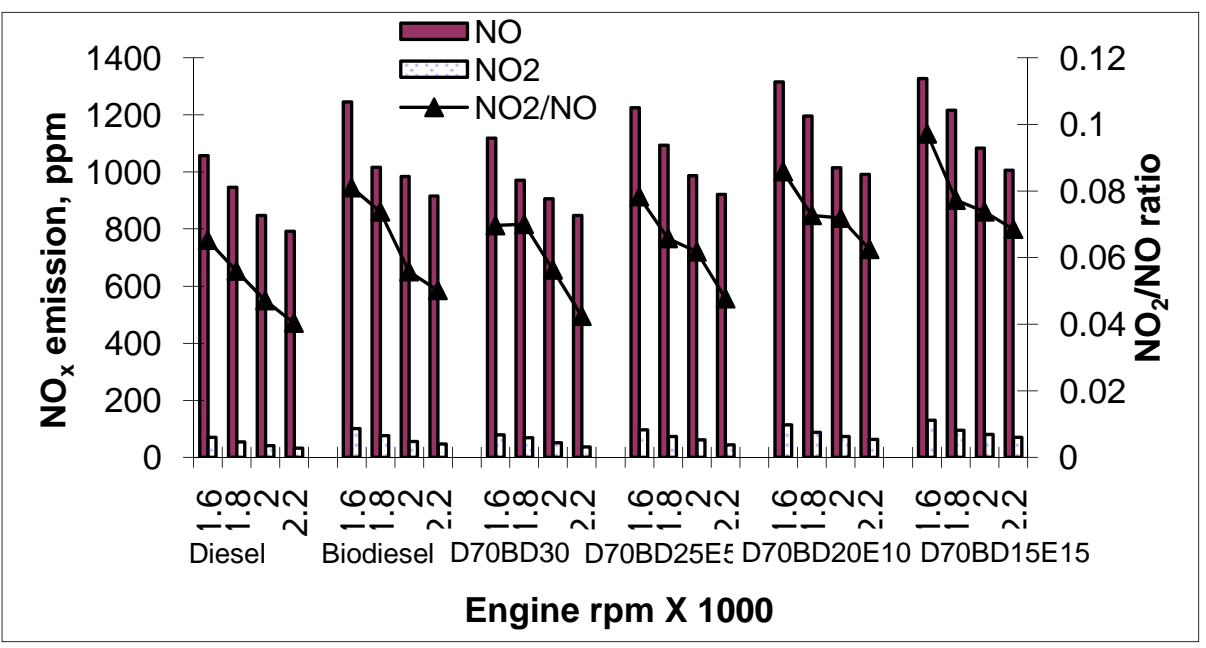

a. Ford 4000 Tractor Engine

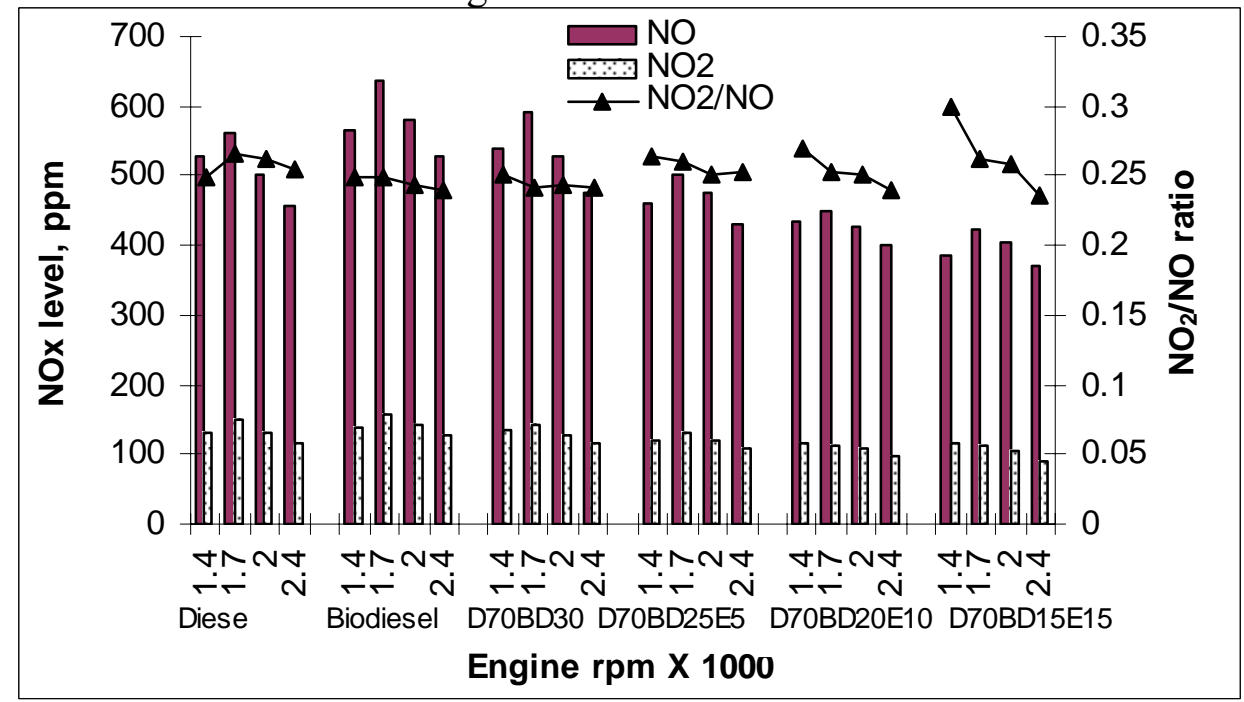

b. John Deere 5103 Tractor Engine

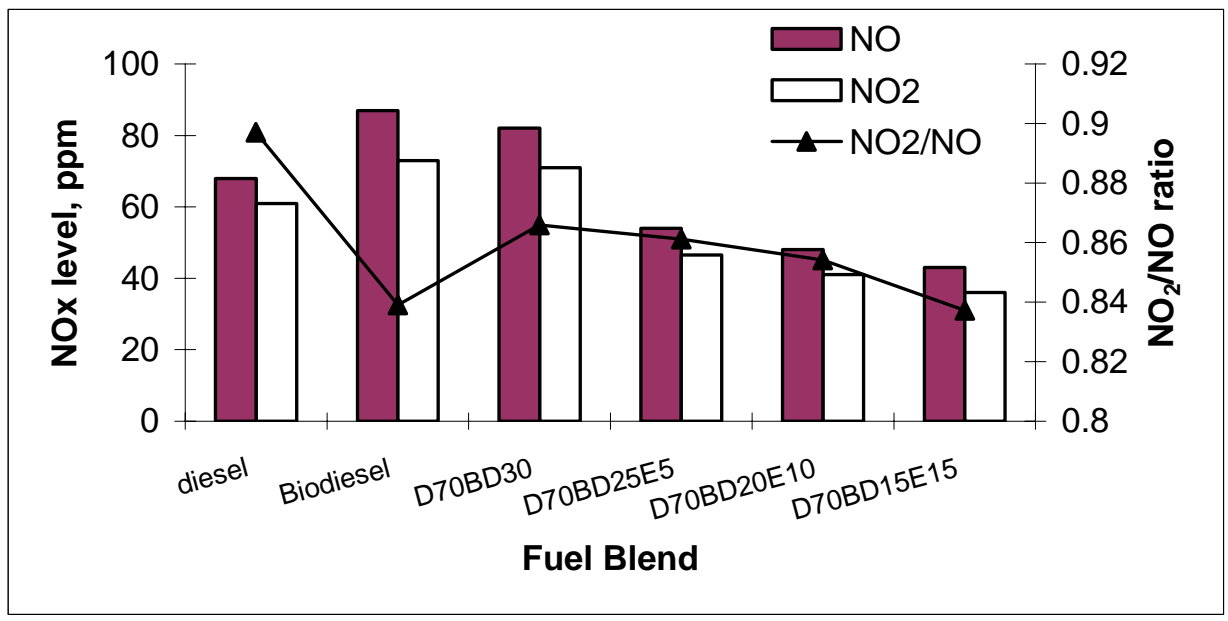


Figure 25. Comparison of the $\mathrm{NO}_{\mathrm{x}}$ Level

Based on the data collected, several general conclusions may be reached regarding the effect of ethanol-biodiesel-diesel emulsions on exhaust emissions. Increase in the ethanol percentage in the biodiesel-diesel blends caused significant changes in fuel properties like cetane number, flash point and Reid vapor pressure demanding more stringent storage requirements than conventional diesel. Biodiesel was associated with lower CO emissions levels compared to levels associated with diesel fuel. Adding ethanol however increased $\mathrm{CO}$ emissions. Using biodiesel generally tended to increase $\mathrm{NO}_{\mathrm{x}}$ emissions. Substituting neat biodiesel for diesel fuel, resulted in an increase of $\mathrm{NO}_{\mathrm{x}}$ emissions by roughly 10-20 percent. Adding ethanol showed two different trends in $\mathrm{NO}_{\mathrm{x}}$ emissions. With new engines, increase in ethanol proportion in the fuel blend resulted in a decline of $\mathrm{NO}_{\mathrm{x}}$ emissions, although the old Ford 4000 engine demonstrated an almost reverse trend in $\mathrm{NO}_{\mathrm{x}}$ emissions. It is possible that other properties of ethanol and biodiesel or interaction with characteristics of the combustion process and combustion chamber dynamics may have caused this variation in the expected trend toward $\mathrm{NO}_{\mathrm{x}}$ emissions. More research is needed to fully understand the dependence of $\mathrm{NO}_{\mathrm{x}}$ emissions on the diesel-biodiesel-ethanol and other parameters. 


\section{References}

1. The American Soybean Association. Soy Stats 2005. http://soystats.com/2005/Default-frames.htm . (2005).

2. DOE NREL. A Look Back at the U.S. Department of Energy's Aquatic Species Program: Biodiesel from Algae. NREL/TP-580-24190. 1998. DOE.

3. Water Environment Federation Activated Sludge MOP OM-9 2nd Edition. Water Environment Federation, (2002).

4. Nelson, D., M.Cox Principles of Biochemistry. W.H. Freeman and Company, (2005).

5. Dufreche et al. Extraction of Lipids from Municipal Wastewater Plant Microorganisms for Production of Biodiesel. JAOCS . 1-4-2007.

6. Hwu, C. S., Donlon, B., Lettinga, G. Comparative toxicity of long-chain fatty acid to anaerobic sludges from various origins. WATER SCIENCE AND

TECHNOLOGY 34, 351-358 (1996).

7. Rinzema, A., Boone, M., van Knippenberg, K., Lettinga, G. Bactericidal effect of long chain fatty acids in anaerobic digestion. Water Environment Reseach 66, 4049 (1994).

8. Liu H, F. H. Extraction of extracellular polymeric substances (EPS) of sludges. Journal of Biotechnology 95(3), 249-256 (2002).

9. Wagner M, L. A. N. R. P. U. L. N. D. H. Microbial community composition and function in wastewater treatment plants. ANTONIE VAN LEEUWENHOEK International Journal of General and Molecular Biology 81(1-4), 665-680 (2002).

10. Eikelboom DH, G. B. Filamentous micro-organisms observed in industrial activated sludge plants. Water Science and Technology 46(1-2), 535-542 (2001).

11. Barttelbort R.A. Characteristics of waters from apartment buildings. Public Works 88 (1966).

12. Farrington, J. W., Quinn, J. G. Petroleum Hydrocarbons and Fatty Acids In Wastewater Effluents. Journal Water Pollution Control Federation 45, 704-712 (1973).

13. Keefer C.E., Kratz H. Digestion of garbage with sewage sludge. Sewage Works Journal 15 (1934).

14. Mahlie W.S. Oil and Grease in Sewage. Sewage Works Journal 527 (1940). 
15. Quemeneur, M., Marty, Y. Fatty acids and sterols in domestic wastewaters. Water Research 28, 1217-1226 (1994).

16. Dueholm TE, A. K. N. P. Transformation of lipids in activated sludge. Water Science and Technology 43(1), 165-172. 2001.

17. Conrad, A. et al. Fatty Acids of Lipid Fractions in Extracellular Polymeric Substances of Activated Sludge Flocs. Lipids 38, 1093-1105 (2003).

18. Fang H.H., Jia X.S. Extraction of extracellular polymer from anaerobic sludges. Biotechnology Technology 10, 803-808 (1996).

19. Martinez F, F.-T. E. G. J. Oscillations of exopolymeric composition and sludge volume index in nitrifying flocs. Applied Biochemistry and Biotechnology 87(3), 177-188 (2000).

20. Fahmy, G. T., Hao, O. J. Characterization of activated sludge foams from two plants. Journal of Environmental Engineering 116, 991-997 (1990).

21. Loehr, R., C.Navarra Jr. Grease Removal at A Municipal Treatment Facility. Journal WPCF 41, 142-154 (1959).

22. Tiehm A, N. K. Z. M. N. U. Ultrasonic waste activated sludge disintegration for improving anaerobic stabilization. Water Research 35(8), 2003-2009 (2001).

23. Casado, A. G., Alonso Hernandez, E. J., Espinosa, P. \& Vilchez, J. L. Determination of total fatty acids (C8 - C22) in sludges by gas chromatographymass spectrometry. Journal of Chromatography A 826, 49-56 (1998).

24. Lepage, G., Roy, C. C. Direct transesterification of all classes of lipids in a onestep reaction. Journal of Lipid Research 27, 114-120 (1986).

25. Previato, et. al. Structural Characterization of a Novel Class of Glycophosphosphingolipids from the Protozoan Leptomonas samueli. Journal of Biological Chemistry 267, 24279-24285 (1992).

26. Morita, Y. S. et al. Compartmentalization of lipid biosynthesis in mycobacteria. Journal of Biological Chemistry 280, 21645-21652 (2005).

27. Bligh E.G., Dyer W.J. A rapid method of total lipid extraction and purification. Can. J. Biochem. Physiol. 37, 911-917 (1959).

28. Izard, J., Limberger, R. Rapid screening method for quantitation of bacterial cell lipids from the whole cells. Journal of Microbiological Methods 55, 411-418 (2003). 
29. Lambert M.A., M. C. W. Comparison of the effects of acid and base hydrolyses on hydroxy and cyclopropane fatty acids in bacteria. J.Clin.Microbiol. 18, 13701377 (1983).

30. Werker, A. G., Becker, J., Huitema, C. Assessment of activated sludge microbial community analysis in full-scale biological wastewater treatment plants using patterns of fatty acid isopropyl esters (FAPEs). Water Research 37, 2162-2172 (2003).

31. Demirbas, A. Supercritical fluid extraction and chemicals from biomass with supercritical fluids. Energy Conversion and Management 42, 279-294 (2001).

32. Molina Grima, E. et al. Comparison between extraction of lipids and fatty acids from microalgal biomass. JAOCS 71, 955-959 (1994).

33. Enssani, E. Correlation analysis for the extraction of hydrocarbons from wastewater-grown microalgal biomass. 2, 87-92. 1993. Atlanta, GA, USA, Publ by SAE, Warrendale, PA, USA. Proceedings of the Intersociety Energy Conversion Engineering Conference.

34. Anon Martek Polyunsatuated Fatty Acid Process. Industrial Bioprocessing 25, 2 (2003).

35. Ohr L.M. Nutraceuticals \& Functional Foods. Food Technology 59, 63-65 (2005).

36. Gimenez Gimenez, A. et al. Downstream processing and purification of eicosapentaenoic (20:5n-3) and arachidonic acids (20:4n-6) from the microalga Porphyridium cruentum. Bioseparation 7, 89-99 (1998).

37. Guil-Guerrero, J. L., Belarbi, E. I. H., Rebolloso-Fuentes, M. M. Eicosapentaenoic and arachidonic acids purification from the red microalga Porphyridium cruentum. Bioseparation 9, 299-306 (2000).

38. Enssani, E. A method for the extraction of liquid hydrocarbons from microalgal biomass. 6, 250-255. 1990. Reno, NV, USA, Publ by IEEE, Piscataway, NJ, USA. Proceedings of the Intersociety Energy Conversion Engineering Conference.

39. Pernet, F., Tremblay, R. Effect of Ultrasonication and Grinding on the Determination of Lipid Class Content of Microalgae Harvested on Filters. Lipids 38, 1191-1195 (2003).

40. Christie, W. Lipid Analysis. The Oily Press, (2003).

41. Rittmann, B., McCarty, P. Environmental Biotechnology: Principles and Applications. McGraw-Hill, New York, NY (2006). 
42. Hansen, C. M. Hansen Solubility Parameters: A User's Handbook. CRC Press, Boca Raton (2000).

43. Gryglewicz, S. Bioresource Technology 70, 249 (1999).

44. Li, Z. Thesis, University of Berlin, Berlin, (2005).

45. H. Zhu, H., Wu, Z., Chen, Y., Zhang, P., Duan, S., Liu, X., Mao, Z. Cuihua Xuebao, Journal written in Chinese 27(5), 391 (2006).

46. Kouzu, M., Umemoto, M., Kasuno, T., Tajika, M., Aihara, Y., Sugimoto, Y., Hidaka, J. Journal of the Japan Institute of Energy 85(2), 135 (2006).

47. Xie, W., Huang, X. Catalysis Letters 107(1-2), 53 (2006).

48. Xie, W., Li, H. Journal of Molecular Catalysis A:Chemical 255(1-2), 1 (2006).

49. Hak-Joo, K., Bo-seung, K., Min-Ju, K., Moo, P.Y., Deog-Keun, K., KwanYoung, L. Catalysis Today 93-95, 315 (2004).

50. Darnoko, D., Cheryan, M. JAOCS 77(12), 1263 (2000).

51. Noureddini, H., Zhu, D. JAOCS 74(11), 1457 (1997).

52. Freedman, B., Butterfield., R.O., Pryde, E.H. JAOCS 63(10), 1375 (1986).

53. Sharp, C.A., Howell, S.A., Jobe, J. The effect of biodiesel fuels on transient emissions from modern diesel engines, part I-regulated emissions and performance. SAE Paper 2000-01-1967 (2000).

54. McCormick, R.L., Graboski, M.S., Herring, A.M., Alleman, T.L. Impact of biodiesel source material and chemical structure on emissions of criteria pollutants from a heavy-duty engine. Environmental Science \& Technology 35(9), 1742-1747 (2001).

55. Grimaldi, C.N., Postrioti, L., Battistoni, M., Millo, F. Common rail HSDI diesel engine combustion and emissions with fossil/bio-derived fuel blends. SAE Paper 2002-01-6085 (2002).

56. Environmental Protection Agency (EPA). A comprehensive analysis of biodiesel impacts on exhaust emissions; draft technical report. Office of Transportation and Air Quality. EPA420-P-02-001. Washington D.C (2002).

57. Dickey, D.W., Ryan, T.W., Matheaus, A.C. $\mathrm{NO}_{\mathrm{x}}$ Control in Heavy-Duty Diesel Engines - What is the Limit? SAE Prep. 980174 (1998). 
58. Schlemmer-Kelling, U., Hopmann, U. The advantages of the variable mediumspeed engine concerning emission and fuel consumption. 22nd Int. Congr.

Combust. Eng., Proc. 4, 841 (1998).

59. Stebler, H., Bouchoulos, K., Eberle, M.K., Geist, M., Vlaskos, I. Reduction of $\mathrm{NO}_{\mathrm{x}}$-emissions of a medium-speed DI Diesel engine using Miller system, exhaust gas recirculation, variable nozzle turbocharger and common rail fuel injection.

Int. Congr. Combust. Eng., Proc. 22(4), 857 (1998).

60. Kass, M.D., Thomas, J.F., Storey, J.M., Domingo, N., Wade, J., Kenreck, G. Emissions from a 5.9 liter diesel engine fueled with ethanol diesel blends. $S A E$ 2001-01-2018 (2001).

61. Tat, M.E., Gerpen, J.H.V. Fuel property effects on biodiesel. ASAE Paper No.036034. St. Joseph, MI: ASAE (2003).

62. Fernando, S., Hall, C., Jha, S. $\mathrm{NO}_{x}$ Reduction from Biodiesel Fuels. Energy \& Fuels 20, 376-382 (2006).

63. Biodiesel Emissions, National Biodiesel Board (2005).

64. Oxides of Nitrogen, Bacharach, Inc. (2005).

65. Heywood, J.B. Internal combustion engine fundamentals. Singapore: McGrawHill (1988).

66. Kidoguchi, Y., Miwa, K., Mohammadi, A. Reduction Mechanism of $\mathrm{NO}_{\mathrm{x}}$ in Rich and High Turbulence Diesel Combustion. The Fifth International Symposium on Diagnostics and Modeling of Combustion in Internal Combustion Engines (COMODIA) (2001).

67. Gupta, A.K. Thermal characteristics of gaseous fuel flames using high temperature air. J. Eng. Gas Turbine Power 126(1), 9-19 (2004).

68. Schulz, C. Laser-based imaging measurements in combustion: New results for fuel/air mixture and temperature diagnostics. Journal of Physics: Conference Series 45(1), 27 (2006).

69. Nakajima, H., Shiozaki, T., Miyashita, A., Suzuki, H. Analysis of combustion flame in a DI diesel engine. Proc. SPIE 3173, 27-37 (1997).

70. Borman, G.L., Ragland, K.W. Combustion Engineering. McGraw-Hill (1998).

71. Knothe, G. Dependence of biodiesel fuel properties on the structure of fatty acid alkyl esters. Fuel Processing Technology 86, 1059-1070 (2005). 
72. Drysdale, D.D. An Introduction to Fire Dynamics. Second Edition. New York: John Wiley and Sons (1998).

73. Incropera, F.P., De Witt, D.P. Fundamentals of Heat and Mass Transfer. Fifth Edition. New York: John Wiley and Sons (2002).

74. Williamson, J.W. Characterizing cigarette lighter flames to reduce unwanted ignition. M. S. Dissertation. University of Maryland, College Park, MD (2003).

75. Knothe, G., Steidley, K.R. Kinematic viscosity of biodiesel fuel components and related compounds. Influence of compound structure and comparison to petrodiesel fuel components, Fuel 84, 1059-1065 (2005).

76. Ericson, C., Andersson, M., Egnell, R., Westerberg, B. Modelling Diesel Engine Combustion and $\mathrm{NO}_{\mathrm{x}}$ Formation for Model Based Control and Simulation of Engine and Exhaust Aftertreatment Systems. SAE paper 2006-01-0687 (2006).

77. Musculus, M.P.B. Measurements of the influence of soot radiation on in-cylinder temperatures and exhaust nox in a heavy-duty D1 diesel engine. SAE transactions (SAE transact.), Journal of Engines 114(3), 845-866 (2005).

78. Egnell, R. A Simple Approach to Studying the Relation Between Fuel Rate, Heat Release Rate and No Formation in Diesel Engines. SAE Paper - 1999-01-3548 (1999).

79. Moser, F.X., Sams, T., Cartellieri, W. Impact of Future Exhaust Gas Emission Legislation on the Heavy Duty Truck Engine. SAE Paper 2001-01-0186 (2001).

80. Walsh, M.P. Global Trends in Diesel Emissions Regulation -- A 2001 Update. SAE Paper 2001-01-0183 (2001).

81. Environmental Protection Agency (EPA). A comprehensive analysis of biodiesel impacts on exhaust emissions; draft technical report. Office of Transportation and Air Quality. EPA420-P-02-001. Washington D.C. (2002).

82. McCormick, B. Biodiesel Research Update. US DOE 10th Annual Diesel Engine Emissions Reduction Conference, Colarado (2004).

83. International, O. Methyl Soyate Evaluation of Various Diesel Blends in a DDC 6V-92 TA Engine. Ortech Final Report \# 93-E14-21 (1993).

84. Graboski, M.S., Ross, J.D., McCormick, R.L. Transient Emissions From No. 2 Diesel and Biodiesel Blends in a DDC Series 60 Engine. SAE 961166 (1996). 
85. Signer, M., Heinze, P., Mercogliano, R., Stein, H.J. European Programme on Emissions, Fuels and Engine Technology (EPEFE) - Heavy Duty Diesel Study. SAE Technical Paper 961074 (1996).

86. Ullman, T., Mason, R., Montalvo, D. Study of Cetane Number and Aromatic Content Effects on Regulated Emissions from a Heavy-Duty Engine. Coordinating Research Council Contract VE-1; Southwest Research Institute: San Antonio, TX (1990).

87. Fernando, S., Hall, C., Jha, S. $\mathrm{NO}_{\mathrm{x}}$ Reduction from Biodiesel Fuels. Energy \& Fuels 20, 376-382 (2006).

88. Fernando, S., Hanna, M. Comparison of viscosity characteristics of soybean oils with a mineral oil two-stroke engine lubricant. Trans. ASAE 44(6), 1403-1407 (2001).

89. Knothe, G., Dunn, R.O. Biofuels derived from vegetable oils and fats. In Proc. Oleochemical Manufacture and Applications:106-163 (2001).

90. Fernando, S., and Hanna, M. Development of a novel biofuel blend using ethanolbiodiesel-diesel microemulsions: EB-diesel. Energy and Fuels 18(6), 1695-1703 (2004).

91. Fernando, S., Hanna, M. Phase Behavior of the Ethanol-Biodiesel-Diesel Microemulsion System. Trans. of the ASAE 48(3), 903-908 (2005).

92. Ajiv, E.A., Singh, B., Bhattacharya, T.K. Thermal balance of a single-cylinder diesel engine operating on alternative fuels. Energy Conservation and Management 41(14), 1533-1541 (2000).

93. Abu-Qudais, M., Haddad, O., Qudaisat, M. The effect of alcohol fumigation on diesel engine performance and emissions. Energy Conversion and Management 41(4), 389-399 (2000).

94. Meiring, P., Hansen, A.C., Vosloo, A.P., Lyne, P.W.L. Tractor performance and durability with ethanol-diesel fuel. Trans. ASAE 26(1), 59-62 (1983).

95. Wrage, K.E., Goering, C.E. Technical feasibility of diesohol. Trans. ASAE 23(6), 1338-1343 (1980).

96. deCaro, P.S., Mouloungui, Z., Vaitilingom, G., Berge, J.C. Interest in combining an additive with diesel ethanol blends for use in diesel engines. Fuel 80(4), 565574 (2001).

97. Kass, M.D., and coauthors. Emissions from a 5.9 liter diesel engine fueled with ethanol diesel blends. SAE Paper 2001-01-2018 (SP-1632) (2001). 
98. Marek, N., Evanoff, J. The use of ethanol blended diesel fuel in unmodified, compression engines: An interim case study. In Proc. AWMA 94th Annual Conference and Exhibition. Pittsburgh, Pa:: Air and Waste Management Association (2001).

99. Schaus, J.E., McPartlin, P.M., Cole, R.L., Poola, R.B., Sekar, R. Effect of ethanol fuel additive on diesel emissions. Report for the Illinois Department of Commerce and Community Affairs and the U.S. Department of Energy. Argonne, Ill.: Argonne National Laboratory (2000).

100. Spreen, K. Evaluation of oxygenated diesel fuels. Final report for Pure Energy Corporation. San Antonio, Texas: Southwest Research Institute (1999).

101. Ajiv, E.A., Singh, B., Bhattacharya, T.K. Experimental study of some performance parameters of a constant-speed stationary diesel engine using ethanol-diesel blends as fuel. Biomass and Bioenergy 17(4), 357-365 (1999).

102. Buchholz, B.A., Cheng, A.S., and Dibble, R.W. Isotopic tracing of bio-derived carbon from ethanol-in-diesel blends in the emissions of a diesel engine. In Research in Alternative Fuel Development, SAE Special Publication SP-1716, 3745 (2002).

103. Ali, Y., Hanna, M.A. Physical properties of tallow ester and diesel fuel blends. Bioresource Tech 47(2), 131-134 (1994).

104. Fernando, S., Hanna, M. Phase Behavior of the Ethanol-Biodiesel-diesel microemulsion system. Transactions of the ASAE 48(3), 903-908 (2005).

105. Peterson, C.L., and Reece, D.L. Emissions characteristics of ethyl and methyl ester of rapeseed oil compared with low sulfur diesel control fuel in a chassis dynamometer test of a pickup truck. Transactions of the ASAE 39(3), 805-816 (1996).

106. Peterson, C.L., andReece, D.L. Emissions testing with blends of esters of rapeseed oil fuel with and without a catalytic converter. $S A E$ Tech. Paper No. 961114 (1996).

107. Sharp, C.A., Howell, S.A., Jobe, J. The Effect of Biodiesel Fuels on Transient Emissions from Modern Diesel Engines, Part I Regulated Emissions and Performance. SAE Paper 2000-01-1967 (2000).

108. Sharp, C.A., Howell, S.A., Jobe, J. The Effect of Biodiesel Fuels on Transient Emissions from Modern Diesel Engines, Part II Unregulated Emissions and Chemical Characterization. SAE Paper 2000-01-1968 (2000). 
109. Mittelbach, M., Tritthart, P. Diesel fuels derived from vegetable oils, III. Emission tests using methyl esters of used frying oil. JAOCS 65(7), 1185-1187 (1988).

110. Rickeard, D.J., Thompson, N.D. A review of the potential for bio-fuels as transportation fuels. SAE Paper 932778 (1993).

111. Monyem, A. The effect of biodiesel oxidation on engine performance and emissions. Biomass and Bioenergy 20(4), 317-325(9) (1998). 